\title{
Avaliação da influência do canal do Valo Grande na composição molecular e isotópica da matéria orgânica depositada no Sistema Estuarino-Lagunar de Cananéia-Iguape-SP
}

Tese apresentada ao Instituto Oceanográfico da Universidade de São Paulo como parte dos requisitos para obtenção do título de Doutor em Ciências, área de Oceanografia.

Orientadora:

Prof $^{\mathrm{a}}$. Dra . Márcia Caruso Bícego

Co-orientador:

Prof. Dr. Michel Michaelovitch de Mahiques 


$$
\begin{gathered}
\text { Universidade de São Paulo } \\
\text { Instituto Oceanográfico } \\
\text { Laboratório de Química Orgânica Marinha }
\end{gathered}
$$

\section{Avaliação da influência do canal do Valo Grande na composição molecular e isotópica da matéria orgânica depositada no Sistema Estuarino-Lagunar de Cananéia-Iguape-SP}

\section{Ana Cecília Rizzatti de Albergaria-Barbosa}

Tese apresentada ao Instituto Oceanográfico da Universidade de São Paulo, como parte dos requisitos para obtenção do título de Doutor em Ciência, área de Oceanografia (versão corrigida).

Julgada em por:

Prof $^{\mathrm{a}}$. Dr ${ }^{\mathrm{a}}$. Márcia Caruso Bícego conceito

Departamento de Oceanografia Física do Instituto Oceanográfico da Universidade de São Paulo (IO-USP)

Prof(a). $\operatorname{Dr}(\mathrm{a})$. conceito

$\operatorname{Prof}(a)$. Dr(a). conceito

Prof(a). Dr(a). conceito

Prof(a). $\operatorname{Dr}(a)$. conceito 
“...Deus ao mar o perigo e o abismo deu;

Mas nele é que espelhou o céu."

(Fernando Pessoa) 
Aos meus grandes incentivadores: meus pais! 


\section{Agradecimentos}

A elaboração deste trabalho não teria sido possível se não houvesse a colaboração e o estímulo de diversas pessoas. Aqui deixo os meus mais sinceros agradecimentos.

Primeiramente, agradeço a Deus, por estar sempre ao meu lado, me ajudando a tomar as melhores decisões. Acredito que ter trabalhado e conhecido pessoas tão maravilhosas ao longo de minha formação acadêmica não foi coincidência! Muito Obrigada!

À minha amiga e orientadora, Profa. Dra. Márcia Caruso Bícego. A ela não existem agradecimentos que cheguem. Muito obrigada pela orientação neste trabalho, pela competência, por toda confiança e interesse em mim depositados desde meu primeiro ano de graduação. Também agradeço muito por ter contado com seu apoio nos momentos que eu mais precisei. Pelos conselhos, pela amizade, pelas risadas e por ter sido uma grande incentivadora na hora de superar meus limites.

Ao Prof. Dr. Michel Michaelovitch de Mahiques, diretor do Instituto Oceanográfico, pela co-orientação deste trabalho. Muito obrigada por ter acreditado em mim, me dando a oportunidade de trabalhar ao seu lado. Muito obrigada também pela ajuda na elaboração deste projeto. Agradeço a você por ter cedido as amostras de testemunhos que usei em meu estudo e por ter me ensinado tanto sobre o Valo Grande e o Sistema Estuarino-Lagunar e Cananéia-Iguape.

An Herrn Dr. Enno Schefuß, für das Vertrauen an mich und Bereitschaft mir zu helfen während mein Prakțikum und mich angenommen zuhaben. Ohne Zweifel habe ich viel gelernt und bin sehr dankbar, dass Ich die Gelegenheit, mit einer von die Besten Fachleuten mitgearbeitet zu haben. Die Erfahrungen, die ich erlebt habe, Kann ich mit Worten mich nicht ausdrücken. An Frau Dr. Britta Beckmann und alle anderen die mir unterstützen und geholfen haben im Zentrum für Marine und Gewissenschaften.

Ao Prof. Dr. Ilson Silveira e ao Prof. Dr. Eduardo Siegle, presidentes da Comissão de Pós-graduação. À Profá. Dra.Rosalinda Carmela Montone, vice-presidente da Comissão de Pós-Graduação e Coordenadora do Programa de Oceanografia Química e Geológica, pelas ajudas nas horas burocráticas, por toda amizade, e por todos almocinhos e conversas que tivemos.

À Dra. Satie Taniguchi pela amizade e por sua paciência. Não sei o que seria de mim sem você! Obrigada por toda ajuda, por todo conhecimento transmitido e pela total disponibilidade! Obrigada por ter sido um excelente ombro amigo nas horas em que precisei. 
Ah... E muito obrigada por contar as historias mais divertidas do Eric e por trazê-lo ao laboratório, alegrando o meu dia!

Ao Prof. Dr. Rubens Cesar Lopes Figueira pela cooperação inestimável na realização deste trabalho. Obrigada pela coleta das amostras superficiais e pela ajuda na datação de meus testemunhos. Obrigada também por toda a amizade e paciência. Sempre esteve disposto a me ajudar com o que eu precisasse. Obrigada pelas colaborações durante e após o exame de qualificação.

Ao Prof. Dr. Moyses Gonsalez Tessler pela colaboração e sugestões dadas no exame de qualificação.

A Profa. Dra. Marília Cunha Lignon pelas dicas e ajudas com a vegetação de mangue e de macrófitas.

Ao Paulo Alves de Lima Ferreira, ao Alexandre Salaroli, à Samara Cazzoli Goya, ao Edilson Oliveira e ao Daniel Pavani pela inestimável colaboração em diferentes fases deste trabalho.

Agradeço ao Lourival Pereira de Souza, pelos conselhos e compantia no Laboratório. Ao Prof. Dr. Rolf Roland Weber pela amizade em todos estes anos.

Ao Robeto Lasdenia e Prof. Msc. Mauricio Tassoni Filho, pelo auxílio na coleta das plantas e pela ajuda na discussão dos resultados gerados por elas.

Aos funcionários da Biblioteca Prof. Dr. GelsoVazzoler, em especial ao Wagner Pinheiro, pela ajuda na revisão bibliográfica. Às funcionárias da secretaria de pós-graduação do IO-USP (Ana Paula Evangelista, Silvana Reginaldo e Letícia Rodrigues) e da secretaria do DOF (Angélica Miguel e Eliete Maciel) por toda paciência que tiveram comigo. Ao Eder Correapor todos "problemas computacionais" resolvidos mais do que prontamente. Ao Jorge Gruda e ao Pedro Garcia Filho pela ajuda nesta etapa final. A todos os funcionários e alunos do IO-USP que contribuíram, direta ou indiretamente, na realização deste trabalho.

Ao pessoal do tão famoso "cantinho da vadiagem", membros (querendo ou não) do "LabQOM runners" e associados: Silvio (Manuel Sam) e Patrícia (huuumm... 6olo), Fermanda (agora americana), Caio Vinícius e Mari (agora franceses), Caio Augusto (papai Gabi), Mauro (papai da Manu), Patrick e Lu (papais da Hell), Felipe (posso ficar 100 páginas descrevendo meu adorado Felipe), Patrícia (não vou falar nada, que me disseram que ela é Grava), Mandão (cuidado com o carro, hein?), Ju (de quem roubei a mesa), Paula (nova companheira de bile), Renato e Hanna (casal dos pães de mel pagos com moedas de 1 real), 
Ligia (que dá Groncas no laboratório) e dos novos integrantes: Ana Paula, Natalia e Denise. Não poderia esquecer a Sandrinha, o Vito, o Dalton e o pessoal da "velha guarda": Verinha, Renato, Diego, Hiléia, Josi, Mariana, César, Rafael, Dênis, Maurício, Fernando, Eliete, Edgar, Armando, Gabi, Carioca, Simone, Karina ("in memorian”), Carol, Bia, Débora e a todos que já passaram por este laboratório.

À minha amada "família paulistana" e aos melhores amigos que alguém poderia ter, por toda paciência quando eu mais precisei: Alice, Bia, Samanta e Matheus, Nathaly e Matheus, Enzo e Larissa, Bruna e Gulão, Débora e Nico, Lilian e Daniel, Li Marconato, Marcinha, Jana, Roga e Paula. É muito bom ter amigos com quem a gente sabe que pode contar!

An meine 6eliebte "Bremer" Familie: Rodrigo, Carine, Grasi und Wil6or, Aline, Marquinhos und Noemi, Gabi, Denis (die mir geholfen haben diesen Text) und Patrick, Danny, Foca, Mário und Ale, Meral und Sebastian und an alle anderen die mich meine Heimat weniger vermissen haben. In meinem Aufenthalt in Bremen habe ich kennen gelernt und wieder getroffen wunderschönen Freunden.

Agradecimentos mais do que especiais aos melhores amigos que alguém pode ter: meus pais! Agradeço a vocês (Célia e Ricardo) pelo incentivo e, principalmente, exemplo que tive, tanto pessoal quanto profissionalmente, em todos os momentos da minha vida. Eu amo vocês demais! Agradeço todos os dias a Deus por ter tido vocês que, muito além de pais, são meus melhores amigos. Não conseguiria ser a metade do que sou, nem ter feito a metade do que fiz, se não fosse pelo apoio de vocês. Muito obrigada!

Ao meu anjo, Vinicius, que me apoiou em momentos bons ou ruins durante toda a elaboração deste doutorado. Ao longo destes 6 anos que nos conhecemos, você deixou de ser apenas um grande amigo e se tornou metade de mim. Te amo!

Ao Conselho Sacional de Desenvolvimento Científico e Tecnológico (CNNPq) e à Coordenação de Aperfeiçoamento de Pessoal de Nivel Superior (Capes), pela concessão da 6olsa de doutorado e pela bolsa de estágio sanduíche.

A todos aqueles que direta ou indiretamente contribuíram na execução deste trabalho. Muito obrigada! 


\section{ÍNDICE}

TABELAS

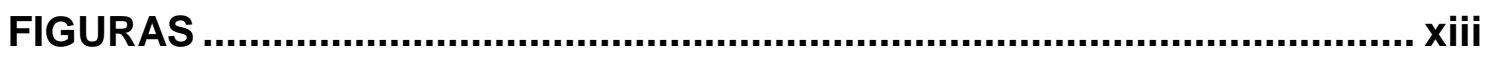

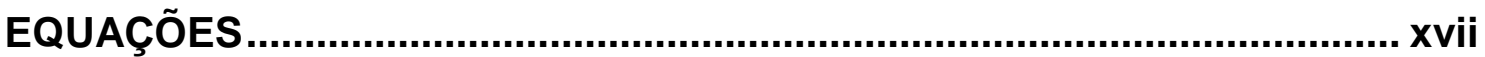

LISTA DE ABREVIAÇÕES.................................................................... xviii

RESUMO

ABSTRACT

1. INTRODUÇÃO

1.1. Sistema Estuarino-Lagunar de Cananéia-Iguape e a problemática do canal do Valo Grande .............................................................................. 1

1.2. Marcadores orgânicos moleculares .................................................... 4

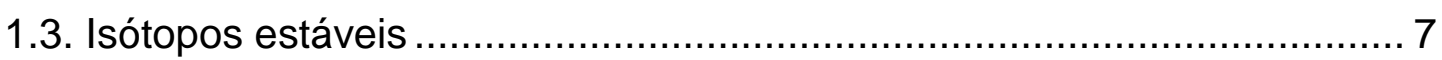

1.3.1. Análise Isotópica de compostos específicos ................................... 9

1.4. Caracterização dos n-alcanos na vegetação ....................................... 10

2. HIPÓTESE DE TRABALHO

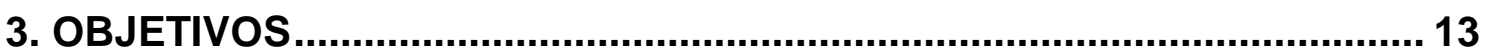

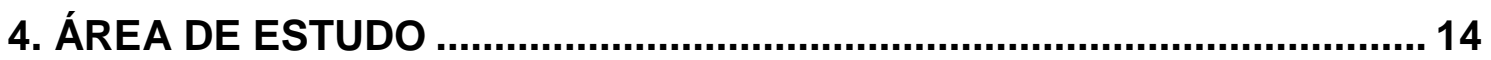

4.1. Características e evolução geológica ................................................. 14

4.2. Clima 


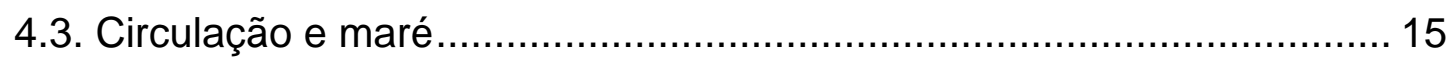

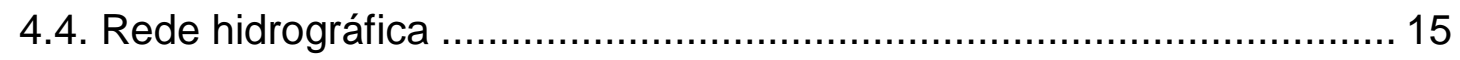

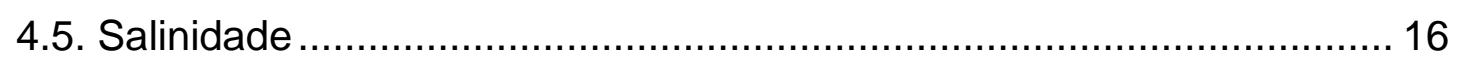

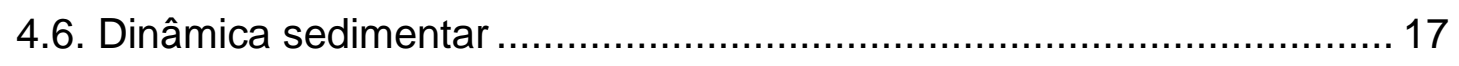

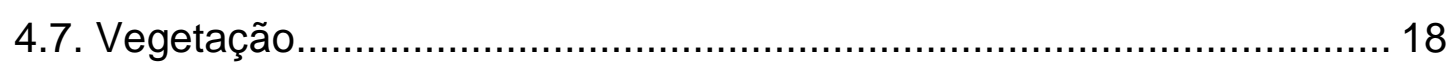

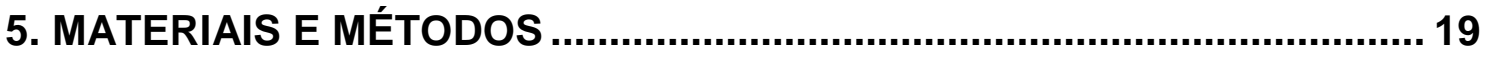

5.1. Amostragem dos sedimentos ....................................................... 19

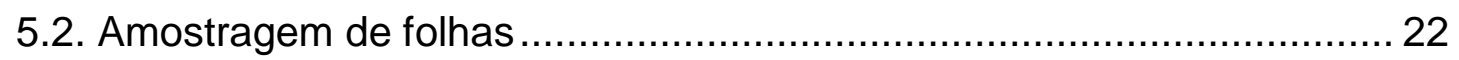

5.3. Taxa de sedimentação e modelo de idade .......................................... 24

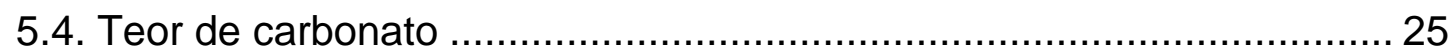

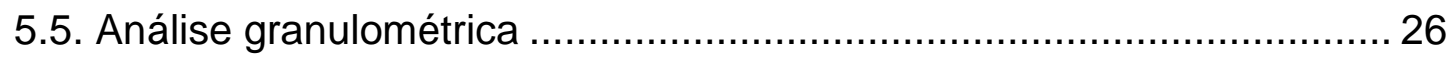

5.6. Características composicionais da matéria orgânica............................. 26

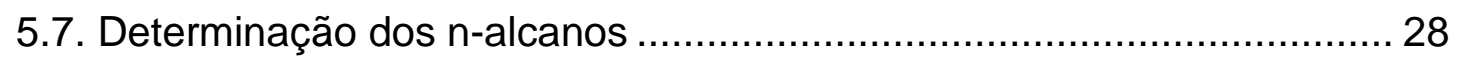

5.7.1. Tratamento dos reagentes e limpeza do material .......................... 28

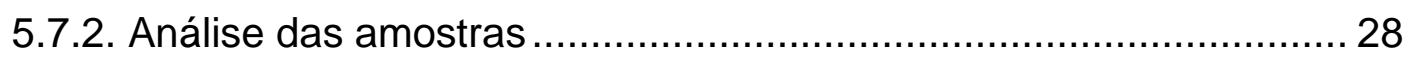

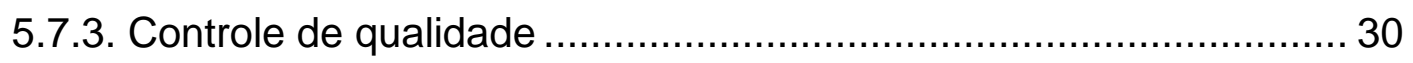

5.8. Análise da razão isotópica em compostos específicos (n-alcanos) ........ 36

\section{RESULTADOS E DISCUSSÕES}

6.1. Composição dos n-alcanos na flora amostrada.................................... 39

6.2. Matéria orgânica nas amostras superficiais......................................... 49

6.2.1. Distribuição das frações sedimentares e do conteúdo de carbonato de cálcio no Sistema Estuarino-Lagunar de Cananéia-Iguape .................. 49

6.2.2. Distribuição e fonte da matéria orgânica no sistema Estuarino-

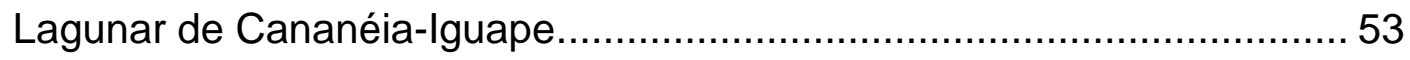

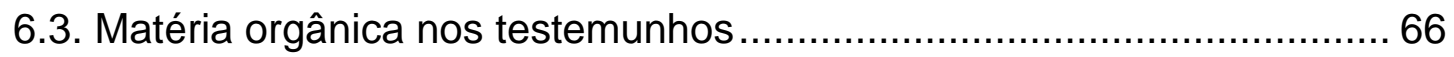

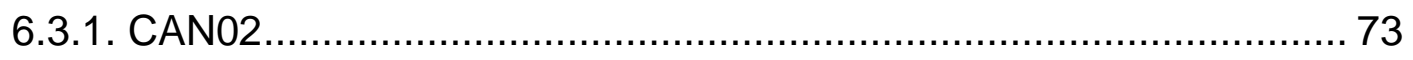




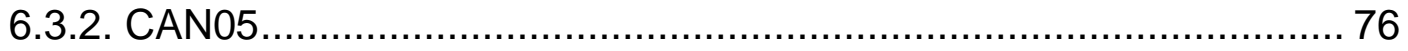

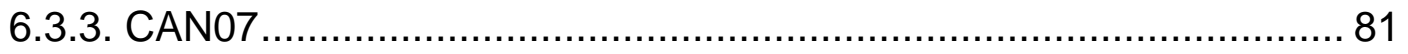

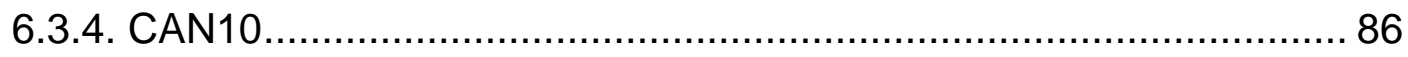

6.3.5. Comparação entre os testemunhos amostrados............................ 90

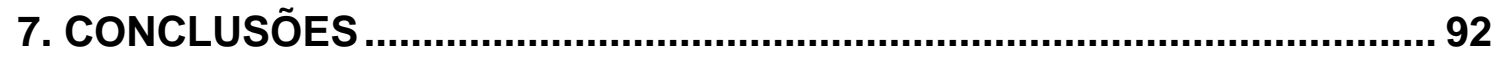

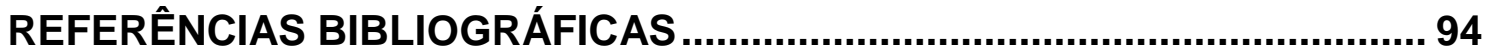




\section{TABELAS}

Tabela 1: Localização geográfica e comprimento dos testemunhos coletados.

Tabela 2: Localização geográfica das amostras superficiais coletadas para o presente estudo. As amostras destacadas em vermelho apresentaram conteúdo de material orgânico detectável pelo EA-IRMS e foram selecionadas para avaliação dos marcadores geoquímicos. 21

Tabela 3: Classificação das espécies de plantas amostradas no presente estudo.

Tabela 4: Programação da rampa de aquecimento do GC-FID na determinação dos $n$-alcanos. 29

Tabela 5: Limite de detecção (LDM) obtido para os $n$-alcanos $\left(\mu \mathrm{g} \mathrm{g}^{-1}\right.$ peso seco).

Tabela 6: Resultados obtidos ( $\mathrm{ng} \mathrm{g}^{-1}$ peso seco) na análise em duplicata da amostra coletada por Lourenço (2007) (amostra 6952 - 24-26 cm). Os valores variaram em -50 e $120 \%$ em, pelo menos, $80 \%$ dos compostos. 34

Tabela 7: Resultados obtidos na análise do branco fortificado $\left(n g \mu \mathrm{L}^{-1}\right)$ e a diferença entre as concentrações obtidas na matriz fortificada e na matriz (amostra $6952\left(24-26 \mathrm{~cm}\right.$ ), apresentada em Lourenço (2007), $n g \mathrm{~L}^{-1}$ ). Os valores devem ter uma recuperação entre 40 e $130 \%$ em, pelo menos, $80 \%$ dos compostos (concentração $5 \mathrm{ng} \mu \mathrm{L}^{-1}$ ).

Tabela 8: Resultados obtidos por Lourenço (2007) na amostra $6952(24-26 \mathrm{~cm})$ e os obtidos no presente estudo para esta mesma amostra ( $\mathrm{ng} \mathrm{g}^{-1}$ peso seco). Os valores devem ter um desvio padrão menor que $30 \%$ em, no mínimo, $80 \%$ dos compostos. 
Tabela 9: Parâmetros dos $n$-alcanos encontrados nas folhas das espécies de plantas amostradas no presente estudo.

Tabela 10: $\delta^{13} \mathrm{C}(\% \circ)$ e $\delta \mathrm{D}(\%)$ dos $n$-alcanos detectados em cada espécie estudada. (n.d.=não detectado, n.a.=não avaliado)

Tabela 11: Diferenças entre os índices e razões isotópicas $\left(\delta^{13} C_{n \text {-alcanos }}\right.$ e $\delta D{ }_{n}$ alcanos) dos $n$-alcanos detectados em distintos grupos de vegetação com base nas amostras de folhas avaliadas no presente estudo. $\mathrm{ACL}_{23-33}=$ tamanho médio de cadeia; Al=índice alcano;

Tabela 12: Conteúdo de argila (\%), silte (\%), areia (\%) e carbonato de cálcio (Carb., \%) nas amostras de sedimento superficiais coletadas no Sistema Estuarino-Lagunar de Cananéia-Iguape. 50

Tabela 13: Conteúdo de carbono orgânico total (TOC, \%), conteúdo de nitrogênio total (TN, \%), razão entre carbono orgânico total e nitrogênio total $(\mathrm{C} / \mathrm{N}), \delta^{13} \mathrm{C}$ do carbono orgânico total, $\delta^{15} \mathrm{~N}$ do nitrogênio total (\%),contribuição de matéria orgânica terrestre $(F, \%)$, concentração de $n$-alcanos totais (AlcTot, $\mathrm{ng} \mathrm{g}^{-1}$ de sedimento seco), índice preferencial de carbono (CPI), tamanho médio de cadeia $\left(\mathrm{ACL}_{23-33}\right)$, índice de produção aquática (Paq) e índice alcano (Al) calculados para o Sistema Estuarino-Lagunar de Cananéia-Iguape (n.d.= não detectado; n.c.= não calculado). 55

Tabela 14: $\delta^{13} \mathrm{C}$ dos $n$-alcanos $n-\mathrm{C}_{25}, n-\mathrm{C}_{29}, n-\mathrm{C}_{31}(\%)$ e $\delta \mathrm{D}$ dos $n$-alcanos $n$ $\mathrm{C}_{29}, n-\mathrm{C}_{31}(\%)$ detectados nas amostras de superfície coletadas no Sistema Estuarino-Lagunar de Cananéia-Iguape. (n.d. =não detectado) 65

Tabela 15: Valores mínimos (mín.), máximos (máx.) e média dos teores de argila (\%), silte (\%), areia (\%), carbono orgânico total (TOC, \%), nitrogênio total

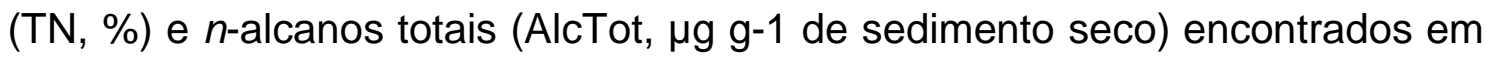
cada testemunho estudado (Test.). ( $n=$ número amostras). 67 
Tabela 16: Valores mínimos (mín.), máximos (máx.) e média (méd.) das razões isotópicas de carbono $\left(\delta^{13} \mathrm{C}, \%\right.$ e nitrogênio $\left(\delta^{15} \mathrm{~N}, \% \circ\right)$ da matéria orgânica total, razão entre o carbono orgânico total e o nitrogênio total $(\mathrm{C} / \mathrm{N})$; índice preferencial de carbono ( $\mathrm{CPI}$ ), tamanho médio de cadeia $\left(\mathrm{ACL}_{23-33}\right)$, índice de produção aquática $(\mathrm{Paq})$, índice alcano $(\mathrm{Al})$ e razões isotópicas de carbono dos $n$-alcanos $n-\mathrm{C}_{25}\left(\delta^{13} \mathrm{C} n-\mathrm{C}_{25}, \% \circ\right), n-\mathrm{C}_{29}\left(\delta^{13} \mathrm{C} n-\mathrm{C}_{29}, \%\right.$ ) e $n-\mathrm{C}_{31}\left(\delta^{13} \mathrm{C} n-\mathrm{C}_{31}, \%\right.$ \%) encontrados em cada testemunho estudado (Test.). (n=número amostras).... 68 


\section{FIGURAS}

Figura 1: Localização dos principais canais, ilhas, desembocaduras, toponímias do Sistema Estuarino-Lagunar de Cananéia-Iguape.

Figura 2: Figura da localização geográfica dos testemunhos coletados.

Figura 3: Mapa com a localização geográfica das amostras de sedimentos superficiais usadas no presente estudo. (A) região mais ao norte, (B) região mais ao sul.

Figura 4: Histogramas da distribuição molecular dos $n$-alcanos encontrados nas amostras de folha das espécies Laguncularia racemosa, Rhizophora mangle, Musa ssp, Inga uruguensis.

Figura 5: Histogramas da distribuição molecular dos $n$-alcanos encontrados nas amostras de folha das espécies Calophyllum brasiliensis, Cecropia pachystachya, Spartina alterniflora, Pteridium aquilinum, Syagrus romanzoffiana.

Figura 6: Distribuição espacial dos conteúdos de areia (A), silte (B) e argila (C) encontrados nas amostras superficiais coletadas no Sistema Estuarino-Lagunar de Cananéia-Iguape. 51

Figura 7: Distribuição espacial dos conteúdos de carbonato de cálcio $\left(\mathrm{CaCO}_{3}\right)$ encontrados nas amostras superficiais coletadas no Sistema Estuarino-Lagunar de Cananéia-Iguape. 52

Figura 8: Distribuição espacial dos conteúdos de carbono orgânico total (TOC, A), nitrogênio total (TN, B) e $n$-alcanos totais (AlcTot, C) das amostras superficiais coletadas no Sistema Estuarino-Lagunar de Cananéia-Iguape. ... 56 
Figura 9: Correlação entre os conteúdos de TOC (\%) e TN (\%) em todas as amostras ( $n=22)$ (A) e quando a amostra $S 17$ (com altos níveis de TOC) é excluída $(n=21)(B)$

Figura 10: Distribuição especial da razão entre os teores de carbono orgânico total e de nitrogênio total $(\mathrm{C} / \mathrm{N})$ das amostras superficiais do Sistema EstuarinoLagunar de Cananéia-Iguape. 59

Figura 11: Exemplo de histogramas obtidos na distribuição molecular dos $n$ alcanos encontrados nas amostras de sedimentos superficiais coletados ao longo do Sistema Estuarino-Lagunar de Cananéia-Iguape. Os histogramas são correspondentes às amostras S08 (A), S15 (B), S52(C) e S76 (D). 60

Figura 12: Distribuição espacial dos valores de tamanho médio de cadeia $\left(\mathrm{ACL}_{23-33}, \mathrm{~A}\right)$, índice preferencial de carbono $(\mathrm{CPI}, \mathrm{B})$, índice de produção aquática (Paq, C) e índice alcano ( $\mathrm{Al}, \mathrm{D}$ ) encontrados nas amostras de sedimento superficiais coletadas no Sistema Estuarino-Lagunar de CananéiaIguape. 62

Figura 13: Perfil dos teores de argila (arg, \%), silte (\%) e areia (\%); conteúdo de carbonato de cálcio (Carb., \%); concentração de carbono orgânico total (TOC,\%) e nitrogênio total (TN,\%); $\delta^{13} \mathrm{C}(\% \circ)$ e $\delta^{15} \mathrm{~N}(\%)$ da matéria orgânica total; razão entre TOC e TN $(\mathrm{C} / \mathrm{N})$; concentração de $n$-alcanos totais (AlcTot, $\mu \mathrm{g}$ $\mathrm{g}^{-1}$ p.s.), índice preferencial do carbono (CPI), tamanho médio de cadeia $\left(\mathrm{ACL}_{23}\right.$ $\left.{ }_{33}\right)$, índice de produção aquática (Paq), índice alcano ( $\mathrm{Al}$ ) e $\delta^{13} \mathrm{C}$ dos $n$-alcanos

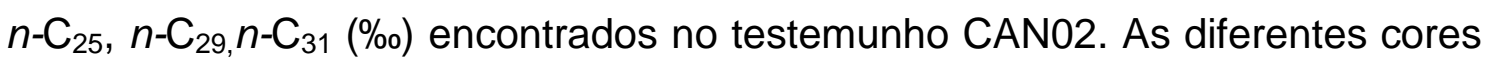
representam os diferentes períodos de deposição de carbono orgânico. 69

Figura 14: Perfil dos teores de argila (arg, \%), silte (\%) e areia (\%); conteúdo de carbonato de cálcio (Carb., \%); concentração de carbono orgânico total (TOC,\%) e nitrogênio total (TN,\%); $\delta^{13} \mathrm{C}\left(\% \circ\right.$ e $\delta^{15} \mathrm{~N}(\%$ ) da matéria orgânica total; razão entre TOC e TN $(\mathrm{C} / \mathrm{N})$; concentração de $n$-alcanos totais (AlcTot, $\mu \mathrm{g}$ $\mathrm{g}^{-1}$ p.s.), índice preferencial do carbono (CPI), tamanho médio de cadeia $\left(\mathrm{ACL}_{23}\right.$ $\left.{ }_{33}\right)$, índice de produção aquática (Paq), índice alcano ( $\mathrm{Al}$ ) e $\delta^{13} \mathrm{C}$ dos $n$-alcanos 
$n-\mathrm{C}_{25}, n-\mathrm{C}_{29,}, n-\mathrm{C}_{31}(\%)$ encontrados no testemunho CAN05. As diferentes cores representam os diferentes períodos de deposição de carbono orgânico

Figura 15: Perfil dos teores de argila (arg, \%), silte (\%) e areia (\%); conteúdo de carbonato de cálcio (Carb., \%); concentração de carbono orgânico total (TOC,\%) e nitrogênio total (TN,\%); $\delta^{13} \mathrm{C}(\%)$ e $\delta^{15} \mathrm{~N}(\%)$ da matéria orgânica total; razão entre TOC e TN $(\mathrm{C} / \mathrm{N})$; concentração de $n$-alcanos totais (AlcTot, $\mu \mathrm{g}$ $\mathrm{g}^{-1}$ p.s.); índice preferencial do carbono (CPI); tamanho médio de cadeia $\left(\mathrm{ACL}_{23}\right.$ $\left.{ }_{33}\right)$; índice de produção aquática (Paq); índice alcano (Al) e $\delta^{13} \mathrm{C}$ dos $n$-alcanos

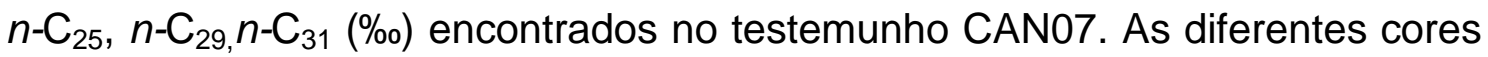
representam os diferentes períodos de deposição de carbono orgânico. 71

Figura 16: Perfil dos teores de argila (arg, \%), silte (\%) e areia (\%); conteúdo de carbonato de cálcio (Carb., \%); concentração de carbono orgânico total (TOC,\%) e nitrogênio total (TN,\%); $\delta^{13} \mathrm{C}\left(\%\right.$ ) e $\delta^{15} \mathrm{~N}(\%$ ) da matéria orgânica total; razão entre TOC e TN $(\mathrm{C} / \mathrm{N})$; concentração de $n$-alcanos totais (AlcTot, $\mu \mathrm{g}$ $\mathrm{g}^{-1}$ p.s.), índice preferencial do carbono (CPI), tamanho médio de cadeia $\left(\mathrm{ACL}_{23}\right.$ $\left.{ }_{33}\right)$, índice de produção aquática (Paq), índice alcano (Al) e $\delta^{13} \mathrm{C}$ dos $n$-alcanos

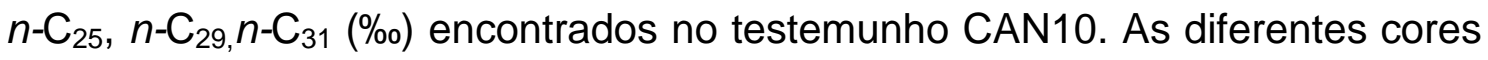
representam os diferentes períodos de deposição de carbono orgânico. 72

Figura 17: Perfil dos teores de lama (\%), carbonato de cálcio $\left(\mathrm{CaCO}_{3}, \%\right)$, carbono orgânico total (TOC,\%), nitrogênio total (TN, \%) e $n$-alcanos totais (AlcTot, $\mu \mathrm{g} \mathrm{g}^{-1}$ p.s.) do testemunho CAN02. As diferentes cores representam os diferentes períodos de deposição de carbono orgânico. 74

Figura 18: Perfil dos valores de $\delta^{13} \mathrm{C}$ do carbono orgânico total $\left(\delta^{13} \mathrm{C}\right.$ do TOC, $\%$ \%), do índice preferencial de carbono (CPI), tamanho médio de cadeia $\left(\mathrm{ACL}_{23}\right.$ 33), índice de produção aquática (Paq) e do índice alcano (Al) encontrados no testemunho CAN02. As diferentes cores representam os diferentes períodos de deposição de carbono orgânico. 75 
Figura 19: Perfil dos teores de lama (\%), carbono orgânico total (TOC,\%) e $n$ alcanos totais (AlcTot, $\mu \mathrm{g} \mathrm{g}{ }^{-1}$ p.s.) do testemunho CAN05. As diferentes cores representam os diferentes períodos de deposição de carbono orgânico. 78

Figura 20: Perfil dos valores de $\delta^{13} \mathrm{C}$ do carbono orgânico total $\left(\delta^{13} \mathrm{C}\right.$ do TOC, $\%$ ), do índice alcano (Al) e do $\delta^{13} \mathrm{C}$ do $n-\mathrm{C}_{31}$ (\%o) encontrados no testemunho CAN05. As diferentes cores representam os diferentes períodos de deposição de carbono orgânico. 79

Figura 21: Perfil dos teores de lama (\%), carbono orgânico total (TOC,\%), nitrogênio total (TN, \%) e $n$-alcanos totais (AlcTot, $\mu \mathrm{g} \mathrm{g}^{-1}$ p.s.) do testemunho CAN07. As diferentes cores representam os diferentes períodos de deposição de carbono orgânico. 83

Figura 22: Perfil dos valores de $\delta^{13} \mathrm{C}$ do carbono orgânico total $\left(\delta^{13} \mathrm{C}\right.$ do TOC, $\%$ \%), do índice preferencial de carbono (CPI), do índice de produção aquática (Paq) e do índice alcano (Al) encontrados no testemunho CAN07. As diferentes cores representam os diferentes períodos de deposição do carbono orgânico.

Figura 23: Perfil dos teores de lama (\%), carbonato de cálcio $\left(\mathrm{CaCO}_{3}, \%\right)$, carbono orgânico total (TOC,\%), nitrogênio total (TN, \%) e $n$-alcanos totais (AlcTot, $\mu \mathrm{g} \mathrm{g}^{-1}$ p.s.) do testemunho CAN10. As diferentes cores representam os diferentes períodos de deposição de carbono orgânico. 88

Figura 24: Perfil dos valores do índice de produção aquática (Paq) e do índice alcano (Al) encontrados no testemunho CAN10. As diferentes cores representam os diferentes períodos de deposição de carbono orgânico. 89

Figura 25: Resumo das mudanças observadas ao longo do Sistema EstuarinoLagunar de Cananéia-Iguape relacionadas à abertura do canal do Valo Grande. (A) período anterior à abertura do canal do Valo Grande; (B) período após a construção deste canal; (C) período posterior ao seu fechamento; (D) período posterior à sua reabertura........................................................................... 91 


\section{EQUAÇÕES}

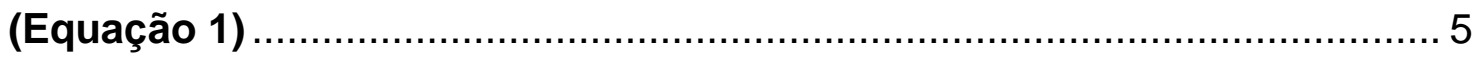

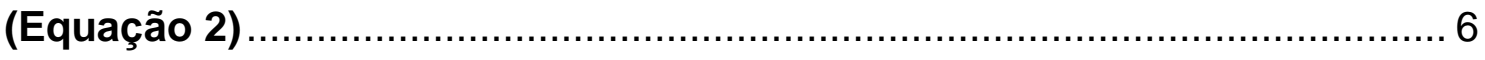

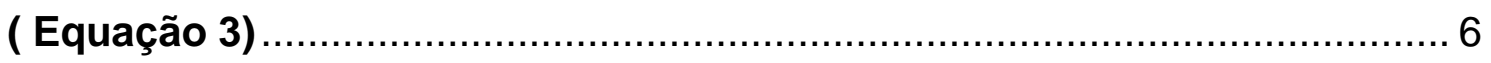

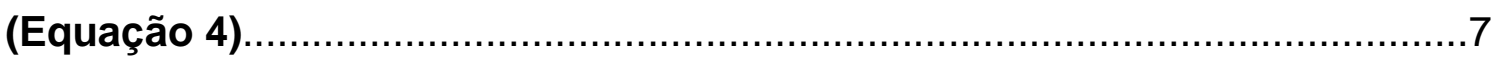

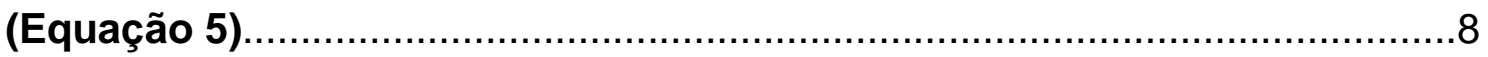

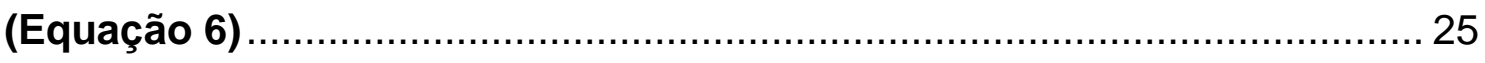

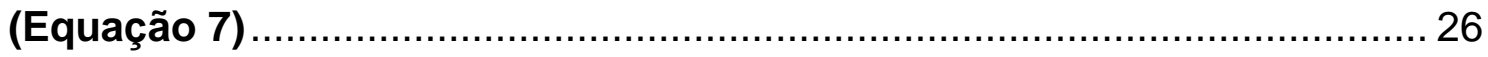

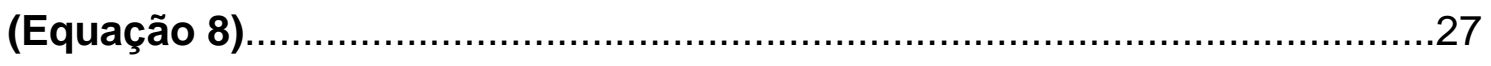

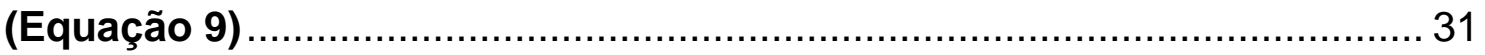

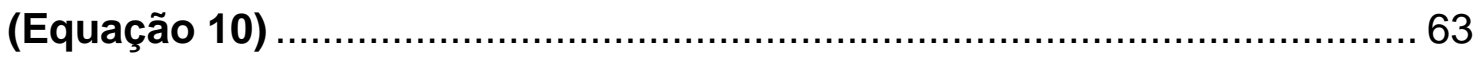




\section{LISTA DE ABREVIAÇÕES}

$\mathrm{ACL}_{23-33}=$ Tamanho Médio de Cadeia

$\mathrm{Al}=$ Índice Alcano

AlcTot $=n$-alcanos totais

$\mathrm{C} / \mathrm{N}$ = razão entre teor de carbono orgânico total e nitrogênio total

$\mathrm{C}_{3}$ = plantas cujo padrão fotossintético é do tipo $\mathrm{C}_{3}$ (Calvin-Benson)

$\mathrm{C}_{4}$ = plantas cujo padrão fotossintético é do tipo $\mathrm{C}_{4}$ (Hatche-Slack)

$\mathrm{CaCO}_{3}=$ teor de carbonato de cálcio

CIELS = Sistema Estuarino-Lagunar de Cananéia-Iguape

$\mathrm{CPI}=$ Índice Preferencial de Carbono

CSIA = análise isotópica de compostos específicos

DAEE = Departamento de Água e Energia Elétrica do Estado de São Paulo

$\mathrm{DCM}=$ diclorometano

$\mathrm{EA}=$ Analisdor elementar

$F=$ contribuição de matéria orgânica terrestre 
FID = detector de ionização de chama

$\mathrm{GC}=$ cromatógrafo a gás

$\mathrm{HEX}=n$-hexano

IAEA = International Atomic Energy Agency

10 = Instituto Oceanográfico

IRMS= Espectômetro de massa de razão isotópica

LDM = limite de detecção do método

MARUM = Zentrumfür Marine Umweltwissenschaften

$\mathrm{n}=$ número de amostras

n.a. $=$ não avaliado

n.c. $=$ não calculado

n.d. $=$ não detectado

$\mathrm{NADPH}=$ nicotinamida adenina dinucleotídeo fosfato reduzido

$\mathrm{OM}$ = matéria orgânica

P.A. = padrão analítico

p.s. $=$ peso seco

Paq = Índice de Produção Aquática 
$\mathrm{PDB}=$ PeeDeeBelemnite

$\mathrm{TN}=$ nitrogênio total

TOC = carbono orgânico total

$\mathrm{UB}=$ Universität Bremen

UNESCO = United Nations Educational Scientific and Cultural Organization

USGS = United StateGeologicalSurvey

USP $=$ Universidade de São Paulo

$V G=$ canal do Valo Grande 


\section{RESUMO}

O objetivo do presente estudo foi avaliar, através da análise de $n$ alcanos e de suas razões isotópicas, a influência da abertura do canal artificial do Valo Grande (VG) nas fontes de matéria orgânica (OM) do Sistema Estuarino-Lagunar de Cananéia-Iguape (CIELS). Os compostos foram analisados em quatro testemunhos, 22 sedimentos superficiais e em folhas de nove espécies de plantas dominantes na região de estudo. Os parâmetros avaliados nas folhas amostradas permitiram separar as espécies estudadas em monocotiledôneas e dicotiledôneas, e em vegetação lenhosa de mangue e de restinga. Esta separação foi útil na identificação das fontes de OM do CIELS. Os dados dos sedimentos superficiais mostraram que a principal fonte de OM no sistema é a vegetação de restinga. Esta se dá principalmente na região norte, onde está presente o VG. A influência fitoplanctônica, das macrófitas emersas e da vegetação de mangue é maior na região sul. Os dados dos testemunhos mostraram que a abertura do VG aumentou a contribuição da vegetação de restinga e das macrófitas aquáticas na OM presente ao longo do CIELS, diminuindo a influência fitoplanctônica e das macrófitas emersas. Assim, a qualidade e quantidade de OM do CIELS foram influenciadas pela presença do VG.

Palavras-chave: Sistema Estuarino-Lagunar de Cananéia-Iguape, Valo Grande, matéria orgânica, $n$-alcanos, razão isotópica de compostos específicos. 


\begin{abstract}
This study aimed to verify, through the use of $n$-alkanes and their isotopic composition, the influence of the Valo Grande artificial channel (VG) on organic matter (OM) sources of the Cananéia-Iguape Estuarine-Lagoon System (CIELS). The compounds were analyzed in four cores, 22 surface samples and nine dominants plants species leaves sampled on the studied area. The parameters evaluated on the leaves permitted to group the studied species in mono and dicotyledonous, and in mangrove and resting vegetation. This was useful to identify the OM sources on the CIELS. The surface sediment data showed that the CIELS OM is mainly composed by restinga vegetation. This occurs mainly on the northern region, where the VG is present. The influence of phytoplankton, of emergent macrophytes and of mangrove trees is higher on the southern region. The cores data showed that the VG opening increased the influences of Atlantic Forest and aquatic macrophytes on the CIELS OM, decreasing the emergent macrophytes and the phytoplankton influence. So, the type and the amount of OM on the CIELS are influenced by the VG presence.
\end{abstract}

Keywords: Cananéia-Iguape Estuarine-Lagoon System, Valo Grande, organic matter, $n$-alkanes, compound specific isotopic ratio. 


\section{INTRODUÇÃO}

\subsection{Sistema Estuarino-Lagunar de Cananéia-Iguape e a problemática do canal do Valo Grande}

O Sistema Estuarino-Lagunar de Cananéia-Iguape (Figura 1) encontrase no Vale do Ribeira, em uma Área de Proteção Ambiental (Decreto Estadual 90.347 e Decreto Federal 91.829 de 23 de outubro de 1984) (Fundação SOS Mata Atlântica, 2004) que é considerada pela UNESCO (United Nations Educational Scientific and Cultural Organization) como Reserva da Biosfera da Mata Atlântica e Patrimônio Mundial Natural da Humanidade (UNESCO, 1999; 2005).

O Vale do Ribeira já passou por diversos ciclos econômicos. Um dos mais importantes atingiu seu apogeu na primeira metade do século XIX e esteve relacionado à cultura do arroz em Iguape. A qualidade deste tinha reconhecimento internacional e sua exportação assegurava o desenvolvimento e a estabilidade da economia local. Dezenas de engenhos de beneficiamento escoavam sua produção através do Porto Grande (ou Porto de Iguape, Figura 1), que acabou se tornando um dos mais importantes do país durante aquela época (Fernandes, 1994; Carvalho, 2001). Este era localizado no interior do sistema costeiro (Mar Pequeno, Figura 1). Para escoar a produção, as sacas de arroz desciam de canoa pelo Rio Ribeira de Iguape (Figura 1) até o Porto do Ribeira (Figura 1), sendo levadas de carroças até o Porto Grande. 


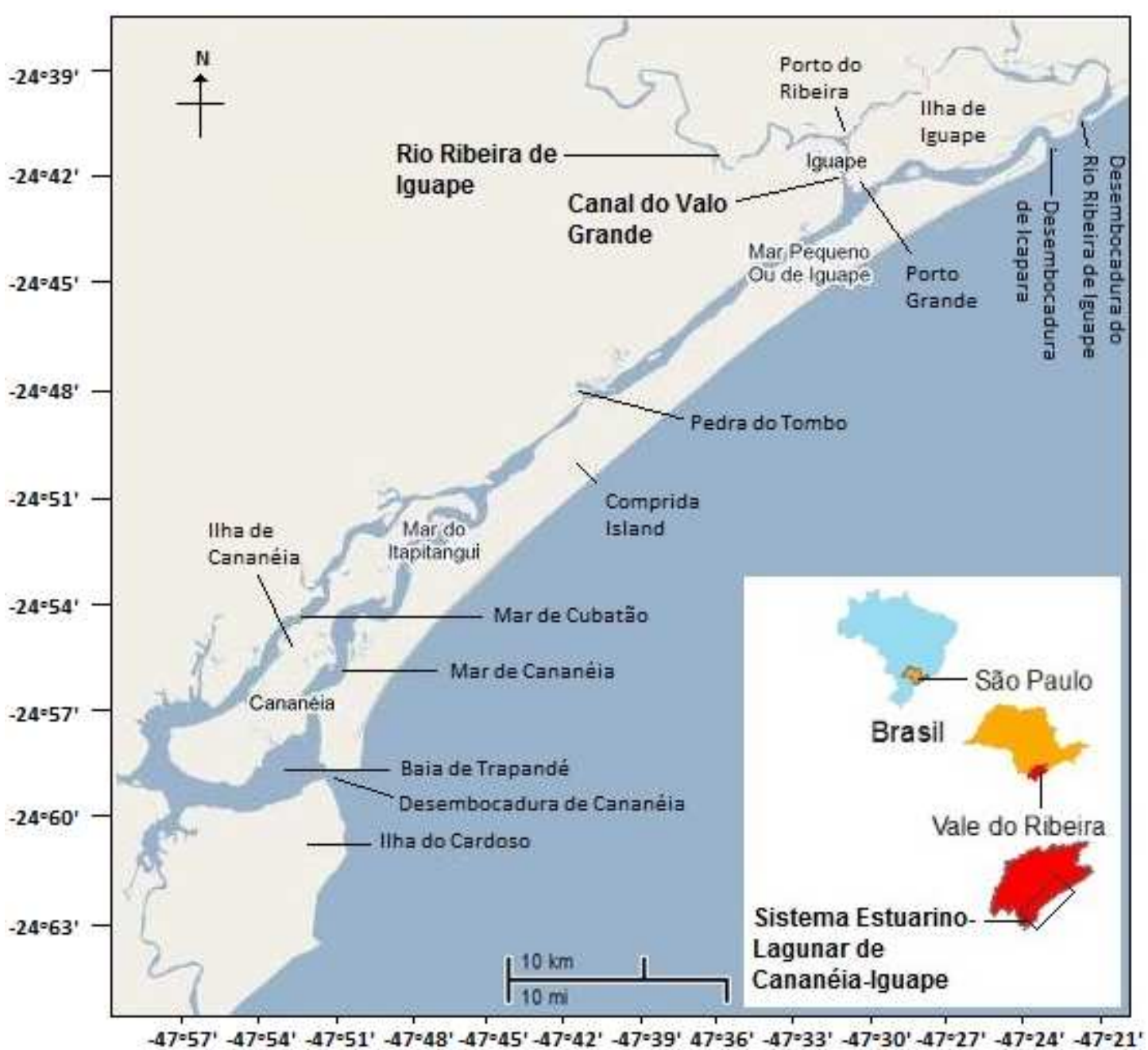

Figura 1: Localização dos principais canais, ilhas, desembocaduras, toponímias do Sistema Estuarino-Lagunar de Cananéia-Iguape.

Entre 1827 e 1852, com a finalidade de facilitar o escoamento do arroz, foi executada a abertura de um canal artificial interligando o Porto do Ribeira ao Porto Grande (Figura 1). Este primeiramente foi denominado Valo do Rocio e hoje é conhecido como canal do Valo Grande (Geobrás, 1966). Através deste canal, parte do fluxo de água do Rio Ribeira de Iguape foi desviado para o Mar Pequeno, causando erosão em suas margens (Geobrás, 1966), e assoreamento de regiões do sistema estuarino-lagunar. Esses fenômenos combinados levaram às primeiras alterações ambientais de grande magnitude no Sistema Estuarino-Lagunar de Cananéia-Iguape. Dentre elas, pode-se citar: a erosão de parte da cidade; diminuição da pesca; assoreamento do porto, do canal de navegação do Mar Pequeno e da Barra de Icapara, dentre outros 
(Sudelpa, 1987; Carvalho, 2001). O canal artificial, que inicialmente não tinha mais do que $4 \mathrm{~km}$ de extensão, $2 \mathrm{~m}$ de profundidade e $4,4 \mathrm{~m}$ de largura, foi rapidamente erodido pelo curso fluvial. Passado pouco mais de um século, o Valo Grande já havia atingido 235 metros de largura e 7 metros de profundidade (Geobrás, 1966). Neste período, o Porto de Iguape havia sido abandonado como polo exportador da região. Isso ocorreu devido, não apenas ao assoreamento da área do canal do Mar Pequeno próximo ao porto, mas também pela progressiva perda de importância das atividades econômicas da região.

Em agosto de 1978, o canal foi fechado pela construção de uma barragem de terra e pedra, tornando a direcionar todo seu fluxo através do seu leito original. Em 1983, após um período de chuvas intensas, houve o rompimento desta barragem, fazendo com que as águas do Rio Ribeira de Iguape voltassem a se dividir entre o Valo Grande e seu canal original (Mahiques et al., 2009).

Atualmente o canal do Valo Grande encontra-se aberto. Esta configuração atual introduz uma elevada taxa de água doce no Sistema Estuarino-Lagunar de Cananéia-Iguape, o que reflete não só em uma variação de suas características halinas, mas também nas propriedades físico-químicas do sistema, alterando, assim, a estrutura ecológica da região (Braga, 1995; Barreira-Alba et al., 2007).

Alguns trabalhos já foram realizados para avaliar os impactos causados pela abertura do canal do Valo Grande (p. ex. Tessler \& Furtado, 1983; Tessler \& Souza, 1998; Barcellos, 2005; Barrera-Alba et al., 2007; Nascimento-Filho et al., 2008; Mahiques et al., 2009; 2013; Maluf, 2009; Pisetta et al., 2011). Dentre estes, somente Senatore (2010) investigou as características da matéria orgânica do Sistema Estuarino-Lagunar de Cananéia-Iguape através de marcadores orgânicos moleculares. Este trabalho esteve restrito a sedimentos superficiais e não verificou a influência do canal do Valo Grande. Não houveram estudos onde tenha sido feita a reconstrução histórica de marcadores orgânicos moleculares na região, verificando o impacto deste canal no tipo de matéria orgânica depositada ao longo do tempo. 


\subsection{Marcadores orgânicos moleculares}

Marcadores orgânicos moleculares são compostos que apresentam especificidade de fonte e alta estabilidade química (Philip, 1985; Volkman et al., 1992; Mudge \& Norris, 1997; Takada \& Eganhouse, 1998). Uma vez depositados, permanecem nos sedimentos, podendo ser associados a um determinado tipo de evento ou fonte de matéria orgânica (Colombo et al., 1989). Assim, estes compostos têm sido aplicados na área de geoquímica em estudos paleoambientais (Albaigés et al., 1984; Hu et al., 2009).

Os $n$-alcanos são hidrocarbonetos alifáticos saturados de cadeia linear encontrados nos sedimentos que contêm matéria orgânica (Miles, 1994). Estes compostos são sintetizados por todos os seres vivos, entretanto suas principais fontes naturais para a maioria dos ambientes marinhos são as plantas terrestres e o fitoplâncton (Xing et al. 2011; Izart et al., 2012). Estes organismos biossintetizam os $n$-alcanos através da descarboxilação dos ácidos graxos, que têm, predominantemente, número par de átomos de carbono. Assim, os $n$ alcanos produzidos naturalmente apresentam, na maioria das vezes, predominância de cadeias contendo número ímpar de átomos de carbono (Killops \& Killops, 2005).

As fontes de $n$-alcanos apresentam distribuições característica de seus homólogos. Organismos fitoplanctônicos normalmente sintetizam compostos com cadeias ímpares mais curtas $\left(<n-C_{19}\right)$, predominando aqueles com 15 e 17 átomos de carbono (Blumer et al., 1997). As plantas superiores, com a finalidade de preservar o conteúdo de água de suas folhas através das ceras epicuticulares, sintetizam preferencialmente $n$-alcanos com cadeias mais longas ( $>n-C_{27}$ ), principalmente com 29, 31 e 33 átomos de carbono (Clark \& Blumer, 1967; Kennicutt\& Comet, 1992; Brassel, 1993). As macrófitas, como estão sobre menor estresse hidrológico que a vegetação superior, sintetizam preferencialmente $n$-alcanos com 23 e 25 átomos de carbono (Ficken et al., 2000).

Através das características de distribuição, a origem dos $n$-alcanos pode ser facilmente atribuída aplicando-se determinadas razões das concentrações dos compostos encontrados. O tamanho médio de cadeia $\left(\mathrm{ACL}_{23-33}\right)$ é uma dessas razões. Esta, calculada através da Equação 1, descreve qual é o 
número médio de átomos de carbono existente nas moléculas de $n$-alcanos detectadas em uma amostra, baseando-se nos compostos com 23 a 33 átomos de carbono (Poynter \& Eglinton, 1990; Jeng, 2006). Valores mais baixos de $\mathrm{ACL}_{23-33}$ (entre 23 e 25) representam uma maior contribuição de macrófitas à matéria orgânica presente em uma região estudada (Ficken et al., 2000). Valores entre 27 e 33 representam uma maior contribuição de plantas terrígenas (Collister et al., 1994; Rommerskirchen et al., 2006).

$$
A C L_{23-33}=\frac{\sum[n-C i] * i}{\sum[n-C i]}
$$

(Equação 1)

$\mathrm{Ci}=n$-alcanos com i números de carbono (i variando de 23 a 33)

Dentre os $n$-alcanos de origem terrígena, há uma distinção entre aqueles provindos de plantas vasculares, cujo padrão fotossintético é do tipo $\mathrm{C}_{3}$ (CalvinBenson), e aqueles produzidos por gramíneas, cujo padrão fotossintético é do tipo $\mathrm{C}_{4}$ (Hatche-Slack) (Zhang et al., 2006; Rommerskirchen et al., 2006). Enquanto as do tipo $\mathrm{C}_{4}$ tendem produzir maiores quantidades relativas de $n-C_{31}$ e $n-C_{33}$, as do tipo $C_{3}$ produzem mais $n-C_{27}$ e $n$ - $C_{29}$ (Schefuß et al., 2003). Baseando nestas diferenças, estabeleceu-se o índice alcano (Al), calculado através da Equação 2 (Schwark et al., 2002; Schefuß et al., 2003; Rommerskirchen et al., 2003; Zhang et al., 2006). Valores superiores a 0,5 são indicativos que a fonte predominante entre os $n$-alcanos de origem terrígena é as gramíneas do tipo $\mathrm{C}_{4}$; e valores inferiores a 0,5 indicam predominância de plantas do tipo $\mathrm{C}_{3}$ (Rommerskirchen et al., 2003). 


$$
A \boldsymbol{I}=\frac{\left[n-\mathrm{C}_{31}\right]}{\left[n-\mathrm{C}_{29}\right]+\left[n-\mathrm{C}_{31}\right]}
$$

(Equação 2)

Há diferenças também entre os $n$-alcanos produzidos pelos distintos tipos de macrófitas. As submersas (p. ex. Utricularia foliosa) e flutuantes (p.ex. Echornia crassipes) sintetizam mais $n$-alcanos de cadeias medianas $\left(n-C_{23}\right.$ e $n$ $\mathrm{C}_{25}$ ) que as macrófitas emersas (p.ex. Spartina alterniflora e Scirpus californicus) e plantas superiores. A abundância relativa do $n-\mathrm{C}_{23}$ e do $n-\mathrm{C}_{25}$ em comparação ao $n-C_{29}$ e $n-C_{31}$ tem sido usada para verificar a contribuição dessas plantas aquáticas em ambientes marinhos (Ficken et al., 2000; Mead et al., 2005; Damsté et al., 2011). Esta é feita através do índice de produção aquática (Paq), calculado por intermédio da Equação 3 (Ficken et al., 2000). Valores de Paq menores que 0,1 indicam predominância de fontes terrígena. Valores entre 0,1 e 0,4 são referentes ao predomínio de plantas aquáticas emersas. Valores maiores que 0,4 são referentes ao predomínio de plantas aquáticas submersas e flutuantes (Ficken et al., 2000).

$$
\boldsymbol{P A Q}=\frac{\left[n-\mathrm{C}_{23}\right]+\left[n-\mathbb{C}_{25}\right]}{\left[n-\mathbb{C}_{28}\right]+\left[n-\mathbb{C}_{25}\right]+\left[n-\mathbb{C}_{29}\right]+\left[n-C_{31}\right]}
$$

(Equação 3)

Outro índice que é empregado em estudos paleoambientais com $n$ alcanos é o índice preferencial do carbono (CPI). Este expressa a dominância de $n$-alcanos com números ímpares de carbono entre os compostos de cadeias longas (Eglinton et al., 1962; Eglinton \& Hamilton, 1963, 1967). O CPI é normalmente usado para verificar se as fontes de hidrocarbonetos para o meio são naturais ou antropogênicas (petróleo) (PietroGrande et al., 2010). 
Entretanto, ele também pode ser usado para separar contribuições provindas de diferentes grupos de vegetação (Eglinton et al., 1962). O CPI é calculado através da Equação 4 (Aboul-Kassim \& Simoneit, 1996):

$$
\begin{aligned}
\text { CPI }=\frac{1}{2} \times\left(\frac{\left[n-C_{25}\right]+\left[n-C_{27}\right]+\left[n-C_{29}\right]+\left[n-C_{31}\right]+\left[n-C_{33}\right]}{\left[n-C_{24}\right]+\left[n-C_{26}\right]+\left[n-C_{28}\right]+\left[n-C_{30}\right]+\left[n-C_{32}\right]}\right. \\
\left.\quad+\frac{\left[n-C_{25}\right]+\left[n-C_{27}\right]+\left[n-C_{29}\right]+\left[n-C_{31}\right]+\left[n-C_{33}\right]}{\left[n-C_{26}\right]+\left[n-C_{28}\right]+\left[n-C_{30}\right]+\left[n-C_{32}\right]+\left[n-C_{34}\right]}\right)
\end{aligned}
$$

(Equação 4)

Aplicando-se estas razões, a interpretação da distribuição de $n$-alcanos nos sedimentos pode ser valiosa para investigar as diferentes fontes de matéria orgânica em uma determinada região.

\subsection{Isótopos estáveis}

Isótopos são átomos de um mesmo elemento químico que contêm diferentes números de nêutrons em seus núcleos (Boutton, 1991). Estes podem ser divididos em dois grupos: os radioisótopos e os isótopos estáveis. Enquanto os componentes do primeiro grupo emitem radiação e decaem, os isótopos estáveis não emitem e, dessa forma, possuem uma razão relativamente constante entre si ao longo do tempo (Fry, 2006).

Durante a transferência dos elementos através de processos bióticos (respiração, fotossíntese, metabolismo, etc.) e abióticos (precipitação, evaporação, congelamento, etc), há um fracionamento dos isótopos estáveis presentes nas diferentes matrizes. Isso ocorre porque os átomos mais leves (ex.: ${ }^{12} \mathrm{C},{ }^{14} \mathrm{~N}$ e H) são preferencialmente assimilados em relação aos mais pesados (ex.: ${ }^{13} \mathrm{C},{ }^{15} \mathrm{~N}$ e D). A proporção entre o isótopo mais leve e o mais pesado é expressa na forma de uma razão (ex.: ${ }^{13} \mathrm{C} /{ }^{12} \mathrm{C},{ }^{15} \mathrm{~N} /{ }^{14} \mathrm{~N}$ e D/H) (Fry, 2006). Estudos ecológicos expressam a composição isotópica em termos de $\delta$, 
que representa a diferença entre a razão isotópica da amostra e a de um padrão internacional (Equação 5) (Sleiman, 2008).

$$
\delta \mathrm{X} \% \mathrm{o}=\left(\frac{R_{\text {amostra }}-R_{\text {padrăo }}}{R_{\text {padrล̃o }}}\right) \times 1000
$$

(Equação 5)

$\delta \mathrm{X} \%$ (amostra $)=$ enriquecimento isotópico da amostra relativo ao padrão.

$\mathrm{R}_{\mathrm{amostra}}=$ razão isotópica da amostra (por exemplo: no caso do carbono, ${ }^{13} \mathrm{C} /{ }^{12} \mathrm{C}$ );

$R_{\text {padrão }}=$ razão isotópica do padrão.

O controle da composição isotópica em todos os organismos é similar. Este é dependente da razão isotópica da fonte do composto (carbono e nitrogênio, por exemplo) e de seus mecanismos de assimilação (Pancost \& Pagani, 2006).

$\mathrm{O} \delta^{13} \mathrm{C}$ dos organismos marinhos fotossintetizantes é dependente da razão isotópica do carbono inorgânico dissolvido na água. Este se apresenta sob três formas: $\mathrm{CO}_{2 \mathrm{aq}}, \mathrm{HCO}_{3}{ }^{-}$e $\mathrm{CO}_{3}{ }^{2-}$. $\mathrm{O} \mathrm{CO}_{2 a q}$, quando comparado ao $\mathrm{CO}_{2}$ gasoso, é empobrecido em ${ }^{13} \mathrm{C}$; e $0 \mathrm{HCO}_{3}{ }^{-}$e o $\mathrm{CO}_{3}{ }^{2-}$ são enriquecidos (Pancost \& Pagani, 2006). O carbono orgânico de origem fitoplanctônica apresenta um valor de $\delta^{13} \mathrm{C}$ variando de $-23 \%$ a $-12 \%$ (Schubert \& Calvert, 2001; Zhou et al., 2006).

O substrato de carbono para a vegetação superior é o $\mathrm{CO}_{2}$ atmosférico. Nas plantas do tipo $\mathrm{C}_{3}$ há uma maior discriminação do ${ }^{13} \mathrm{CO}_{2}$ durante 0 processo de fotossíntese, fazendo com que os seus valores de $\delta^{13} \mathrm{C}$ sejam menores (Lehninger, 1982). Nas plantas do tipo $\mathrm{C}_{4}$, para evitar perdas de água, há uma redução no fluxo de $\mathrm{CO}_{2}$, que diminui a discriminação do ${ }^{13} \mathrm{C}$ (Lehninger, 1982; Pancost \& Pagani, 2006). O resultado desses diferentes modos de assimilação do $\mathrm{CO}_{2}$ pelas plantas superiores é expresso nos valores de $\delta^{13} \mathrm{C}$ encontrados no carbono orgânico total. Plantas do tipo $\mathrm{C}_{3}$ apresentam $\delta^{13} \mathrm{C}$ entre $-34 \%$ e $-23 \%$. Plantas do tipo $\mathrm{C}_{4}$ apresentam $\delta^{13} \mathrm{C}$ entre $-17 \%$ o $-9 \%$ (Schubert \& Calvert, 2001; Zhou et al., 2006). 
A razão isotópica do nitrogênio $\left(\delta^{15} \mathrm{~N}\right)$ também pode ser aplicada em conjunto ao $\delta^{13} \mathrm{C}$ na determinação das fontes de matéria orgânica (Zhou et al., 2006). O $\delta^{15} \mathrm{~N}_{\text {do }} \mathrm{NO}_{3}{ }^{-}$dissolvido varia entra 7 e $10 \%$, e o $\mathrm{N}_{2}$ atmosférico apresenta $\delta^{15} \mathrm{~N}$ em torno de $0 \%$ (Meyers, 1997). O fitoplâncton apresenta uma preferência assimilatória pelo isótopo mais leve de nitrogênio dissolvido, resultando em um $\delta^{15} \mathrm{~N}$ entre 5 e $6 \%$. Já as plantas terrestres em sistemas estuarinos, que assimilam $\mathrm{N}_{2}$ atmosférico, têm $\delta^{15} \mathrm{~N}$ próximos a $0,4 \%$ (Meyers, 1997).

\subsubsection{Análise Isotópica de compostos específicos}

Nas últimas décadas, tem sido desenvolvido um método capaz de avaliar a razão isotópica dos marcadores orgânicos moleculares (Ishiwatari et al., 1994; Meier-Augenstein,1999). Este, denominado análise isotópica de compostos específicos (CSIA), usa a técnica de cromatografia a gás acoplada a um espectrômetro de massa de razão isotópica (GC-IRMS), separando e identificando a composição isotópica de cada composto presente em uma mistura de marcadores orgânicos moleculares (Cortes et al., 2010).

A aplicação da CSIA gera um maior grau de detalhamento sobre a fonte da matéria orgânica depositada (Schefuß et al., 2003; Duan \& Hen, 2011; Wang et al., 2013).

As razões isotópicas avaliadas em $n$-alcanos são $\circ \delta^{13} \mathrm{C}$ e $\circ \delta \mathrm{D}$. Os valores destas razões são dependentes do fracionamento isotópico ocorrido durante a fotossíntese (Hayes, 1993; Sessions et al., 1999; Chikaraishi et al., 2004). $O \delta^{13} \mathrm{C}$ nos $n$-alcanos é geralmente menor do que o $\delta^{13} \mathrm{C}$ da matéria orgânica total devido ao fracionamento isotópico ocorrido durante a biossíntese desses compostos (Bird et al., 1995; Schefuß et al., 2003). Os motivos pelos quais os $n$-alcanos das plantas do tipo $\mathrm{C}_{3}$ são menos enriquecidos em ${ }^{13} \mathrm{C}$ que os das plantas do tipo $\mathrm{C}_{4}$ são os mesmos que os do carbono orgânico total. Enquanto que as plantas do primeiro grupo apresentam uma maior discriminação do ${ }^{13} \mathrm{CO}_{2}$ durante o processo fotossintético (Lehinger, 1982), nas espécies do segundo grupo há uma redução no fluxo de $\mathrm{CO}_{2}$, aumentando a assimilação do ${ }^{13} \mathrm{C}$ (Lehinger, 1982; Pancost \& Pagani, 2006). Plantas do tipo 
$\mathrm{C}_{3}$ apresentam valores de $\delta^{13} \mathrm{C}$ em seus $n$-alcanos variando entre $-39 \%$ e $-31 \%$. Em plantas do tipo $\mathrm{C}_{4}$, estes valores variam entre $-25 \%$ o $-18 \%$ o (Bi et al., 2005; Schefuß et al., 2003).

$O \delta D$ dos $n$-alcanos também pode ser usado na identificação das fontes de matéria orgânica. Sabe-se que o $\delta \mathrm{D}$ médio de monocotiledôneas do tipo $\mathrm{C}_{3}$ é $-149 \pm 28 \%$, enquanto que em dicotiledôneas este valor é de $-113 \pm 31 \%$. A variabilidade no enriquecimento de $D$ nos marcadores moleculares pode ser ocasionada pelas diferenças fisiológicas das espécies avaliadas (Sachse et al., 2012). A arquitetura da folha de cada grupo, bem como o tempo de síntese das ceras cuticulares, podem ser as responsáveis por estas diferenças (Sachse et al., 2012). Também há distinções no $\delta D$ de plantas do tipo $C_{4}$ e do tipo $C_{3}$. As monocotiledôneas do primeiro grupo são mais enriquecidas em deutério (com valor médio de $\delta \mathrm{D}$ de $-134 \pm 27 \%$ ) que as monocotiledôneas do segundo grupo. Estas distinções podem estar relacionadas aos diferentes padrões de formação do NADPH (nicotinamida adenina dinucleotídeo fosfato) das espécies de cada grupo (Sachse et al., 2012).

Diferenças mais acentuada no $\delta \mathrm{D}$ dos compostos específicos estão relacionadas às mudanças ambientais (Smith \& Freeman, 2006; Sachse et al., 2012). Plantas de uma mesma espécie apresentam valores distintos de $\delta \mathrm{D}$ em seus compostos devido às condições climáticas a qual elas estão submetidas (Chikaraishi \& Naraoka, 2001, 2007; Pedentchouk et al., 2008; Feakins \& Sessions, 2010). A composição isotópica do hidrogênio de $n$-alcanos de cadeia longa (origem terrestre) pode refletir, por exemplo, a composição isotópica da precipitação local ou transpiração das folhas e evaporação dos solos (Smith \& Freeman, 2006; Chikaraishi \& Naraoka, 2007; Sachse et al., 2012).

\subsection{Caracterização dos $n$-alcanos na vegetação}

O estudo da composição dos marcadores orgânicos moleculares em ceras epicuticulares é útil para compreender os processos bioquímicos envolvidos na síntese destes compostos (Sessions et al., 2002; Rommerskirchen et al., 2006). Estes geram informações importantes sobre a relação entre as espécies de plantas e o meio ambiente em que elas 
cresceram, auxiliando na interpretação de estudos paleoambientais (Schefuß et al., 2003).

Nas últimas décadas, diversos trabalhos foram realizados na determinação da composição das ceras epicuticulares de diferentes tipos de vegetação (Haye et al., 1989; Hayes, 1993; Terwilliger \& DeNiro, 1995; Chikaraishi \& Naraoka, 2001; Kahmen et al., 2013a). Hoje, sabe-se, por exemplo, que o $\delta \mathrm{D}$ dos $n$-alcanos de plantas de clima tropical podem refletir as condições de precipitação (Kahmen et al., 2013a). A baixa umidade, a radiação solar incidente, o calor, etc; podem interferir na proporção de $n$-alcanos mais pesados (Sachse et al., 2006; Pedentchouk et al., 2008). As proporções e a razão isotópica dos $n$-alcanos produzidos em altas e baixas latitudes são diferentes (Liu \& Yang, 2008).

A integridade do paradigma de que a predominância de determinados $n$ alcanos e que as suas razões isotópicas correspondem a certos grupos de vegetação deve ser sempre testada em relação ao ambiente que uma determinada planta cresceu (Reddy et al, 2000). A maioria dos estudos de caracterização dos $n$-alcanos em ceras epicuticulares de vegetação superior foi realizada em amostras coletadas em condições climáticas temperadas (Chikaraishi\& Naraoka, 2001; Bi et al., 2005; Sachse et al., 2006). Poucos trabalhos foram realizados no Brasil (Belligotti et al., 2007) e estes geralmente tinham como objetivo gerar dados para estimar a ingestão e composição botânica da dieta de herbívoros (Oliveira \& Prates, 2000; Côrtes et al., 2005). Não houveram trabalhos realizados no Sistema Estuarino-Lagunar de Cananéia-Iguape para estudos paleoambientais. 


\section{HIPÓTESE DE TRABALHO}

A composição molecular e isotópica da matéria orgânica depositada no Sistema Estuarino-Lagunar de Cananéia-Iguape foi influenciada pelo Rio Ribeira de Iguape através da abertura do canal do Valo Grande. Essa influência pode ser observada tanto superficialmente quanto ao longo do tempo através da avaliação de marcadores orgânicos moleculares como $n$-alcanos em sedimentos superficiais e nas amostras dos testemunhos coletados ao longo do sistema. 


\section{OBJETIVOS}

O presente estudo tem como objetivo verificar a possível influência do canal do Valo Grande na quantidade e qualidade da matéria orgânica depositada no Sistema Estuarino-Lagunar de Cananéia-Iguape. Pretende-se também reconstituir a história deposicional da região, avaliando as diferenças nas fontes da matéria orgânica antes e após a abertura deste canal. Estes objetivos deverão ser alcançados através das seguintes ações:

- Verificar a composição dos $n$-alcanos e de suas razões isotópicas $\left(\delta^{13} \mathrm{C}\right.$ e $\left.\delta \mathrm{D}\right)$ em espécies de plantas representativas da região;

- Quantificar os $n$-alcanos nas frações de sedimentos dos testemunhos e das amostras superficiais coletadas, determinando também suas razões isotópicas, e comparando-as com as encontradas na vegetação representativa da região;

- Determinar o teor de carbonato de cálcio, o teor de carbono orgânico total, o teor de nitrogênio total, o $\delta^{13} \mathrm{C}$ e $\delta^{15} \mathrm{~N}$ da matéria orgânica total, a razão entre o teor de carbono orgânico total e de nitrogênio total, e as frações sedimentares das amostras de forma a compreender e complementar os resultados de $n$-alcanos;

- Verificar qual o tipo predominante de carbono orgânico depositado na área de estudo. Identificar qual o tipo de matéria orgânica é introduzido na região pelo Rio Ribeira de lguape. A partir destes dados, identificar as variações ao longo da região de estudo e ao longo do tempo, verificando qual a possível influência do canal Valo Grande no carbono orgânico depositado ao longo do Sistema Estuarino-Lagunar de Cananéia-Iguape. 


\section{4. ÁREA DE ESTUDO}

O Sistema Estuarino-Lagunar de Cananéia-Iguape (Figura 1) está situado no extremo sul do Estado de São Paulo, entre as latitudes de $24^{\circ} 40^{\prime} \mathrm{S}$ e $25^{\circ} 05^{\prime} \mathrm{S}$ e as longitudes de $47^{\circ} 25^{\prime} \mathrm{W}$ e $48^{\circ} 10^{\prime} \mathrm{W}$. A região é composta por um complexo sistema de canais localizados entre quatro ilhas: a do Cardoso, de Cananéia, Comprida e de Iguape (Figura 1). A llha Comprida é quem separa o sistema estuarino-lagunar do oceano. Entre esta ilha e o continente, há um canal denominado Mar Pequeno (Figura 1). Na porção mais ao sul, localiza-se a llha de Cananéia. Esta é separada do continente e da llha Comprida por dois canais denominados Mar de Cubatão e Mar de Cananéia (Figura 1). Esses canais são interligados pela Baía de Trapandé (Figura 1). Os canais e os rios presentes na região de estudo desembocam no oceano através das desembocaduras (ou barras) de: Cananéia, Icapara e do Rio Ribeira de Iguape (Figura 1). Os processos de trocas entre as águas marinhas e as lagunares ocorrem através dessas barras (Miyao, 1977; Barcellos, 2005).

\subsection{Características e evolução geológica}

O arcabouço ígneo-metamórfico da região de Cananéia-Iguape é PréCambriano, constituído principalmente por rochas metamórficas (Souza et al., 1996). A evolução do Sistema Estuarino-Lagunar de Cananéia-Iguape data dos eventos transgressivo-regressivos do Quaternário Superior (Besnard, 1950; Suguio \& Martin , 1978).

Atualmente, o Sistema Estuarino-Lagunar de Cananéia-Iguape está sobre uma planície costeira arenosa. Seus processos sedimentares parecem ter sido alterados nos últimos 150 anos, em função da abertura do canal do Valo Grande (Teixeira, 1969). Os canais lagunares que constituem o Sistema Cananéia-Iguape apresentam tendências ao assoreamento, formando ilhas e esporões, onde se desenvolvem manguezais (Tessler \& Furtado, 1983). 


\subsection{Clima}

O clima na região do Sistema Estuarino-Lagunar de Cananéia-Iguape apresenta características tropicais úmidas (Sztutman \& Rodrigues, 2002). A temperatura média anual é $21^{\circ} \mathrm{C}$. No inverno, esta média desce para $18^{\circ} \mathrm{C}$ (julho), e no verão, sobe para $25^{\circ} \mathrm{C}$ (fevereiro) (Schaeffer-Novelli et al., 1990). A precipitação média anual varia de 2000 a 2300 mm. Valores pluviométricos máximos ocorrem no verão, com média mensal de 267 mm. Valores mínimos ocorrem no inverno, com média mensal 95 mm (Ramos et al.,1980; Silva \& Herz, 1987;Barcellos, 2005).

\subsection{Circulação e maré}

As marés do Sistema Estuarino-Lagunar de Cananéia-Iguape são semidiurnas, com amplitudes máximas de 1,20 m em sizígia, e de 0,13 m em quadratura. Durante a enchente, a onda de maré penetra no sistema através das barras de Cananéia e de Icapara, encontrando-se no Mar Pequeno, na região conhecida como "Pedra do Tombo"(Figura 1) (Miyao et al., 1986; Miyao \& Harari, 1989). Durante a maré vazante, há um fluxo de saída nestas duas barras, que promove uma divisão do fluxo a partir da Pedra do Tombo (Miniussi, 1959 apud Maluf, 2009).

O movimento das marés é o principal responsável pela circulação na área de estudo (Bonetti-Filho, 1995). Há também contribuição da drenagem continental (Mendonça, 2007). As correntes ocorrem principalmente segundo o eixo longitudinal dos canais, com velocidades superiores a $1 \mathrm{~m} \mathrm{~s}^{-1}$ (Miyao, 1977).

\subsection{Rede hidrográfica}

A bacia de drenagem fluvial que alimenta o sistema com água doce é constituída por duas bacias principais: a da Serra de Itapitangui e a do Rio Ribeira de lguape. 
A Bacia da Serra de Itapitangui é localizada na parte sudoeste do sistema. Os principais rios desta bacia são: Taquari/Carapara, Minas/Mandira, Itapitangui e Iririaia-Açu. Estes apresentam uma capacidade de drenagem pequena (1339 km²) (Mishima et al., 1985) e contribuem com um fluxo médio de água doce que varia entre 47 e $50 \mathrm{~m}^{3} \mathrm{~s}^{-1}$ (Bonetti-Filho \& Miranda, 1997; Bérgamo, 2000).

A Bacia do Rio Ribeira de Iguape está localizada na região norte do sistema. Ela é constituída pelo Rio Ribeira de Iguape, cuja capacidade de drenagem é de $23.350 \mathrm{~km}^{2}$ e a vazão média é de $770 \mathrm{~m}^{3} \mathrm{~s}^{-1}$ (Bérgamo, 2000. Após a construção do Valo Grande, as águas do Rio Ribeira de Iguape passaram a ser introduzidas na região através deste canal, cooperando com uma descarga de sólidos no sistema da ordem de $1.000 .000 \mathrm{~m}^{3}$ ano $^{-1}$ (Geobrás, 1966). O Rio Ribeira de lguape é o maior contribuinte de material terrígeno para o Sistema Estuarino-Lagunar de Cananéia-lguape (Geobrás, 1966).

Semelhantes a cursos fluviais, diversas gamboas desembocam nos canais lagunares. Estes pequenos cursos d'água não têm débito próprio, apresentando fluxo bi-direcional induzido pelas marés. As gamboas têm grande importância no que diz respeito ao transporte de compostos orgânicos para o sistema lagunar (Barcellos, 2005).

\subsection{Salinidade}

A salinidade do Sistema Estuarino-Lagunar de Cananéia-Iguape varia em função da maré e das descargas fluviais. As ondas de maré promovem a mistura das águas oceânicas e fluviais, ocasionando variações na distribuição da salinidade no sistema (Miyao, 1977).

Kato (1966) apud Barcellos (2005) observou que a salinidade do Sistema Estuarino-Lagunar de Cananéia-Iguape aumenta da superfície para o fundo, variando de acordo com a oscilação da maré. Foram também observadas variações na sua distribuição longitudinal. Salinidades médias próximas a 24 são encontradas nas águas superficiais da Barra de Cananéia, e próximas a 2 são encontradas na região da Pedra do Tombo. 
O Valo Grande influenciou de maneira significativa nos valores médios de salinidade do sistema. Durante o período em que este canal esteve fechado (1978 a 1983), o sistema foi classificado como parcialmente misturado e fracamente estratificado (tipo 2a). Após a reabertura da barragem em 1983, a introdução de água doce aumentou. O sistema foi, então, caracterizado como parcialmente misturado e altamente estratificado (tipo 2b) durante maré de sizígia das estações de verão, outono e primavera. No inverno, o sistema retoma as características de tipo 2a. O mesmo ocorre no outono e na primavera durante as marés de quadratura (Miranda et al., 1995; Bérgamo, 2000).

\subsection{Dinâmica sedimentar}

O Sistema Estuarino-Lagunar de Cananéia-Iguape é composto por uma grande diversidade de ambientes deposicionais (Barcellos, 2005). O predomínio é de sedimentos arenosos provindos da ressupensão, da erosão das margens e da deposição arenosa dos ciclos oscilatórios do nível do mar (Tessler, 1982; Bonetti-Filho et al., 1996). O responsável pela distribuição destes sedimentos são as correntes geradas pela maré. Durante a maré enchente, as águas marinhas entram pelo fundo dos canais, ressuspendendo os sedimentos. Estes são incorporados aos fluxos de vazante, sendo redistribuídos em direção às desembocaduras do sistema (Tessler \& Furtado, 1983; Barcellos, 2005).

Há também um aporte atual significativo de material pelítico em suspensão (Bonetti-Filho et al., 1996). Este ocorre através dos rios que drenam as serras localizadas ao sul e sudoeste da região e, principalmente, ao norte através do Valo Grande (Barcellos, 2005).

Atualmente, toda a região sofre um forte processo de assoreamento que é evidenciado pelo crescimento de feições sedimentares, pela deposição de materiais mais finos e pelas altas taxas de sedimentação $(1 \mathrm{~cm}$ ano-1) (Saito et al., 2001; Saito, 2002). 


\subsection{Vegetação}

O Valo do Ribeira reúne cerca da metade de toda a vegetação nativa remanescente do Estado de São Paulo, com uma das maiores áreas preservadas de Mata Atlântica (Veloso et al., 1992). Dentre os ecossistemas presentes nesta vegetação, podemos citar a floresta ombrófila densa, a floreta ombrófila mista, os campos de altitude, a restinga e os manguezais. O termo restinga apresenta diferentes significados em distintos ramos das ciências naturais (Suguio \& Tessler, 1984; Lacerda et al., 1984; Pereira et al., 2011). No geral, ele é um termo usual para designar o ecossistema que ocupa as planícies do litoral do Brasil, formados por sedimentos de origem marinha. Este ecossistema ocorre sobre depósitos arenosos costeiros e apresenta um conjunto de comunidades vegetais fisionomicamente distintas que está sob influência marinha e flúvio-marinha (Sampaio et al., 2010; Pereira et al., 2011). Dentre as principais espécies de árvores presentes neste ecossistema pode-se citar: Euterpe edulis (Palmito-juçara), Cecropia pachystachya (Embaúba), Calophyllum brasiliensis (Jacareúba), Ocotea ssp (Canela), Netandra ssp (Canela), Tabebuia ssp (Ipê), Syagrus romanzoffiana (Jerivá), Tapirira guianensis (Tapirirá), etc (Sampaio et al., 2010). A vegetação de restinga ainda apresenta espécies de bromélia, samambaias, orquídeas, begônias e heliconias (Freitas et al., 2000; Fraga \& Peixoto, 2004; Sampaio et al., 2010; Gasper et al., 2012).

No Sistema Estuarino-Lagunar de Cananéia-lguape, há ainda extensas áreas de manguezais bem estruturados (Sudelpa, 1987). A vegetação predominante é a de mangue, com presença também de marisma e restinga (Cunha-Lignon, 2001). As principais espécies são: Rhizophora mangle (Mangue-vermelho); Laguncularia racemosa (Mangue-branco) e Spartina alterniflora (Capim-marinho) (Schaeffer-Novelli \& Cintrón-Molero, 1990; CunhaLignon, 2001; Cunha-Lignon \& Kampel, 2011).

Junto aos núcleos urbanos de Iguape e da llha Comprida, bem como no Baixo Vale do Ribeira, há ainda extensas áreas agrícolas. Estes estão diretamente associados a processos de desmatamento, erosão e assoreamento dos canais fluviais (Afonso, 1999). As principais culturas da região são: arroz, chá e banana. 


\section{MATERIAIS E MÉTODOS}

\subsection{Amostragem dos sedimentos}

As coletas foram realizadas em duas fases distintas, com o auxílio do barco de pesquisa Velliger II da Universidade de São Paulo.

A primeira fase foi realizada em abril de 2008 pela equipe do Prof. Dr. Michel Michaelovitch de Mahiques, do Instituto Oceanográfico (IO) da Universidade de São Paulo (USP), onde foram coletados 4 testemunhos ao longo do Sistema Estuarino-Lagunar de Cananéia-Iguape (Figura 2, Tabela 1) com um testemunhador vibrocorer Rossfelder modelo VT1. Após a coleta, os testemunhos foram abertos e seccionados em intervalos de $2 \mathrm{~cm}$. As amostras foram armazenadas individualmente em bandejas de alumínio calcinadas $\left(400^{\circ} \mathrm{C}\right.$ durante $\left.4 \mathrm{~h}\right)$ e congeladas a $-20^{\circ} \mathrm{C}$. Em laboratório, essas amostras foram liofilizadas, maceradas e armazenadas em frascos de vidro calcinados.

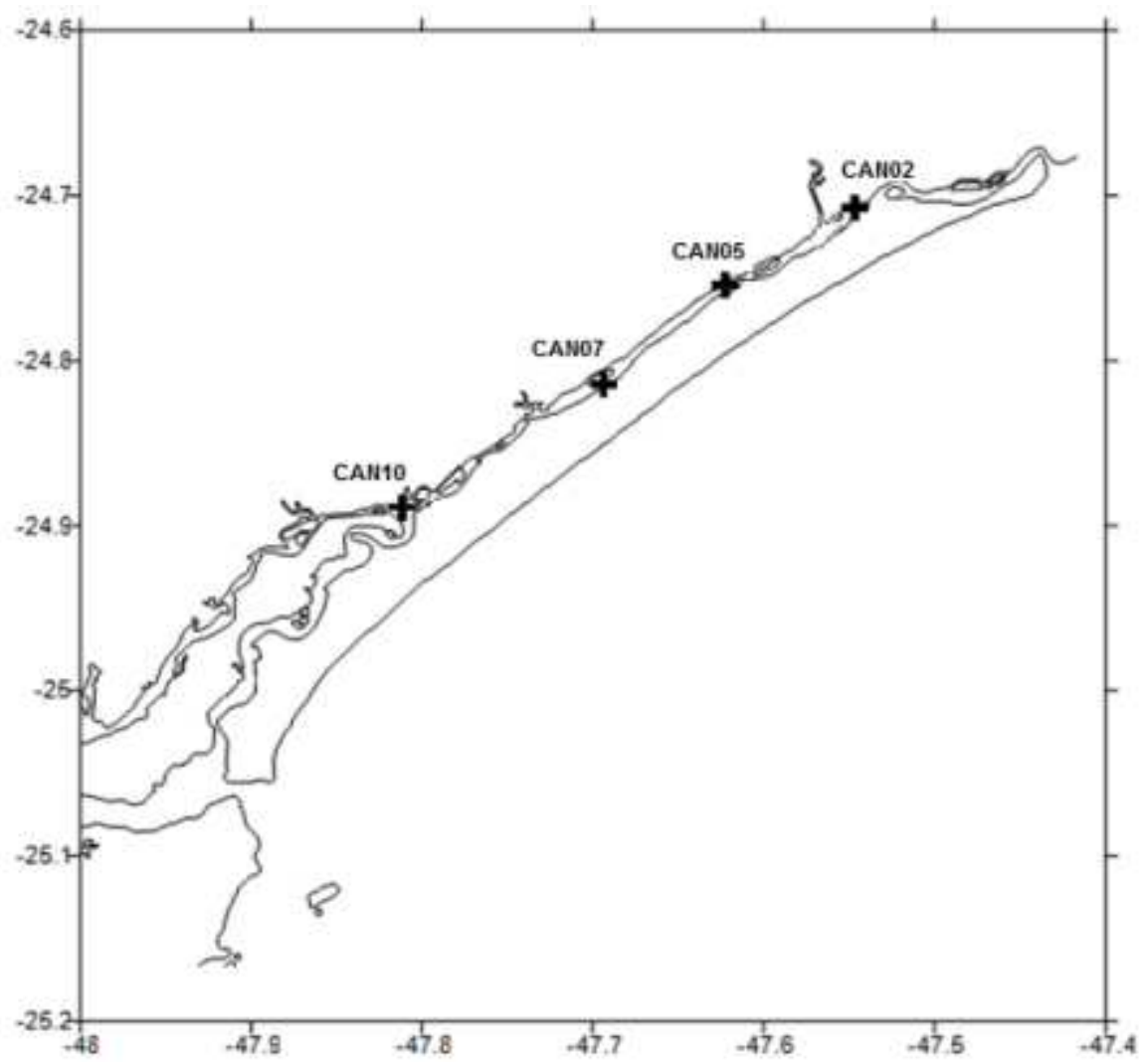

Figura 2: Figura da localização geográfica dos testemunhos coletados. 
Tabela 1: Localização geográfica e comprimento dos testemunhos coletados.

\begin{tabular}{cccc}
\hline TESTEMUNHO & Latitude (S) & Longitude (W) & Comprimento (m) \\
\hline CAN02 & $24^{\circ} 42,477$ & $47^{\circ} 32,787$ & 1,44 \\
CAN05 & $24^{\circ} 45,245$ & $47^{\circ} 37,370$ & 2,00 \\
CAN07 & $24^{\circ} 48,895$ & $47^{\circ} 41,612$ & 1,27 \\
CAN10 & $24^{\circ} 53,330$ & $47^{\circ} 48,700$ & 1,53
\end{tabular}

A segunda fase de coleta foi realizada em março de 2011 pela equipe do Prof. Dr. Rubens Cesar Lopes Figueira do IO da USP. No total, 85 amostras superficiais foram coletadas ao longo da região de estudo (Tabela 2). Após as coletas, as amostras foram armazenadas individualmente em bandejas de alumínio calcinadas, sendo posteriormente congeladas a $-20^{\circ} \mathrm{C}$. Elas foram, então, liofilizadas, maceradas e armazenadas em frascos de vidro calcinados. Posteriormente, as amostras superficiais foram submetidas à análise de teor de carbono orgânico total (TOC), através de um analisador elementar acoplado a um detector de espectrometria de massas com razão isotópica (EA-IRMS). Dentre as amostras que apresentaram conteúdo de matéria orgânica detectável, selecionaram-se aquelas localizadas próximas à desembocadura do canal do Valo Grande (Figura 3, Tabela 2). Algumas amostras com TOC detectáveis da região da Pedra do Tombo e da região sul também foram selecionadas (Figura 3, Tabela 2). No total, avaliou-se 22 amostras superficiais (Figura 3, Tabela 2). 
Tabela 2: Localização geográfica das amostras superficiais coletadas para o presente

estudo. As amostras destacadas em vermelho apresentaram conteúdo de material

orgânico detectável pelo EA-IRMS e foram selecionadas para avaliação dos marcadores

geoquímicos.

\begin{tabular}{|c|c|c|c|c|c|c|c|c|}
\hline Estação & $\begin{array}{l}\text { Latitude } \\
\left.\text { ( }{ }^{\circ} \mathrm{S}\right)\end{array}$ & $\begin{array}{l}\text { Longitude } \\
\qquad\left({ }^{\circ} \mathrm{W}\right)\end{array}$ & Estação & $\begin{array}{l}\text { Latitude } \\
\left.\text { ( }{ }^{\circ} \mathrm{S}\right)\end{array}$ & $\begin{array}{l}\text { Longitude } \\
\qquad\left({ }^{\circ} \mathrm{W}\right)\end{array}$ & Estação & $\begin{array}{l}\text { Latitude } \\
\left.\text { ( }{ }^{\circ} \mathrm{S}\right)\end{array}$ & $\begin{array}{c}\text { Longitude } \\
\left({ }^{\circ} \mathrm{W}\right)\end{array}$ \\
\hline 01 & $47^{\circ} 34,068$ & $24^{\circ} 40,900$ & 30 & $47^{\circ} 26,795$ & $24^{\circ} 40,768$ & 58 & $47^{\circ} 39,138$ & $24^{\circ} 46,614$ \\
\hline 02 & $47^{\circ} 34,019$ & $24^{\circ} 41,074$ & 31 & $47^{\circ} 26,549$ & $24^{\circ} 40,510$ & 59 & $47^{\circ} 39,831$ & $24^{\circ} 47,141$ \\
\hline 03 & $47^{\circ} 34,130$ & $24^{\circ} 41,269$ & 32 & $47^{\circ} 26,143$ & $24^{\circ} 40,510$ & 60 & $47^{\circ} 40,382$ & $24^{\circ} 47,689$ \\
\hline 04 & $47^{\circ} 34,291$ & $24^{\circ} 41,526$ & 33 & $47^{\circ} 31,104$ & $24^{\circ} 42,037$ & 61 & $47^{\circ} 40,921$ & $24^{\circ} 48,335$ \\
\hline 05 & $47^{\circ} 34,312$ & $24^{\circ} 41,804$ & 34 & $47^{\circ} 31,482$ & $24^{\circ} 42,180$ & 62 & $47^{\circ} 41,609$ & $24^{\circ} 48,855$ \\
\hline 06 & $47^{\circ} 34,235$ & $24^{\circ} 41,985$ & 35 & $47^{\circ} 31,846$ & $24^{\circ} 42,066$ & 63 & $47^{\circ} 42,350$ & $24^{\circ} 49,311$ \\
\hline 07 & $47^{\circ} 34,138$ & $24^{\circ} 42,229$ & 36 & $47^{\circ} 33,018$ & $24^{\circ} 42,547$ & 64 & $47^{\circ} 43,150$ & $24^{\circ} 49,762$ \\
\hline 08 & $47^{\circ} 34,096$ & $24^{\circ} 42,347$ & 37 & $47^{\circ} 33,146$ & $24^{\circ} 42,747$ & 65 & $47^{\circ} 44,035$ & $24^{\circ} 50,012$ \\
\hline 09 & $47^{\circ} 33,977$ & $24^{\circ} 42,722$ & 38 & $47^{\circ} 33,198$ & $24^{\circ} 42,858$ & 66 & $47^{\circ} 44,576$ & $24^{\circ} 50,586$ \\
\hline 10 & $47^{\circ} 33,832$ & $24^{\circ} 43,161$ & 39 & $47^{\circ} 34,038$ & $24^{\circ} 43,451$ & 67 & $47^{\circ} 45,330$ & $24^{\circ} 51,236$ \\
\hline 11 & $47^{\circ} 33,523$ & $24^{\circ} 43,139$ & 40 & $47^{\circ} 33,976$ & $24^{\circ} 43,624$ & 68 & $47^{\circ} 46,171$ & $24^{\circ} 51,685$ \\
\hline 12 & $47^{\circ} 33,226$ & $24^{\circ} 43,091$ & 41 & $47^{\circ} 34,204$ & $24^{\circ} 43,788$ & 69 & $47^{\circ} 46,448$ & $24^{\circ} 52,181$ \\
\hline 13 & $47^{\circ} 33,087$ & $24^{\circ} 42,911$ & 42 & $47^{\circ} 34,368$ & $24^{\circ} 43,631$ & 70 & $47^{\circ} 47,308$ & $24^{\circ} 52,879$ \\
\hline 14 & $47^{\circ} 33,038$ & $24^{\circ} 42,799$ & 43 & $47^{\circ} 34,815$ & $24^{\circ} 43,980$ & 71 & $47^{\circ} 48,127$ & $24^{\circ} 53,345$ \\
\hline 15 & $47^{\circ} 32,934$ & $24^{\circ} 42,577$ & 44 & $47^{\circ} 35,050$ & $24^{\circ} 44,088$ & 72 & $47^{\circ} 48,533$ & $24^{\circ} 54,105$ \\
\hline 16 & $47^{\circ} 32,630$ & $24^{\circ} 42,395$ & 45 & $47^{\circ} 35,392$ & $24^{\circ} 44,232$ & 73 & $47^{\circ} 49,320$ & $24^{\circ} 54,593$ \\
\hline 17 & $47^{\circ} 32,318$ & $24^{\circ} 42,263$ & 46 & $47^{\circ} 35,666$ & $24^{\circ} 44,356$ & 74 & $47^{\circ} 50,392$ & $24^{\circ} 54,196$ \\
\hline 18 & $47^{\circ} 32,047$ & $24^{\circ} 42,139$ & 47 & $47^{\circ} 35,943$ & $24^{\circ} 44,531$ & 75 & $47^{\circ} 50,369$ & $24^{\circ} 55,240$ \\
\hline 19 & $47^{\circ} 31,766$ & $24^{\circ} 41,797$ & 48 & $47^{\circ} 36,254$ & $24^{\circ} 44,712$ & 76 & $47^{\circ} 50,912$ & $24^{\circ} 55,512$ \\
\hline 20 & $47^{\circ} 31,447$ & $24^{\circ} 41,603$ & 49 & $47^{\circ} 34,439$ & $24^{\circ} 43,908$ & 77 & $47^{\circ} 51,542$ & $24^{\circ} 56,464$ \\
\hline 21 & $47^{\circ} 31,034$ & $24^{\circ} 41,665$ & 50 & $47^{\circ} 34,736$ & $24^{\circ} 44,109$ & 78 & $47^{\circ} 51,824$ & $24^{\circ} 57,433$ \\
\hline 22 & $47^{\circ} 30,889$ & $24^{\circ} 41,846$ & 51 & $47^{\circ} 35,001$ & $24^{\circ} 44,202$ & 79 & $47^{\circ} 52,358$ & $24^{\circ} 57,917$ \\
\hline 23 & $47^{\circ} 30,559$ & $24^{\circ} 41,992$ & 52 & $47^{\circ} 35,285$ & $24^{\circ} 44,430$ & 80 & $47^{\circ} 53,511$ & $24^{\circ} 57,724$ \\
\hline 24 & $47^{\circ} 29,995$ & $24^{\circ} 41,902$ & 53 & $47^{\circ} 35,499$ & $24^{\circ} 44,625$ & 81 & $47^{\circ} 54,241$ & $24^{\circ} 58,168$ \\
\hline 25 & $47^{\circ} 29,447$ & $24^{\circ} 42,046$ & 54 & $47^{\circ} 35,761$ & $24^{\circ} 44,779$ & 82 & $47^{\circ} 53,973$ & $24^{\circ} 59,195$ \\
\hline 26 & $47^{\circ} 29,190$ & $24^{\circ} 42,014$ & 55 & $47^{\circ} 37,002$ & $24^{\circ} 45,225$ & 83 & $47^{\circ} 54,146$ & $25^{\circ} 0,129$ \\
\hline 27 & $47^{\circ} 28,479$ & $24^{\circ} 41,960$ & 56 & $47^{\circ} 37,778$ & $24^{\circ} 45,620$ & 84 & $47^{\circ} 54,938$ & $25^{\circ} 0,566$ \\
\hline 28 & $47^{\circ} 27,893$ & $24^{\circ} 41,843$ & 57 & $47^{\circ} 38,459$ & $24^{\circ} 46,093$ & 85 & $47^{\circ} 55,297$ & $25^{\circ} 1,138$ \\
\hline 29 & $47^{\circ} 27,227$ & $24^{\circ} 41,290$ & & & & & & \\
\hline
\end{tabular}




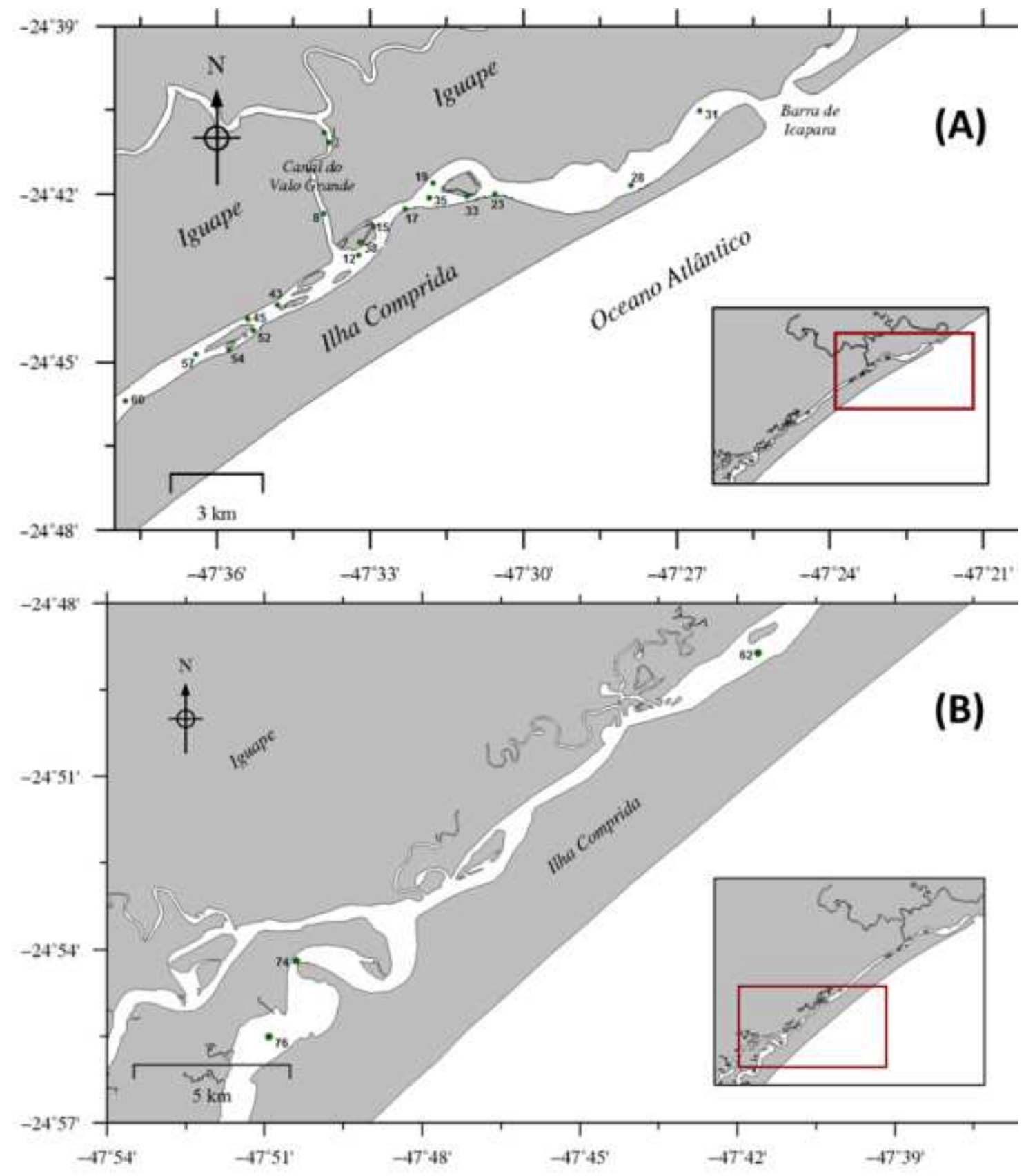

Figura 3: Mapa com a localização geográfica das amostras de sedimentos superficiais usadas no presente estudo. (A) região mais ao norte, (B) região mais ao sul.

\subsection{Amostragem de folhas}

Dentre as espécies de plantas predominantes na região de estudo, observadas por Cunha-Lignon (2001) e por Sampaio et al. (2010), algumas foram selecionadas para se verificar os perfis de $n$-alcanos e de suas razões isotópicas. Estas espécies foram as seguintes: 
- Syagrus romanzoffiana (Jerivá), Cecropia pachystachya (Embaúba), Calophyllum brasiliensis (Jacareúba), Inga uruguensis (Ingá), Pteridium aquilinum (samambaia) - representativas da vegetação de restinga do Vale do Ribeira;

- Rhizophora mangle (mangue vermelho) e Laguncularia racemosa (mangue branco) - representativas do mangue presente na região de estudo;

- Spartina alterniflora - representativa da vegetação de marisma (macrófita emersa) presente no sistema em questão;

- Musa ssp (bananeira), representativa da vegetação introduzida na região;

As coletas das folhas foram realizadas nas proximidades da cidade de Cananéia-SP, onde está localizada a base de pesquisa do IO-USP "Clarimundo de Jesus". Através de uma tesoura limpa com mistura de diclorometano (DCM) e $n$-hexano (HEX), coletou-se de 3 a 4 folhas inteiras em diferentes árvores da mesma espécie. Estas foram agrupadas conforme a espécie, totalizando cerca de 20 folhas por amostra. As folhas coletadas foram limpas com água destilada e armazenadas em folhas de alumínio, sendo congeladas a $-20^{\circ} \mathrm{C}$. Posteriormente, elas foram liofilizadas, maceradas e armazenadas em frascos de vidro calcinados.

$\mathrm{Na}$ discussão, as amostras foram classificadas entre monocotiledôneas e dicotiledôneas; e entre vegetação de mangue, vegetação de restinga e vegetação introduzida. Na Tabela 3 estão apresentadas as classificações das espécies amostradas. 
Tabela 3: Classificação das espécies de plantas amostradas no presente estudo.

\begin{tabular}{|c|c|c|c|c|}
\hline & Gênero e espécie & Nome popular & Família & $\begin{array}{c}\text { Grupo } \\
\text { metabólico }\end{array}$ \\
\hline $\begin{array}{l}\text { Vegetação do } \\
\text { Sistema }\end{array}$ & S. alterniflora & Capim marinho & Poaceae & Monocotiledônea \\
\hline $\begin{array}{l}\text { Estuarino- } \\
\text { Lagunar de }\end{array}$ & L. racemosa & Mangue branco & Combretacea & Dicotiledônea \\
\hline Cananéia-Iguape & R. mangle & Mangue vermelho & Rhizophoracea & Dicotiledônea \\
\hline \multirow{5}{*}{$\begin{array}{l}\text { Vegetação de } \\
\text { restinga }\end{array}$} & I.uruguensis & Inga & Mimosaceae & Dicotiledônea \\
\hline & C. brasiliensis & Jacareuba & Clusiaceae & Dicotiledônea \\
\hline & C. pachystachya & Embauba & Cecropiaceae & Dicotiledônea \\
\hline & S. romanzoffiana & Jerivá & Arecaceae & Monocotiledônea \\
\hline & P.aquilinum & Samambaia & Dennstaedtiacea & Pteridófita \\
\hline $\begin{array}{l}\text { Vegetação } \\
\text { introduzida }\end{array}$ & Musa ssp & Bananeira & Polypodiaceae & Dicotiledônea \\
\hline
\end{tabular}

\subsection{Taxa de sedimentação e modelo de idade}

A taxa de sedimentação e o modelo de idade dos testemunhos são fatores importantes que devem ser considerados na interpretação dos dados históricos de uma determinada região (Mahiques et al., 2008). Nos testemunhos coletados no presente estudo, estas análises foram feitas conforme o método usado Mahiques et al. (2013), através do decaimento radioativo do ${ }^{210} \mathrm{~Pb}$. A contagem das emissões radioativas da matriz foi realizada no Laboratório de Espectrometria Gama do IO-USP, sob supervisão do Prof. Dr. Rubens Cesar Lopes Figueira. Para isto, cerca de $20 \mathrm{~g}$ de amostra liofilizada e macerada foram acondicionados em recipientes de plástico de $5 \mathrm{~cm}$ de diâmetro e $1 \mathrm{~cm}$ de altura. Estes potes foram selados e guardados por aproximadamente 20 dias, para que $0{ }^{226} \mathrm{Ra}$ entrasse em equilíbrio radioativo 
com o ${ }^{222} \mathrm{Rn}$ (Canet \& Jacquemin, 1990). As contagens das emissões radioativas foram realizadas através de um espectrômetro gama (EG\&G Ortec modelo GMX 25190P), com uma linha de emissão de 47keV, conforme descrito por Figueira et al. (2007).

A taxa de sedimentação, determinada pela medida do ${ }^{210} \mathrm{~Pb}$ é determinada através da Equação 6.

$$
S=\frac{\lambda x D}{\operatorname{Ln}\left(\frac{c_{0}^{210} P b}{c^{210} P b}\right)}
$$

(Equação 6)

$S=$ Taxa de sedimentação $\left(\mathrm{cm} \cdot \mathrm{ano}^{-1}\right)$;

$\lambda=$ constante de decaimento radioativo do ${ }^{210} \mathrm{~Pb}\left(0,31076\right.$ ano $\left.^{-1}\right)$;

$\mathrm{D}=$ distância entre o topo do testemunho e a camada medida $(\mathrm{cm})$

$\mathrm{C}_{0}{ }^{210} \mathrm{~Pb}=$ contagem do ${ }^{210} \mathrm{~Pb}$ não suportado no topo do testemunho;

$\mathrm{C}^{210} \mathrm{~Pb}=$ contagem do ${ }^{210} \mathrm{~Pb}$ não suportado na camada medida do testemunho;

O calculo da taxa de sedimentação foi feita através do método "Constant Initial Concentration" (Appleby\&Oldfield, 1978). A partir dos dados da concentração ${ }^{210} \mathrm{~Pb}$ não suportado, foram construídos gráficos da concentração deste em função da profundidade e, através do coeficiente angular da reta de regressão, determinou-se a taxa de sedimentação.

\subsection{Teor de carbonato}

O teor de carbonato de cálcio $\left(\mathrm{CaCO}_{3}\right)$ do sedimento tem sido usado por diversos autores como marcador das condições ambientais de deposição (Khim et al., 2008; Fernandez, 2010; Giuliani et al., 2011).

$\mathrm{O} \mathrm{CaCO}_{3}$ no sedimento foi determinado mediante a digestão ácida do material biodetrítico. Uma alíquota de sedimento (aproximadamente $2 \mathrm{~g}$ ) foi pesada em balança analítica. Homogeneizou-se esta alíquota com $4 \mathrm{~mL}$ de ácido clorídrico $\left(\mathrm{HCl}, 1 \mathrm{~mol} \mathrm{~L}^{-1}\right)$, permanecendo em reposuo por, pelo menos, $10 \mathrm{~h}$. Foram, então, adicionadas duas a três gotas de $\mathrm{HCl}$ concentrado (Padrão analitico - P.A.) afim de certificar a total eliminação do $\mathrm{CaCO}_{3}$. Adicionou-se $12 \mathrm{~mL}$ de água Milli-Q, para posterior centrifugação a $2500 \mathrm{rpm}$ por $10 \mathrm{~min}$. $\mathrm{O}$ 
sobrenadante foi descartado, permanecendo somente o sedimento. Esse procedimento de lavagem foi repetido cinco vezes para total eliminação do $\mathrm{HCl}$. As amostras foram secas em estufa a $60^{\circ} \mathrm{C}$ e pesadas em balança analítica. $\mathrm{O}$ teor de $\mathrm{CaCO}_{3}$ (expresso em \%) foi determinado pela diferença de massa do sedimento inicial através da Equação 7 :

$$
\text { Teor de } \mathrm{CaCO}_{3}=\frac{\left(\text { Peso }_{\text {inicial }}-\text { Peso }_{\text {final }}\right)}{\text { Peso }_{\text {inicial }}} * 100
$$

(Equação 7)

$$
\begin{aligned}
& P_{e s O_{\text {inicial }}=\text { peso da amostra antes de acidificá-la; }} \\
& \text { Peso }_{\text {final }}=\text { peso da amostra após sua acidificação e secagem. }
\end{aligned}
$$

\subsection{Análise granulométrica}

A determinação das características granulométricas foi feita no Laboratório de Sedimentologia do 10 da USP sob supervisão do Prof. Dr. Michel Michaelovitch de Mahiques. O método usado está descrito e detalhado em Mahiques et al. (2013). Brevemente, as amostras descarbonatadas e sem matéria orgânica foram analisadas através de um analisador a laser Malvern Mastersizer 2000.

Os dados gerados foram divididos em areia (diâmetro do grão entre 64 $\mu \mathrm{m}$ e $2 \mathrm{~mm}$ ), silte (diâmetro do grão entre $4 \mu \mathrm{m}$ e $64 \mu \mathrm{m}$ ) e argila (diametro do grão menor que $4 \mu \mathrm{m})$.

\subsection{Características composicionais da matéria orgânica}

As características composicionais da matéria orgânica dos sedimentos coletados foram determinadas segundo os seguintes descritores: teor de carbono orgânico total (TOC), razão isotópica do carbono orgânico total $\left(\delta^{13} \mathrm{C}\right)$, teor de nitrogênio total $(T N)$, razão isotópica do nitrogênio total $\left(\delta^{15} \mathrm{~N}\right)$. Calculou-se também a razão entre TOC e TN (razão C/N). 
O TOC e o $\delta^{13} \mathrm{C}$ foram determinados em alíquotas de sedimento liofilizadas submetidas à remoção do $\mathrm{CaCO}_{3}$, como descrito no item 5.4. O TN e $\circ \quad \circ \delta^{15} \mathrm{~N}$ foram determinados em alíquotas de sedimento liofilizadas. Aproximadamente $10 \mathrm{mg}$ de cada sedimento, pesados em balança analítica, foram acondicionados em cartuchos de estanho $(5 \times 9 \mathrm{~mm})$ e submetidos a análise elementar e isotópica no analisador elementar Costec Instruments Elemental Combustion System acoplado a um detector de espectrometria de massas com razão isotópica Thermo Scientific Delta $V$ Advantage Isotope Ratio MS (EA-IRMS).

Os teores de TOC e TN, expressos em porcentagem (\%), foram obtidos através da relação da Equação 8:

$\%$ Amostra $=\left(\frac{\% \text { padrão } x \text { massa padrão }}{\text { área padrão }}\right) x$ área amostra

(Equação 8)

O padrão adotado na quantificação em massa foi o Solo LECO 502-309 - LECO Corporation. Os teores de carbono e nitrogênio do padrão são, respectivamente, $13,77 \%$ e $0,092 \%$.

A calibração para as análises isotópicas do carbono orgânico e do nitrogênio total foram feitas através de dois padrões: um certificado pela United State Geological Survey (USGS): O USGS-40 (ácido glutamínico: $\delta^{13} \mathrm{C}=-26,389 \%$ VS Pee Dee Belemnite - PDB; $\delta 15 \mathrm{~N}=-4,5 \%$ vs ar); e outro pela International Atomic Energy Agency (IAEA): O IAEA-600 (cafeína: $\delta^{13} \mathrm{C}=-27,771 \%$ VS PDB; $\delta 15 \mathrm{~N}=+1,0 \%$ vs ar). As razões isotópicas do carbono orgânico e do nitrogênio foram expressas na notação $\delta^{13} \mathrm{C}$ e $\delta^{15} \mathrm{~N}$, respectivamente, calculadas através da Equação 5 .

A avaliação da repetibilidade das análises foi realizada através da análise em replicata $(n=10)$ de uma amostra de sedimento marinho, adotada como padrão secundário. A repetibilidade do TOC, do TN e de suas razões isotópicas foi: $\delta^{13} \mathrm{C}=0,17 \%$; TOC $=0,09 \% ; \delta^{15} \mathrm{~N}=0,13 \%$; TN=0,002\%. 


\subsection{Determinação dos n-alcanos}

\subsubsection{Tratamento dos reagentes e limpeza do material}

Para análise de compostos orgânicos foi utilizado apenas solvente para análise de resíduos orgânicos. A sílica, a alumina e o sulfato de sódio foram calcinados a $400^{\circ} \mathrm{C}$ por 4 horas em uma mufla para eliminar possíveis interferentes orgânicos. Depois, estes foram armazenados em frascos de vidro calcinados e estocados em um dessecador a vácuo, evitando umidade.

Antes da utilização, a sílica e a alumina foram ativadas em uma estufa a $140^{\circ} \mathrm{C}$, resfriadas em dessecador a vácuo e parcialmente desativadas com $5 \%$ em massa de água. A água utilizada para esta desativação estava isenta de compostos orgânicos através de sua extração com $n$-hexano $(7 \times 30 \mathrm{~mL}$ de $n$ hexano / 2 L de água).

Toda a vidraria utilizada na extração das amostras foi deixada em banho de Extran alcalino (Merk) durante 8 horas. O material foi enxaguado em água corrente e por fim em água destilada, sendo seco em estufa. Depois de secos, estes materiais foram calcinados por aproximadamente 4 horas a $400^{\circ} \mathrm{C}$, com exceção dos materiais volumétricos que foram secos à temperatura ambiente e limpos com HEX e DCM antes do uso.

\subsubsection{Análise das amostras}

Em10 gramas do sedimento seco ou $200 \mathrm{~g}$ de folhas maceradas foram

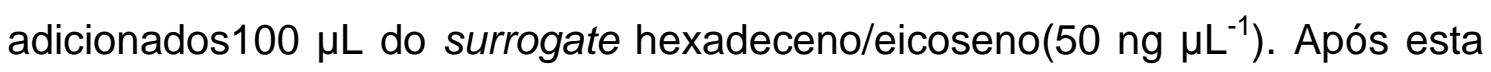
adição, o sedimento foi extraído com $50 \mathrm{~mL}$ de uma mistura de DCM e $n$-hexano (HEX) (1:1 v/v) pelo sistema acelerador de reações por microondas MARS 5. A extração por microondas foi programada para aquecer a mistura de solventes até $71^{\circ} \mathrm{C}$ em 5 minutos, mantendo esta temperatura por mais 5 minutos, seguido de resfriamento. Após a extração, a solução foi transferida para balões de vidro, sendo adicionados fios de cobre para remoção do enxofre presente. Após 1 hora, os fios de cobre foram retirados e o extrato foi 
concentrado em evaporador rotativo a vácuo até o volume de $1 \mathrm{~mL}$. A solução resultante foi submetida ao procedimento de purificação e separação em uma coluna contendo $2 \mathrm{~g}$ de sílica e $1 \mathrm{~g}$ de alumina. Foram utilizados $6 \mathrm{~mL}$ de HEX e $10 \mathrm{~mL}$ de uma mistura de HEX/DCM (1:9 v/v) como eluentes para separar os $n$ alcanos dos outros compostos da solução.

As soluções com os $n$-alcanos ( $F 1$ ) foram concentradas até aproximadamente $0,5 \mathrm{~mL}$, sendo então adicionados $100 \mu \mathrm{L}$ de uma solução de tetradeceno (50 $\left.\mathrm{ng} \mu \mathrm{L}^{-1}\right)$. Após esta adição, foram adicionadas aproximadamente $400 \mu \mathrm{L}$ de $n$-hexano, acertando o volume para $1 \mathrm{~mL}$. A cada 27 amostras, foi realizada a análise de uma amostra branco (sulfato de sódio), a qual passou pelo mesmo procedimento que as amostras, verificando se houve contaminação durante a aplicação do método.

Os $n$-alcanos presentes nas soluções $F 1$ finais foram identificados $\mathrm{e}$ quantificados através de um cromatógrafo a gás Agilent (modelo 6890) com injetor automático Agilent (modelo 7683), equipado com detector de ionização de chama (GC-FID). A coluna cromatográfica utilizada foi de $50 \mathrm{~m} \times 0,32 \mathrm{~mm} \times$ $0,17 \mu \mathrm{m}$, sendo a fase estacionária composta por $5 \%$ difenil e $95 \%$ dimetilpolisiloxano. $\mathrm{O}$ gás de arraste foi o $\mathrm{H}_{2}$ (pureza $>99,999 \%$ ), com pressão constante de 7,24 psi no injetor. As injeções foram feitas em modo splitless. A rampa de aquecimento da coluna foi programada de acordo com a Tabela 4.

Tabela 4: Programação da rampa de aquecimento do GC-FID na determinação dos $n$ alcanos.

\begin{tabular}{cccc}
\hline & $\begin{array}{c}\text { Taxa de aquecimento } \\
\left({ }^{\circ} \mathbf{C} \mathbf{~ m i n ~}^{-1}\right)\end{array}$ & $\begin{array}{c}\text { Temperatura final } \\
\left({ }^{\circ} \mathbf{C}\right)\end{array}$ & $\begin{array}{c}\text { Tempo de espera } \\
(\mathbf{m i n})\end{array}$ \\
\hline Início & - & 40 & 0 \\
Rampa 1 & 20 & 60 & 0 \\
Rampa 2 & 5 & 250 & 0 \\
Rampa 3 & 20 & 300 & 0 \\
Rampa 4 & 6 & 320 & 30 \\
\hline
\end{tabular}

A identificação dos compostos foi feita com base no padrão externo de referência obtido na AccuStandard (EUA). Foram identificados e quantificados 
os $n$-alcanos $n-C_{12}$ a $n-C_{34}$. Para realizar a quantificação dos compostos é necessária a construção de uma curva analítica obtida a partir da injeção de sete concentrações diferentes de $n$-alcanos. $O$ coeficiente de correlação linear de Pearson foi igual ou superior a $99,5 \%\left(r^{2}=0,995\right)$ para todos os compostos analisados.

A concentração final do analito foi calculada com base no volume final de extrato e na massa de sedimento seca ou de folha seca extraída. O resultado final foi dado em $\mathrm{ng} \mathrm{g}^{-1}$ de sedimento seco ou em $\mu \mathrm{g} \mathrm{g}^{-1}$ de folha seca.

\subsubsection{Controle de qualidade}

O controle de qualidade das análises é o conjunto de técnicas e atividades operacionais que são usadas para fornecer requerimentos de qualidade. Descreve medidas individuais, as quais são relativas à qualidade das análises das amostras, individual ou em grupo (CITAC/EURACHEM, 2002).

\subsubsection{Recuperação do surrogate}

O cálculo de recuperação do padrão surrogate é uma estimativa das variações que ocorrem durante o processamento das amostras. É feito com base na razão entre a concentração do surrogate, o qual é adicionado no início do processo analítico, e a concentração padrão interno, adicionado ao final do processo. No presente estudo aceitou-se uma faixa de recuperação entre $70 \mathrm{e}$ $120 \%$. As amostras que não estiveram dentro desta faixa foram excluídas ou refeitas.

\subsubsection{Limite de detecção}

O limite de detecção de um método (LDM) é definido como a concentração mínima de uma substância que pode ser medida com 99\% de confiança (Wade \& Cantillo, 1994). Para a determinação do LDM, foram 
analisadas 7 replicatas de uma amostra de $10 \mathrm{~g}$ de $\mathrm{Na}_{2} \mathrm{SO}_{4}$ fortificada com $100 \mu \mathrm{L}$ do padrão externo (50 $\mathrm{ng}^{\mathrm{L}} \mathrm{L}^{-1}$ ) de referência obtido pela AccuStandard (EUA). O cálculo do LDM foi realizado através da Equação 9:

$$
\boldsymbol{L D} \boldsymbol{M}=t n-1 x S
$$

(Equação 9)

$\mathrm{S}=$ desvio padrão;

$\mathrm{t}=$ é o valor de $t$-student (com 95\% de confiança - para $\mathrm{n}=7$; $t$-student=3,14);

$\mathrm{n}=\mathrm{n}^{\circ}$ de replicatas (para o presente estudo, $\mathrm{n}=7$ ).

Na Tabela 5, são apresentados os LDMs obtidos no presente estudo.

Tabela 5: Limite de detecção (LDM) obtido para os $n$-alcanos ( $\mu \mathrm{g} \mathrm{g}^{-1}$ peso seco).

\begin{tabular}{cccc}
\hline Composto & LDM $\left(\mu \mathrm{g} \mathrm{g}^{-1}\right)$ & Composto & LDM $\left(\mu \mathrm{g} \mathrm{g}^{-1}\right)$ \\
\hline$n-\mathrm{C}_{12}$ & 0,01 & $n-\mathrm{C}_{24}$ & 0,01 \\
$n-C_{13}$ & 0,01 & $n-C_{25}$ & 0,01 \\
$n-C_{14}$ & 0,02 & $n-C_{26}$ & 0,01 \\
$n-C_{15}$ & 0,01 & $n-C_{27}$ & 0,01 \\
$n-C_{16}$ & 0,02 & $n-C_{28}$ & 0,01 \\
$n-C_{17}$ & 0,01 & $n-C_{29}$ & 0,01 \\
$n-C_{18}$ & 0,01 & $n-C_{30}$ & 0,01 \\
$n-C_{19}$ & 0,02 & $n-C_{31}$ & 0,01 \\
$n-C_{20}$ & 0,02 & $n-C_{32}$ & 0,01 \\
$n-C_{21}$ & 0,02 & $n-C_{33}$ & 0,01 \\
$n-C_{22}$ & 0,02 & $n-C_{34}$ & 0,01 \\
$n-C_{23}$ & 0,02 & & \\
\hline
\end{tabular}

\subsubsection{Avaliação do método analítico}

CITAC/EURACHEM (2002) sugere os seguintes parâmetros para a avaliação da qualidade analítica: análise de branco; análise de branco 
fortificado; análise de matriz fortificada; análise da matriz em duplicada, análise da amostra referência.

\section{- Análise de branco}

A análise do branco do método fornece a identificação de possíveis interferências ao longo do processamento das amostras, tais como: contaminações dos solventes, reagentes, adsorventes ou vidrarias. Este não deve conter nenhum composto de interesse com concentração três vezes superior ao LDM (CITAC/EURACHEM, 2002). Para o presente estudo, 0 branco do método não apresentou nenhum composto avaliado com concentração superior ao LDM estabelecido.

\section{- Análise de amostra em duplicata}

A fim de verificar a repetibilidade do método, a amostra $6952(24-26 \mathrm{~cm})$, analisada em Lourenço (2007), foi analisada em duplicata. No presente estudo, para serem aceitos, mais de $80 \%$ dos compostos tiveram seus valores variando entre -50 e $120 \%$ (Tabela 6). 
Tabela 6). 
Tabela 6: Resultados obtidos ( $\mathrm{ng} \mathrm{g}^{-1}$ peso seco) na análise em duplicata da amostra coletada por Lourenço (2007) (amostra 6952 - 24-26 cm). Os valores variaram em -50 e $120 \%$ em, pelo menos, $80 \%$ dos compostos.

\begin{tabular}{|c|c|c|c|c|c|}
\hline & $\begin{array}{c}\text { Amostra } 6952 \\
(24-26) 1\end{array}$ & $\begin{array}{c}\text { Amostra } 6952 \\
(24-26) 2\end{array}$ & & $\begin{array}{c}\text { Amostra } 6952 \\
(24-26) 1\end{array}$ & $\begin{array}{c}\text { Amostra } 6952 \\
(24-26) 2\end{array}$ \\
\hline$n-C_{12}$ & $<$ L.D. & $<$ L.D. & $n-C_{24}$ & 15,6 & 12,6 \\
\hline$n-C_{13}$ & <L.D. & <L.D. & $n-C_{25}$ & 50,2 & 50,6 \\
\hline$n-C_{14}$ & 20,0 & 39,3 & $n-C_{26}$ & 9,2 & 17,4 \\
\hline$n-C_{15}$ & 4,10 & 35,7 & $n-C_{27}$ & 47,8 & 48,8 \\
\hline$n-C_{16}$ & 3,67 & 41,8 & $n-C_{28}$ & 16,1 & 19,7 \\
\hline$n-C_{17}$ & 20,3 & 38,5 & $n-C_{29}$ & 93,3 & 93,3 \\
\hline$n-C_{18}$ & 21,0 & 21,5 & $n-C_{30}$ & 13,8 & 17,0 \\
\hline$n-C_{19}$ & 9,0 & 10,9 & $n-C_{31}$ & 83,2 & 75,4 \\
\hline$n-C_{20}$ & <L.D. & <L.D. & $n-C_{32}$ & 16,3 & 9,8 \\
\hline$n-C_{21}$ & 18,2 & 16,7 & $n-C_{33}$ & 51,2 & 46,5 \\
\hline$n-C_{22}$ & 22,4 & 21,5 & $n-C_{34}$ & 7,2 & 20,2 \\
\hline$n-C_{23}$ & 29,3 & 26,4 & & & \\
\hline
\end{tabular}

\section{- Análise de branco e de matriz fortificados}

As análises do branco fortificado e da matriz fortificada avaliam o comportamento dos analitos de interesse durante o processamento analítico: extração, purificação, identificação e quantificação. O branco fortificado é uma ferramenta que faz uma estimativa do percentual de recuperação desses analitos durante o processamento analítico. A matriz fortificada tem a mesma função, porém tal avaliação ocorre sob efeito da matriz sedimentar. Para isto, foram adicionados $100 \mu \mathrm{L}$ de um padrão $n$-alcanos a $50 \mathrm{ng} \mu \mathrm{L}^{-1}$ em uma amostra de sulfato de sódio e em uma amostra de sedimento. As soluções finais foram concentradas para $1 \mathrm{~mL}$. Os critérios adotados pela CITAC/EURACHEM (2002) é que $80 \%$ dos analitos devem ter recuperação entre 40 e $130 \%$. No presente estudo, os $n$-alcanos tiveram seus valores com uma variação dentro da faixa permitida tanto para o branco fortificado quanto para a matriz fortificada (Tabela 7 ). 
Tabela 7: Resultados obtidos na análise do branco fortificado ( $\left(n g \mu \mathrm{L}^{-1}\right)$ e a diferença entre as concentrações obtidas na matriz fortificada e na matriz (amostra 6952 (24-26

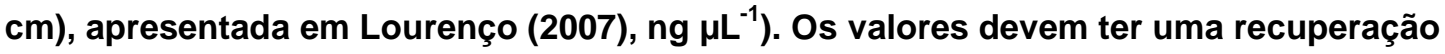
entre 40 e $130 \%$ em, pelo menos, $80 \%$ dos compostos (concentração $5 \mathrm{ng} \mathrm{hL}^{-1}$ ).

\begin{tabular}{|c|c|c|c|c|c|}
\hline & $\begin{array}{c}\text { Branco } \\
\text { fortificado }\end{array}$ & $\begin{array}{c}\text { Matriz-Matriz } \\
\text { fortificada }\end{array}$ & & $\begin{array}{c}\text { Branco } \\
\text { fortificado }\end{array}$ & $\begin{array}{c}\text { Matriz-Matriz } \\
\text { fortificada }\end{array}$ \\
\hline$n-C_{12}$ & 5,60 & 2,10 & $n-C_{24}$ & 5,49 & 5,92 \\
\hline$n-C_{13}$ & 5,84 & 2,20 & $n-C_{25}$ & 5,25 & 6,331 \\
\hline$n-C_{14}$ & 5,56 & 3,36 & $n-C_{26}$ & 5,75 & 6,29 \\
\hline$n-C_{15}$ & 5,78 & 3,75 & $n-C_{27}$ & 6,00 & 6,25 \\
\hline$n-C_{16}$ & 5,91 & 4,78 & $n-C_{28}$ & 5,97 & 6,28 \\
\hline$n-C_{17}$ & 6,43 & 5,05 & $n-C_{29}$ & 6,39 & 6,30 \\
\hline$n-C_{18}$ & 6,19 & 5,52 & $n-C_{30}$ & 6,36 & 6,30 \\
\hline$n-C_{19}$ & 6,44 & 5,76 & $n-C_{31}$ & 6,39 & 6,33 \\
\hline$n-C_{20}$ & 6,36 & 5,76 & $n-C_{32}$ & 6,37 & 6,24 \\
\hline$n-C_{21}$ & 6,22 & 6,09 & $n-C_{33}$ & 6,12 & 6,07 \\
\hline$n-C_{22}$ & 6,43 & 6,22 & $n-C_{34}$ & 6,61 & 5,37 \\
\hline$n-C_{23}$ & 6,33 & 6,28 & & & \\
\hline
\end{tabular}

\section{- Amostra referência}

A amostra referência é analisada para garantir a exatidão dos resultados obtidos com o uso da metodologia analítica empregada no trabalho. Para isso, aplicou-se o procedimento metodológico em um material cujas concentrações já são conhecidas. No presente estudo esta validação foi feita através da amostra do testemunho $6952(24-26 \mathrm{~cm})$, cujos resultados foram apresentados por Lourenço (2007). Os valores obtidos nesta análise devem ter uma variação entre 50 a $120 \%$ dos resultados já encontrados. No presente estudo, os $n$ alcanos tiveram seus valores com uma variação dentro da permitida (Tabela 8 ). 
Tabela 8: Resultados obtidos por Lourenço (2007) na amostra $6952(24-26 \mathrm{~cm})$ e os obtidos no presente estudo para esta mesma amostra ( $\mathrm{ng} \mathrm{g}^{-1}$ peso seco). Os valores devem ter um desvio padrão menor que $30 \%$ em, no mínimo, $80 \%$ dos compostos.

\begin{tabular}{|c|c|c|c|c|c|}
\hline & $\begin{array}{c}\text { Resultados } \\
\text { apresentado em } \\
\text { Lourenço (2007) }\end{array}$ & $\begin{array}{c}\text { Resultado } \\
\text { encontrado no } \\
\text { presente estudo }\end{array}$ & & $\begin{array}{c}\text { Resultados } \\
\text { apresentado em } \\
\text { Lourenço (2007) }\end{array}$ & $\begin{array}{c}\text { Resultado } \\
\text { encontrado no } \\
\text { presente estudo }\end{array}$ \\
\hline$n-\mathrm{C}_{12}$ & <L.D. & <L.D. & $n-C_{24}$ & 23,5 & 12,6 \\
\hline$n-C_{13}$ & <L.D. & <L.D. & $n-C_{25}$ & 38,9 & 50,6 \\
\hline$n-C_{14}$ & 20,7 & 39,3 & $n-C_{26}$ & 17,1 & 17,4 \\
\hline$n-C_{15}$ & 38,3 & 35,7 & $n-C_{27}$ & 79,7 & 48,8 \\
\hline$n-C_{16}$ & 11,1 & 41,8 & $n-C_{28}$ & 27,1 & 19,7 \\
\hline$n-C_{17}$ & 21,9 & 38,5 & $n-C_{29}$ & 133,9 & 93,3 \\
\hline$n-C_{18}$ & 11,1 & 21,5 & $n-C_{30}$ & 29,0 & 17,0 \\
\hline$n-C_{19}$ & 5,0 & 10,9 & $n-C_{31}$ & 81,0 & 75,4 \\
\hline$n-\mathrm{C}_{20}$ & $<$ L.D. & $<$ L.D. & $n-C_{32}$ & 11,2 & 9,8 \\
\hline$n-C_{21}$ & 31,2 & 16,7 & $n-C_{33}$ & 79,8 & 46,5 \\
\hline$n-C_{22}$ & 44,7 & 21,5 & $n-C_{34}$ & 47,7 & 20,2 \\
\hline$n-C_{23}$ & 41,0 & 26,4 & & & \\
\hline
\end{tabular}

5.8. Análise da razão isotópica em compostos específicos (nalcanos)

As análises de isótopos estáveis em $n$-alcanos foram realizadas no Zentrum für Marine Umweltwissenschaften (MARUM) da Universität Bremen (UB), Alemanha, sob a supervisão do Dr. Enno Schefuß. Todas as amostras de vegetação e de sedimentos superficiais foram submetidas às análises de $\delta^{13} \mathrm{C}$ e $\delta \mathrm{D}$ de seus $n$-alcanos. Em todas as amostras do testemunho CAN05 e algumas selecionadas do CAN02, CAN07 e CAN10 foram feitas a análise de $\delta^{13} \mathrm{C}$ de seu $n$-alcanos.

A presença de alcenos e alcinos nas soluções interfere nas análises de $\delta^{13} \mathrm{C}$ e $\delta \mathrm{D}$ dos $n$-alcanos através do GC-IRMS. Para que a razão isotópica destes compostos seja estabelecida, é necessário um segundo processo de purificação, onde estes interferentes são removidos da solução (Pearson \& Eglington, 2000; Lichtfouse et al., 2000; Seki et al., 2006; Breugel, 2006). Em colunas de separação com $7 \mathrm{~mm}$ de diâmetro externo e $5 \mathrm{~mm}$ de diâmetro 
interno, foi colocado $1 \mathrm{~cm}$ de sílica gel impregnada com $\mathrm{AgNO}_{3}$. Lavou-se esta coluna com $1 \mathrm{~mL}$ de $n$-hexano por 4 vezes. Uma alíquota de $500 \mu \mathrm{L}$ das soluções $F 1$ foi separada e submetida à purificação. Como sugerido por Schefuß (comunicação pessoal*), $4 \mathrm{~mL}$ de $n$-hexano foram usados como eluente. As soluções finais ( $\mathrm{F} 1 \mathrm{a})$ foram completamente secas e posteriormente ressuspendidas com tolueno. O volume usado nesta ressuspensão foi baseado na quantidade de material presente em cada amostra (quantificada e calculada na determinação do $n$-alcanos, através de suas analises no GC-FID).

Os GC-IRMS usados para análise de $\delta^{13} \mathrm{C}$ e $\delta \mathrm{D}$ apresentam sensibilidades diferentes. Para determinação de isótopos de carbono em

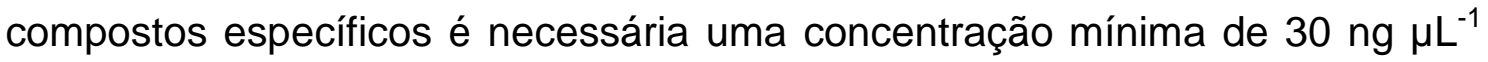
do analito de interesse. Para as análises de isótopos de hidrogênio são necessários ao menos $70 \mathrm{ng} \mathrm{LL}^{-1}$. Assim, não puderam ser avaliadas as razões isotópicas de todos os $n$-alcanos detectados pelo GC-FID. As análises de $\delta^{13} \mathrm{C}$ dos $n$-alcanos extraídos dos sedimentos foram feitas no $n-C_{25}, n-C_{29}$ e $n-C_{31}$ e para vegetação, don- $\mathrm{C}_{25}$ a $n$ - $\mathrm{C}_{31}$. As análises de $\delta \mathrm{D}$ nos $n$-alcanos extraídos dos sedimentos foram feitas nos compostos $n-C_{29}$ e $n-C_{31}$. Nas amostras da vegetação, estas foram feitas nos $n$-alcanos $n-C_{27}, n-C_{29}$ e $n-C_{31}$.

Primeiramente foram realizadas as análises de isótopos de carbono. Para isto as soluções $\mathrm{F} 1 \mathrm{a}$, já dissolvidas em tolueno, foram injetadas em um GC Thermo Scientific Trace Ultra acoplado a um IRMS Finnigan MAT 252, com uma interface de combustão $\mathrm{GC} / \mathrm{C}$ modificada operada a $1000^{\circ} \mathrm{C}$. A coluna usada foi de sílica fundida do tipo Rxi-5ms da Resteke o injetor foi operado a $250^{\circ} \mathrm{C}$ em modo splitless. Os valores de isótopos foram calculados através do uso de gás carbônico de referência. $\mathrm{O}$ forno foi mantido por 3 minutos a $110^{\circ} \mathrm{C}$, sendo depois aquecido a $5^{\circ} \mathrm{C} \min ^{-1}$ até $320^{\circ} \mathrm{C}$, temperatura na qual permaneceu por $15 \mathrm{~min}$.

As amostras foram novamente secas e ressuspendidas em tolueno para análises de $\delta D$. Estas foram feitas um GC Thermo Scientific Trace Ultra acoplado a um IRMS Thermo Scientific MAT 253 através de um reator de

* Correspondência com o Dr. Enno Schefuß, pesquisador do Zentrumfür Marine Umweltwissenschaften da Bremen Universität, Alemanha, realizada em 02/06/2012. 
pirólise. Os valores de $\delta D$ foram calibrados através do uso de gás hidrogênio de referência. As condições do GC foram similares às usadas nas análises de $\delta^{13} \mathrm{C}$ dos $n$-alcanos.

Alguns procedimentos foram estabelecidos com objetivo de gerar dados confiáveis:

- todas as amostras foram co-injetadas com um padrão de esqualano, cujas razões isotópicas são conhecidas. Para os valores de $\delta^{13} \mathrm{C}$ e $\delta \mathrm{D}$ do $n$-alcanos das amostras serem aceitas, $0 \delta^{13} \mathrm{C}$ e $\circ \delta \mathrm{D}$ do esqualano não puderam variar mais do que 0,3 e $0,1 \%$, respectivamente;

- todas as amostras foram injetadas em duplicata. Para as razões isotópicas geradas serem consideradas como válidas, o desvio padrão não pôde ser superior a 5,0 para as análises de $\delta \mathrm{D}$ e a 0,5 para as de $\delta^{13} \mathrm{C}$;

- a cada 6 injeções, avaliou-se uma amostra padrão contendo $\left(n-\mathrm{C}_{23}\right.$ a $n$ $\mathrm{C}_{33}$ ). A média absoluta entre os valores obtidos nesta análise e o valor médio conhecido da amostra não pôde ser maior que $5 \%$ para análises de $\delta \mathrm{D}$ e $0,5 \%$ para análises de $\delta^{13} \mathrm{C}$;

- nas análises de $\delta \mathrm{D}$, avaliou-se o sinal do ${ }^{3} \mathrm{H}$. Este verifica o quanto de trítio esta interferindo nas análises, corrigindo os valores obtidos para cada amostra. $\mathrm{O}$ sinal do ${ }^{3} \mathrm{H}$ não pôde ser superior que 0,4 unidades entre um dia e outro de análise, e não pode ser superior que 10 unidades ao longo de todas as corridas.

As amostras ou grupos de amostras que não apresentaram resultados satisfatórios perante este controle de qualidade foram reinjetadas. 


\section{RESULTADOS E DISCUSSÕES}

\subsection{Composição dos n-alcanos na flora amostrada}

A concentração de $n$-alcanos totais (AlcTot) nas espécies de plantas amostradas variou de 1,49 a $319 \mu \mathrm{g} \mathrm{g}^{-1}$ em peso seco (p.s.) (Tabela 9). Dentre os compostos detectados, houve predominância daqueles com número ímpar de carbono, principalmente entre 25 e 31 átomos deste elemento (Figura 4 e Figura 5). As moléculas pares e aquelas com mais ou menos átomos de carbono também foram detectadas, porém em menor quantidade. Este padrão é comumente observado em ceras epicuticulares de plantas vasculares (Duan \& Ma, 2001; Rommerskirchen et al., 2006; Sachse et al., 2006; Vogts et al., 2009). A presença de $n$-alcanos de cadeias longas nas folhas da vegetação superior tem como função preservar o conteúdo de água presente nelas. A síntese destes compostos ocorre através da descarboxilação dos ácidos graxos, que contêm número par de carbonos. Os $n$-alcanos formados biossinteticamente têm número ímpar deste elemento (Eglington \& Hamilton, 1967).

Os padrões de distribuição dos marcadores orgânicos moleculares geram informações sobre a relação entre as espécies e grupos estudados (Merino et al., 2009). O uso de razões, como o tamanho médio de cadeia

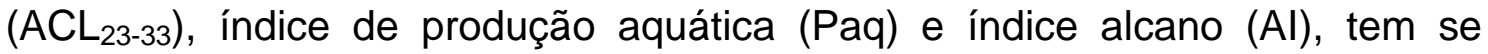
mostrado de grande valor em pesquisas paleoambientais (Nichol et al., 2006; Romerskirchen et al., 2006; Ekpo et al., 2012). A fim de verificar os padrões de $n$-alcanos entre as espécies estudadas, estas razões foram calculadas nos compostos encontrados nas espécies amostradas (Tabela 9). 
Tabela 9: Parâmetros dos $n$-alcanos encontrados nas folhas das espécies de plantas amostradas no presente estudo.

\begin{tabular}{|c|c|c|c|c|c|c|c|c|c|}
\hline & Gênero e espécie & Nome popular & Família & $\begin{array}{c}\text { grupo } \\
\text { metabólico }\end{array}$ & AlcTot & CPI & Paq & Al & $\mathrm{ACL}_{23-33}$ \\
\hline \multirow{3}{*}{$\begin{array}{c}\text { Vegetação do } \\
\text { Sistema Estuarino- } \\
\text { Lagunar de Cananéia- } \\
\text { Iguape }\end{array}$} & S. alterniflora & Capim marinho & Poaceae & Monocotiledônea & 15 & 5 & 0,2 & 0,6 & 29 \\
\hline & L. racemosa & Mangue branco & Combretacea & Dicotiledônea & 188 & 12 & 0,0 & 0,0 & 28 \\
\hline & R. mangle & Mangue vermelho & Rhizophoracea & Dicotiledônea & 21 & 6 & 0,1 & 0,1 & 28 \\
\hline \multirow{5}{*}{$\begin{array}{l}\text { Vegetação da } \\
\text { restinga }\end{array}$} & I.uruguensis & Inga & Mimosaceae & Dicotiledônea & 198 & 14 & 0,0 & 0,2 & 30 \\
\hline & C. brasiliensis & Jacareuba & Clusiaceae & Dicotiledônea & 71 & 12 & 0,0 & 0,7 & 30 \\
\hline & C. pachystachya & Embauba & Cecropiaceae & Dicotiledônea & 319 & 28 & 0,0 & 0,6 & 30 \\
\hline & S. romanzoffiana & Jerivá & Arecaceae & Monocotiledônea & 11 & 5 & 0,1 & 0,7 & 29 \\
\hline & P.aquilinum & Samambaia & Dennstaedtiacea & Pteridófita & 2 & 4 & 0,3 & 0,5 & 28 \\
\hline $\begin{array}{l}\text { Vegetação } \\
\text { introduzida }\end{array}$ & Musa ssp & Bananeira & Polypodiaceae & Dicotiledônea & 280 & 20 & 0,0 & 0,2 & 29 \\
\hline
\end{tabular}

AlcTot (concentração dos $n$-alcanos totais $-\mu \mathrm{g} \mathrm{g}^{-1}$ em peso seco) $=\Sigma\left[\mathrm{nC}_{15}\right]-\left[\mathrm{nC}_{33}\right]$

34 (Aboul-Kassim e Simoneit, 1996)

31 (Ficken et al., 2000)

31 (Rommerskirchen et al., 2003)

$n-C i$, para $\mathrm{i}=23-33$, onde $\mathrm{Ci}$ é o $n$-alcanos com I números de carbono (Collister et al., 1994) 
Laguncularia racemoso

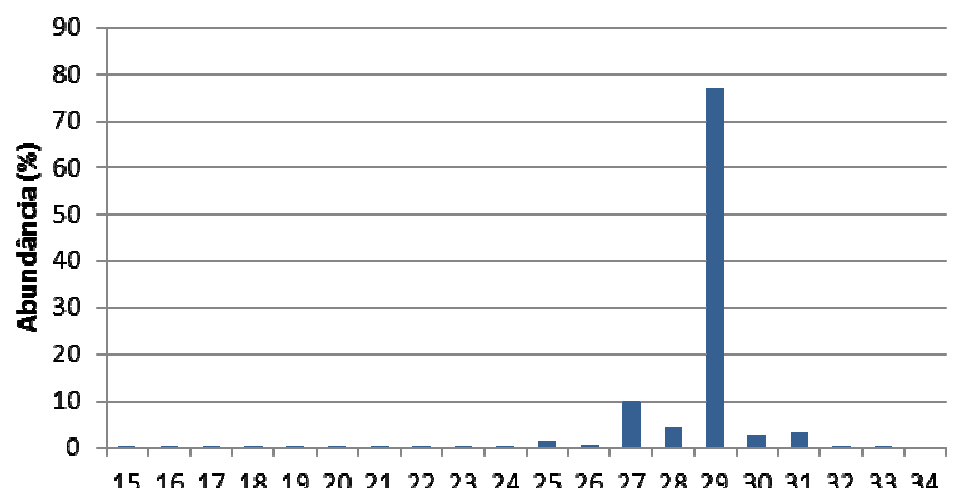

$1516171819202122 \quad 23242526272829303132 \quad 3334$

Rizophora mangle

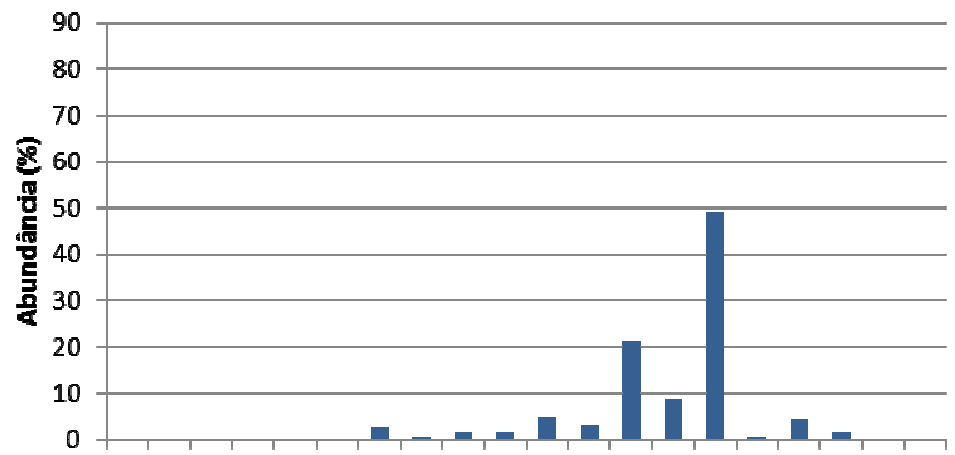

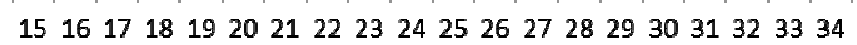
Número de carbonos
Musa ssp

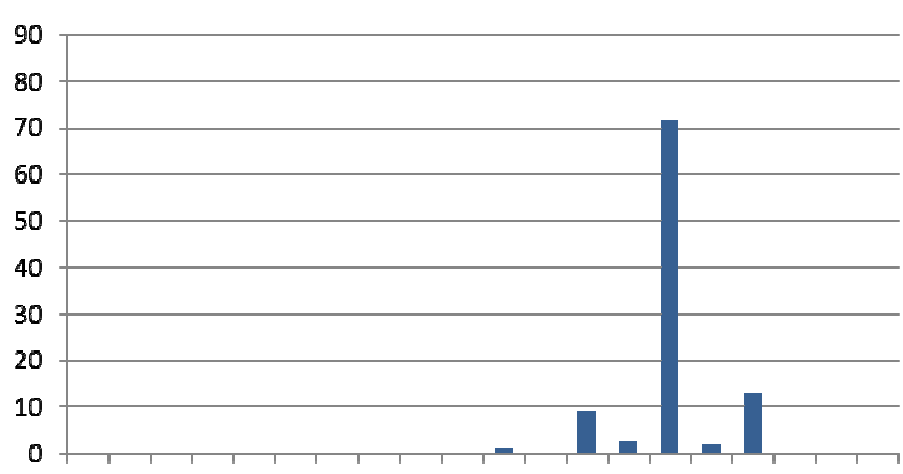

1516171819202122232425262728293031323334

Inga uruguensis

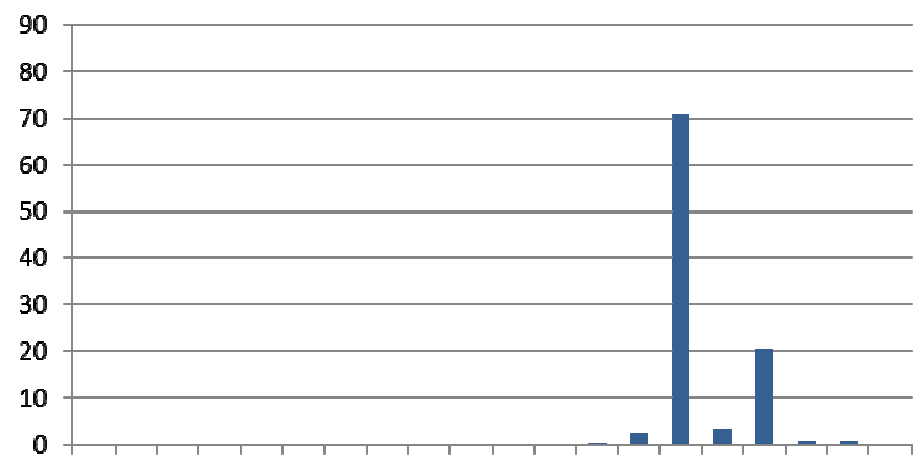

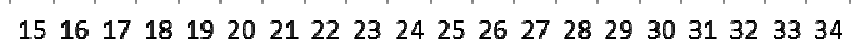
Número de carbonos

Figura 4: Histogramas da distribuição molecular dos n-alcanos encontrados nas amostras de folha das espécies Laguncularia racemosa, Rhizophora mangle, Musa ssp, Inga uruguensis. 


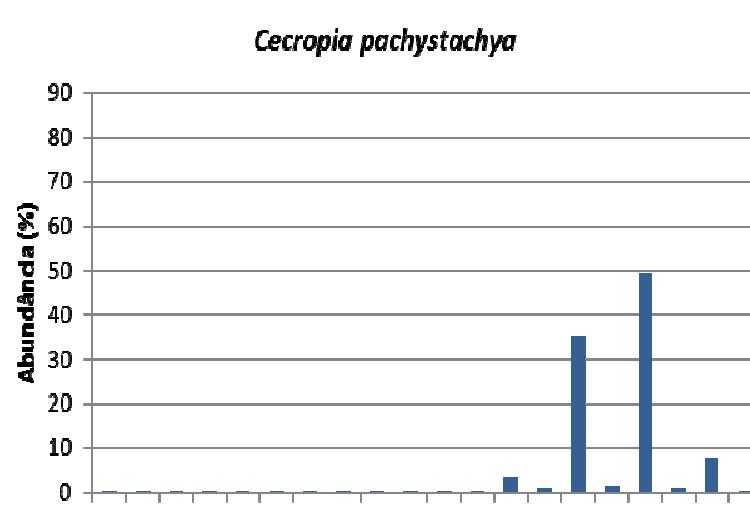

1516171819202122232425262728293031323334

Colophyllum brasiliensis

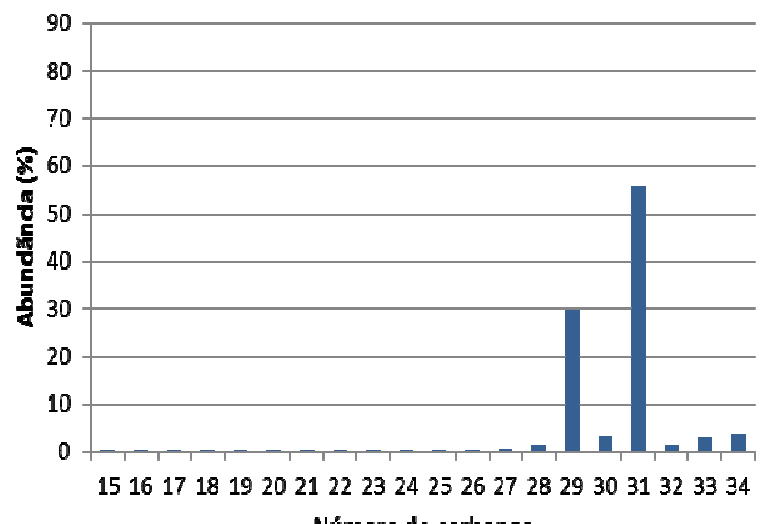

Spartina alternoflora

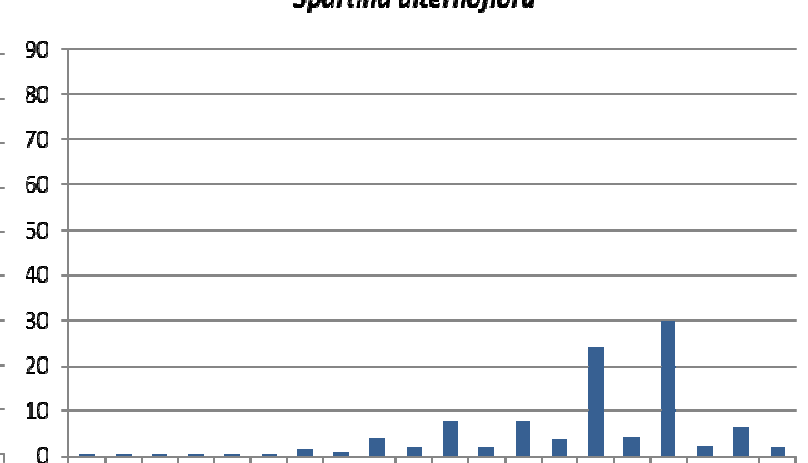

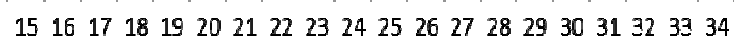

Pteridium aquilinum

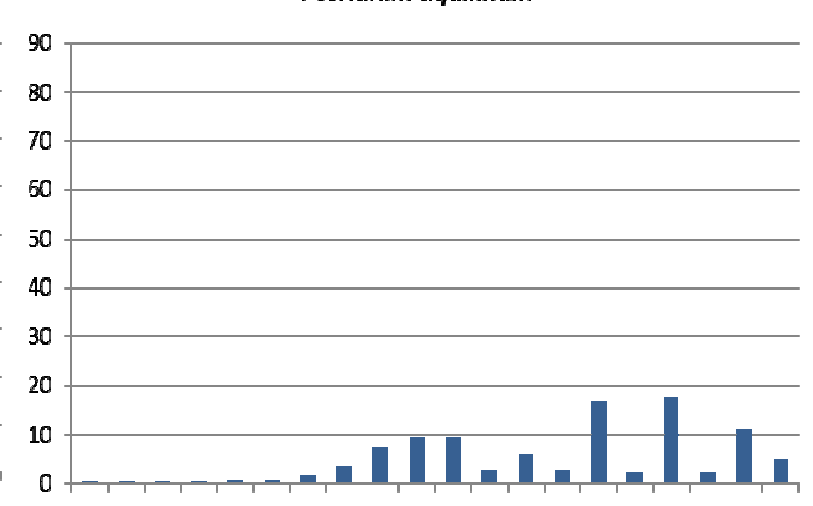

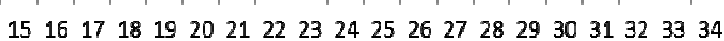
Número de carbonos

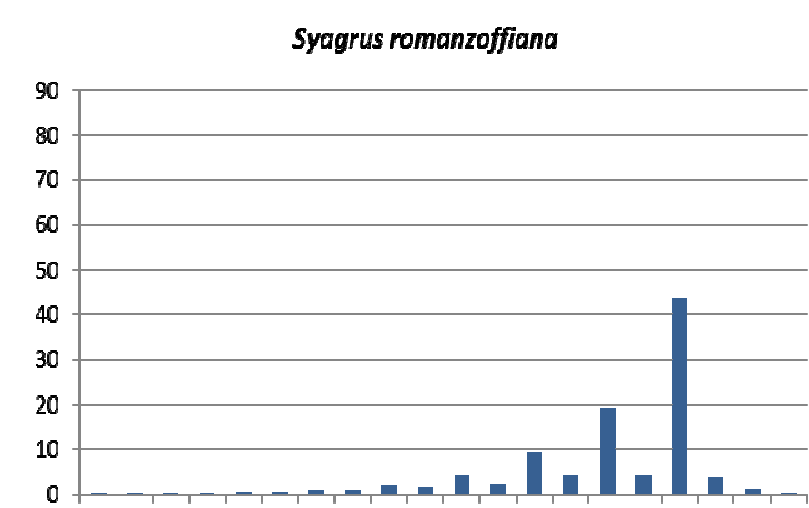

$151617181920212223242526272829303132 \quad 3334$ Número de Carbono

Figura 5: Histogramas da distribuição molecular dos n-alcanos encontrados nas amostras de folha das espécies Calophyllum brasiliensis, Cecropia pachystachya, Spartina alterniflora, Pteridium aquilinum, Syagrus romanzoffiana. 
Os resultados de $\mathrm{ACL}_{23-33}$ encontrado nas espécies avaliadas variaram de 28 a 30 (Tabela 9). Os maiores valores estiveram relacionados às espécies Calophyllum brasiliensis (jacareúba), Cecropia pachystachya (embaúba)e Inga uruguensis (Ingá). Os menores valores estiveram relacionados às árvores de mangue Laguncularia racemosa (mangue branco), Rhizophora mangle (mangue vermelho), e à pteridófita Pteridium aquilinum (samambaia).

Diferenças no $\mathrm{ACL}_{23-33}$ se deram devido às distribuições de cada composto nas espécies estudadas. Na Figura 4 e na Figura 5, estão apresentadas a abundância dos compostos (em \%) em cada espécie. O $n-\mathrm{C}_{29}$ foi predominante em $L$. racemosa, $R$. mangle, I. uruguensis e Musa ssp. Nas duas primeiras ( $L$. racemosa, $R$. mangle), o $n-C_{27}$ foi o segundo $n$-alcano mais abundante, explicando os baixos valores de $\mathrm{ACL}_{23-33}$ nas árvores de mangue. Como R. mangle teve maiores concentrações relativas dos compostos $n-\mathrm{C}_{25} \mathrm{e}$ $n-\mathrm{C}_{27}$ quando comparada à $L$. racemosa, seu $\mathrm{ACL}_{23-33}$ foi o mais baixo. Em $I$. uruguensis e Musa ssp, a porcentagem do $n-C_{29}$ foi elevada, sendo seguida pelo $n-C_{31}$, aumentando o $\mathrm{ACL}_{23-33}$ destas espécies quando comparadas às de mangue. Estes padrões (maiores concentrações relativas de $n-C_{29}$ seguidas pelas de $n-\mathrm{C}_{27}$ e/ou n- $\mathrm{C}_{31}$ ) são comumente encontrados em plantas superiores com caminho fotossintético do tipo $\mathrm{C}_{3}$ (Calvin-Benson) (Cranwell, 1973; Cranwell et al., 1987).

Nas plantas C. pachystachya, C. brasiliensis e Syagrus romanzoffiana houve a predominância do $n$ - $C_{31}$ (Figura 5 ). Esta distribuição é geralmente encontrada na literatura em gramíneas com padrão fotossintético do tipo $\mathrm{C}_{4}$ (Hatche-Slack) (Rommerskirchen et al., 2006). As espécies amostradas no presente estudo são do tipo $\mathrm{C}_{3}$. Em regiões de clima tropical, o aumento relativo na proporção de $n$ - $\mathrm{C}_{31}$, quando comparado aos outros $n$-alcanos, pode ocorrer como mecanismo de defesa das plantas em criar ceras mais rígidas, para evitar a perda de água que ocorre devido ao clima quente (Kozlowski \& Pallardy, 1997; Pedentchouk et al., 2008). Além disso, é sugerido que vegetações de clima tropical quente tenham $n$-alcanos mais longos para proteger suas folhas da radiação incidente (Gagosian \& Peltzer, 1986; Poynter et al., 1989; Sachse et al., 2006). Isto estaria ocasionando o aumento da proporção de $n-C_{31}$ nas espécies $C$. pachystachya, $C$. brasiliensis e $S$. 
romanzoffiana, aumentando seus valores de $\mathrm{ACL}_{23-33}$. Mesmo assim, observase uma alta proporção de $n-\mathrm{C}_{29}$ em $C$. pachystachya e C. brasiliensis; e de $n$ $\mathrm{C}_{29}$ e $n-\mathrm{C}_{27}$ em S. romanzoffiana.

$\mathrm{Na}$ espécie Spartina alterniflora, o $n$-alcano predominante também foi o $n-C_{31}$. Entretanto, houve a presença significativa de cadeias com 23, 25 e 27 átomos de carbono (Figura 5), conforme observado em outras macrófitas emersas (Ficken et al., 2000). Esta configuração está vinculada ao menor estresse hidrológico que esta espécie está submetida.

$P$. aquilinum teve a predominância dos $n$-alcanos $n-\mathrm{C}_{29}$ e $n-\mathrm{C}_{31}$, mas também se pode notar a presença considerável do $n-\mathrm{C}_{27}$ e $n-\mathrm{C}_{33}$, e do $n-\mathrm{C}_{22}$ ao $n$ - $\mathrm{C}_{25}$, sem preponderância de compostos ímpares sobre pares (Figura 5). Espécies de musgos, cladônias e gramíneas do tipo $C_{3}$ também apresentam este comportamento (Romerskirchen et al., 2006; Sachse et al., 2006). A espécie $P$. aquilinum, a única pteridófita amostrada, tem um padrão metabólico diferente das demais espécies avaliadas. Este padrão pode estar afetando a distribuição das moléculas de $n$-alcanos em suas ceras cuticulares.

$\mathrm{Na}$ tentativa de avaliar a abundância do $n-\mathrm{C}_{29}$ em relação ao $n-\mathrm{C}_{31}$ entre as espécies amostradas, calculou-se o Al. Os valores variaram de 0,0 a 0,7 (Tabela 9). Pode-se observar que as árvores de mangue apresentaram menores valores, enquanto que os maiores estiveram relacionados a $C$. brasiliensis e $S$. romanzoffiana. Isso pode estar relacionado ao período de crescimento de cada espécie. Aquelas que têm maior período de crescimento têm tendências de biossintetizar compostos maiores. Uma maior incidência de radiação também pode ser responsável pela presença de compostos maiores, devido a tendência da planta em aumentar a proteção de suas folhas com a presença de cadeias de $n$-alcanos mais longas (Duan \& Hen, 2012). Diferenças nos valores de Al fazem com que este índice possa ser usado para distinguir a matéria orgânica provinda da restinga (superior a 0,2) daquelas provindas do mangue (inferior a 0,1).

Houve também diferenças entre os índices calculados para monocotiledôneas e para dicotiledôneas. Os resultados encontrados de Paq, no geral, foram menores ou iguais a 0,3. As dicotiledôneas apresentaram valores inferiores a 0,1 , enquanto que as monocotiledôneas apresentaram 
valores superiores a 0,1 (Tabela 9). Estes resultados corroboram com os encontrados por Ficken et al. (2000), que observou que valores maiores que 0,4 estão relacionados a macrófitas submersas ou flutuantes; valores entre 0,1 e 0,4 estão relacionados às macrófitas emersas (como a monocotiledônea $S$. alterniflora), e valores menores que 0,1 estão relacionados às plantas superiores.

Valores de CPI, que variaram de 5,23 a 28,2 (Tabela 9), também apresentaram diferenças entre dicotiledôneas e monocotiledôneas. Enquanto as plantas do primeiro grupo apresentaram os maiores valores deste índice (superiores a 5), a pteridófita e as monocotiledôneas apresentaram os menores valores (inferiores a 5). Estes dois últimos grupos (pteridófitas e monocotiledôneas) também apresentaram as menores concentrações de AlcTot. Tulloch (1976) observou que $n$-alcanos com números pares de carbonos podem estar presentes em ceras com baixas concentrações destes compostos. Isto pode estar relacionado a uma variação no início da biossíntese dos ácidos graxos, os precursores dos $n$-alcanos. Ao invés de usar blocos com dois átomos de carbono, formando moléculas pares, o ácido graxo é feito através da junção de moléculas com três carbonos (Shepherd, 2003). Como os $n$-alcanos são formados através da descarboxilação dos ácidos graxos, aqueles que tiverem como precursor uma molécula com número ímpar de átomos de carbono, serão pares. Não se sabe ao certo o porquê que diferentes blocos de construção são usados no começo das reações de síntese (Vogts et al., 2009). Entretanto, as monocotiledôneas tendem a apresentar maior proporção de compostos pares, o que as diferencia quimiotaxônomicamente das dicotiledôneas.

A análise da composição isotópica dos marcadores geoquímicos moleculares também pode ser usada para diferenciar tipos de plantas (Schefuß et al., 2003; Duan e Hen, 2011; Wang et al.,2013). Os valores de $\delta^{13} \mathrm{C}$ e $\delta \mathrm{D}$ calculados nos $n$-alcanos detectados nas espécies avaliadas variaram, respectivamente, de $-42,6 \pm 0,1$ a $-22,6 \pm 0,1 \%$ o e de $-195 \pm 1$ a $-141 \pm 0 \%$ (Tabela 10). As plantas monocotiledôneas apresentaram maiores valores de $\circ \delta^{13} \mathrm{C} \mathrm{e}$ $\delta \mathrm{D}(-28,5 \pm 3,9 \%$ e $-154 \pm 3 \%$, respectivamente, $n=2)$ que as dicotiledôneas $(-35,2 \pm 3,5 \%$ o e $-174 \pm 16 \%$, respectivamente, $n=6)$. 
As diferenças de enriquecimento dos isótopos podem ser devidas às diferenças ambientais que cada espécie está submetida (Terwilliger \& DeNiro, 1995; Bi et al., 2005; Liu e Yang, 2008; Sachse et al., 2006; Kahmen et al., 2011; Kahmen et al., 2013b). Como as plantas avaliadas no presente estudo estão sujeitas às mesmas condições ambientais, sugere-se que as variações observadas na composição isotópica de carbono e hidrogênio tenham se dado, principalmente, devido às distinções fisiológicas entre as espécies. As diferenças no enriquecimento de monocotiledôneas e dicotiledôneas, por exemplo, podem ser causadas pela estrutura venal das folhas (Kahmen et al., 2013b). Plantas monocotiledôneas apresentam veias paralelas longas em suas folhas, enquanto que árvores angiospermas dicotiledôneas têm veias ramificadas (Smith \& Freeman, 2006). O processo de evapotranspiração em plantas dicotiledôneas é menor, o que diminui os valores de $\delta^{13} \mathrm{C}$ e de $\delta \mathrm{D}$ de seus $n$-alcanos (Sachse et al., 2006). Além disso, as monocotiledôneas têm mecanismos de retenção de água que podem influenciar nas suas razões isotópica (Tassoni-Filho, comunicação pessoal ${ }^{\star}$ ). Estas, quando comparadas às dicotiledôneas, permanecem por mais tempo com os estômatos fechados, havendo um maior uso do ${ }^{13} \mathrm{CO}_{2}$ armazenado em suas folhas. Assim, há um aumento do $\delta^{13} \mathrm{C}$ de seus $n$-alcanos. As monocotiledôneas, também, transformam $\circ \mathrm{CO}_{2}$ mais rapidamente e de maneira mais eficiente. Isso diminui a discriminação dos compostos mais pesados, favorecendo o uso do ${ }^{13} \mathrm{C}$ na biossíntese de suas moléculas (Tassoni-Filho, comunicação pessoal*).

\footnotetext{
* Correspondência com o biólogo MSc. Maurício Tassoni-Filho, professor da Pontifícia Universidade Católica de Campinas e doutorando da Escola Superior de Agricultura Luiz de Queiroz da Universidade de São Paulo, realizada em 29/06/2013
} 
Tabela 10: $\delta^{13} \mathrm{C}(\% \circ)$ e $\delta \mathrm{D}(\% \circ)$ dos $n$-alcanos detectados em cada espécie estudada. (n.d.=não detectado, n.a.=não avaliado)

\begin{tabular}{|c|c|c|c|c|c|c|c|c|c|c|}
\hline & & R. mangle & I. uruguensis & S. romanzoffiana & L. racemosa & C. brasiliensis & C. pachystachya & S. alterniflora & Musa ssp & P. aquilinum \\
\hline \multirow{7}{*}{$\frac{0}{10}$} & $n-C_{25}$ & $-31,8 \pm 0,3$ & n.d. & $-32,1 \pm 0,5$ & $-36,3 \pm 0,4$ & n.d. & $-34,8 \pm 1,0$ & $-23,0 \pm 0,1$ & $-32,3 \pm 0,3$ & $-28,2 \pm 0,1$ \\
\hline & $n-C_{26}$ & $-33,1 \pm 0,4$ & n.d. & $-31,4 \pm 0,2$ & n.d. & n.d. & n.d. & $-25,4 \pm 0,5$ & n.d. & $-29,3 \pm 0,1$ \\
\hline & $n-C_{27}$ & $-32,3 \pm 0,1$ & n.d. & $-32,2 \pm 0,0$ & $-36,9 \pm 0,1$ & n.d. & $-35,5 \pm 0,1$ & $-22,6 \pm 0,1$ & $-32,8 \pm 0,0$ & $-27,7 \pm 0,1$ \\
\hline & $n-C_{28}$ & $-32,3 \pm 0,2$ & $-42,2 \pm 0,0$ & $-32,1 \pm 0,4$ & $-37,2 \pm 0,5$ & $-32,8 \pm 0,4$ & $-36,9 \pm 0,1$ & $-24,5 \pm 0,3$ & $-33,7 \pm 0,2$ & $-29,9 \pm 0,3$ \\
\hline & $n-C_{29}$ & $-31,9 \pm 0,1$ & $-42,6 \pm 0,1$ & $-32,7 \pm 0,1$ & $-37,8 \pm 0,0$ & $-33,7 \pm 0,1$ & $-35,5 \pm 0,0$ & $-24,2 \pm 0,0$ & $-32,3 \pm 0,0$ & $-33,1 \pm 0,2$ \\
\hline & $n-C_{30}$ & n.d. & $-41,6 \pm 0,5$ & $-31,5 \pm 0,5$ & $-37,4 \pm 0,3$ & $-32,7 \pm 0,5$ & $-36,1 \pm 0,2$ & $-24,1 \pm 0,2$ & $-33,9 \pm 0,4$ & n.d. \\
\hline & $n-C_{31}$ & n.d. & $-42,4 \pm 0,0$ & $-33,1 \pm 0,0$ & $-37,6 \pm 0,0$ & $-32,5 \pm 0,4$ & $-35,4 \pm 0,1$ & $-23,8 \pm 0,4$ & $-32,9 \pm 0,2$ & n.d. \\
\hline \multirow{3}{*}{ م } & $n-\mathrm{C}_{27}$ & n.a. & n.d. & $-140,6 \pm 0,1$ & $-193,8 \pm 2,1$ & n.d. & $-184,6 \pm 4,0$ & $-151,8 \pm 1,4$ & $-192,5 \pm 0,3$ & $-157,5 \pm 5,0$ \\
\hline & $n-C_{29}$ & n.a. & $-148,5 \pm 0,4$ & $-150,6 \pm 1,0$ & $-176,8 \pm 0,4$ & $-193,5 \pm 0,2$ & $-164,4 \pm 0,3$ & $-150,5 \pm 4,3$ & $-175,0 \pm 0,5$ & $-156,2 \pm 4,2$ \\
\hline & $n-C_{31}$ & n.a. & $-153,6 \pm 1,7$ & $-160,8 \pm 2,5$ & $-185,8 \pm 3,9$ & $-195,0 \pm 1,1$ & $-163,1 \pm 0,4$ & $-160,5 \pm 2,2$ & $-166,2 \pm 1,5$ & n.d. \\
\hline
\end{tabular}


$\mathrm{Na}$ Tabela 11, estão resumidos os valores dos índices e das razões isotópicas dos $n$-alcanos encontrados para os diferentes grupos de vegetação. Estes valores serão comparados com os resultados encontrados nos sedimentos superficiais e dos testemunhos amostrados no presente estudo.

Tabela 11: Diferenças entre os índices e razões isotópicas $\left(\delta^{13} C_{n \text {-alcanos }}\right.$ e $\delta D$-alcanos $)$ dos $n$-alcanos detectados em distintos grupos de vegetação com base nas amostras de folhas avaliadas no presente estudo. $\mathrm{ACL}_{23-33}=$ tamanho médio de cadeia; $\mathrm{Al}=$ =índice alcano;

\begin{tabular}{ccc}
\hline Parâmetro & Grupo & Valores \\
\hline \multirow{2}{*}{$\mathbf{A C L}_{\mathbf{2 3 - 3 3}}$} & Vegetação de mangue & $<29,0$ \\
& Vegetação de restinga & $>29,0$ \\
\hline \multirow{2}{*}{ Al } & Vegetação de mangue & $<0,1$ \\
& Vegetação de restinga & $>0,2$ \\
\hline \multirow{2}{*}{$\mathbf{P a q}$} & Monocotiledôneas & $>0,1$ \\
& Dicotiledôneas & $<0,1$ \\
\hline \multirow{2}{*}{$\mathbf{C P I}$} & Monocotiledôneas & $<5$ \\
& Dicotiledôneas & $>5$ \\
\hline \multirow{2}{*}{$\boldsymbol{\delta}^{13} \mathbf{C}_{n \text {-alcanos }}$} & Monocotiledôneas & $-28,5 \pm 3,9 \%$ \\
& Dicotiledôneas & $-35,2 \pm 3,5 \%$ \\
\hline \multirow{2}{*}{$\mathbf{D D}_{n \text {-alcanos }}$} & Monocotiledôneas & $-154 \pm 3 \%$ o \\
& Dicotiledôneas & $-174 \pm 16 \%$ \\
\hline
\end{tabular}




\subsection{Matéria orgânica nas amostras superficiais}

\subsubsection{Distribuição das frações sedimentares e do conteúdo de carbonato de cálcio no Sistema Estuarino-Lagunar de Cananéia- Iguape}

Os conteúdos de areia, silte e argila das amostras superficiais do presente estudo (Tabela 12) variaram, respectivamente, de 20,7 a $100 \%$, de 0,01 a $61,8 \%$ e de 0,00 a 23,2\%. A fração arenosa foi predominante na maioria das amostras. Sedimentos coletados mais ao norte (S12, S15, S19, S23, S28, S31, S33, S35) apresentaram maiores conteúdos de areia e menores de silte quando comparados com os da região central (S43, S45, S52, S54, S57, S60 e S62) e do Rio Ribeira de Iguape (S08) (Figura 6). Amostras coletadas no canal do Valo Grande (S01 e S02) apresentaram predominância de silte (Figura 6). As amostras coletadas na região da Pedra do Tombo (S57 e S60) também apresentaram predominância de silte, mas com elevados conteúdos de argila (Figura 6).

As fontes de areia e de materiais pelíticos para o Sistema EstuarinoLagunar de Cananéia-Iguape são diferentes (Barcellos, 2005). O aporte de areia ocorre principalmente através do retrabalhamento de depósitos através dos processos de regressão marinha. Os sedimentos pelíticos são principalmente introduzidos no sistema através do canal do Valo Grande, cuja influência pode afetar até porção sul do sistema estudado (Barcellos, 2005).

O principal processo responsável pelos padrões de distribuição dos sedimentos superficiais nos sistemas estuarinos e lagunares é a corrente de maré (Liu et al., 1998). Na região estudada, correntes mais fortes ocorrem durante a maré vazante nas regiões das Barras de Cananéia e Icapara (Miyao et al., 1986). Estas correntes não permitem a deposição de sedimentos mais finos nestas barras, sendo inclusive capazes de erodir o fundo e as margens do local (Barcellos, 2005). Os materiais mais finos são exportados para a região central do sistema, sendo depositados principalmente próximos à Pedra do Tombo. Nesta região, há processos de correntes convergentes que são responsáveis pela redução da velocidade das correntes de maré na área 
(Tessler, 1982; Barcellos et al., 2009). Como a velocidade de sedimentação dos sólidos em suspensão diminui com o tamanho do grão (Sternberg et al., 1999), há um aumento na captura de siltes e argilas que não foram depositados na parte norte do sistema. Assim, a região central, principalmente próximo à Pedra do Tombo, apresenta maiores proporções destas frações.

Tabela 12: Conteúdo de argila (\%), silte (\%), areia (\%) e carbonato de cálcio (Carb., \%) nas amostras de sedimento superficiais coletadas no Sistema Estuarino-Lagunar de Cananéia-Iguape.

\begin{tabular}{|c|c|c|c|c|c|c|c|c|c|}
\hline & Argila & Silte & Areia & Carb. & & Argila & Silte & Areia & Carb. \\
\hline S01 & 2,61 & 59,4 & 38,0 & 1,80 & S35 & 2,08 & 11,0 & 86,9 & 2,19 \\
\hline S02 & 9,02 & 56,5 & 34,5 & 5,94 & S38 & 15,9 & 53,4 & 30,7 & 5,82 \\
\hline S08 & 6,41 & 30,8 & 62,8 & 2,93 & S43 & 17,7 & 56,6 & 25,6 & 5,52 \\
\hline S12 & 0,00 & 0,01 & 100 & 1,22 & S45 & 6,09 & 30,0 & 63,9 & 4,25 \\
\hline S15 & 2,02 & 12,0 & 86,0 & 3,41 & S52 & 4,63 & 22,7 & 72,6 & 3,16 \\
\hline S17 & 6,68 & 61,6 & 31,7 & 23,2 & S54 & 6,37 & 33,3 & 60,3 & 3,75 \\
\hline S19 & 3,07 & 11,8 & 85,0 & 1,89 & S57 & 23,2 & 56,1 & 20,7 & 5,82 \\
\hline S23 & 5,59 & 19,8 & 74,6 & 2,90 & $S 60$ & 22,9 & 56,4 & 20,7 & 6,30 \\
\hline S28 & 3,17 & 10,6 & 86,2 & 3,10 & S62 & 11,9 & 58,9 & 29,2 & 9,17 \\
\hline S31 & 1,13 & 3,87 & 95,0 & 1,40 & $S 74$ & 3,30 & 13,1 & 83,5 & 16,4 \\
\hline S33 & 3,18 & 7,67 & 89,1 & 2,14 & S76 & 8,96 & 33,6 & 57,5 & 13,8 \\
\hline
\end{tabular}




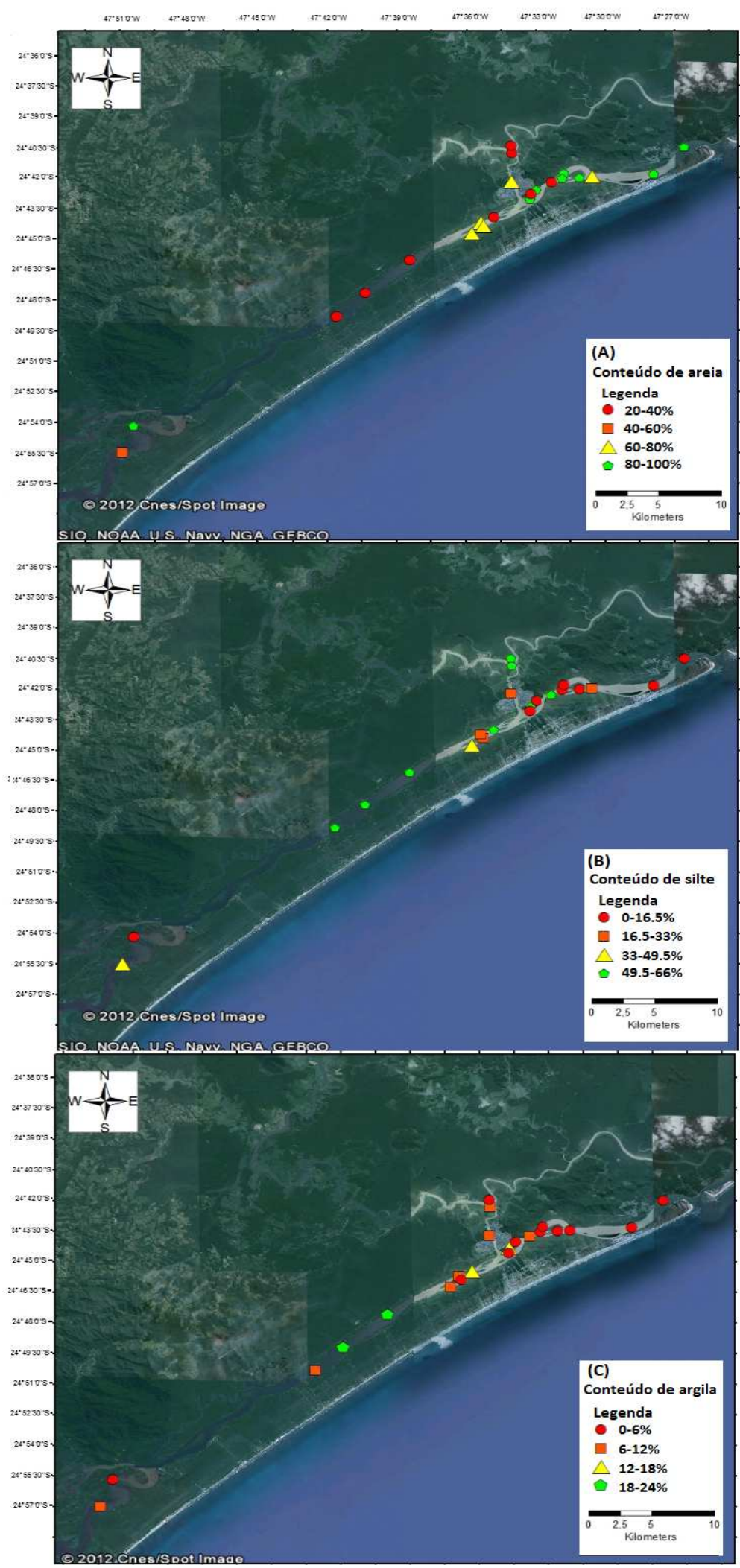

Figura 6: Distribuição espacial dos conteúdos de areia (A), silte (B) e argila (C) encontrados nas amostras superficiais coletadas no Sistema Estuarino-Lagunar de Cananéia-Iguape 
Os teores de carbonato de cálcio $\left(\mathrm{CaCO}_{3}\right)$ encontrados nas amostras de sedimentos superficiais variaram de 1,22 a 23,2\% (Tabela 12). A parte norte do sistema, incluindo as amostras coletadas no canal do Valo Grande e no Rio Ribeira de Iguape, apresentaram menores proporções de $\mathrm{CaCO}_{3}(<5 \%$, Figura 7). Como a região norte tem maiores teores de areia e altas condições hidrodinâmicas, $\mathrm{O} \mathrm{CaCO}_{3}$ introduzido nesta área passa por maior processo de trituração devido ao seu atrito com o fundo. Além disso, esta região do Mar Pequeno encontra-se sobre maior influência de aporte terrígeno, uma vez que nela há o deságue do Rio Ribeira de Iguape através do canal do Valo Grande. Assim, a menor porcentagem de $\mathrm{CaCO}_{3}$ na região norte pode também ser influenciada pelas contribuições terrígenas que diluem esse conteúdo (Duleba, 1997; Teles, 1997). A amostra S17 foi uma exceção na região apresentando níveis relativamente altos de $\mathrm{CaCO}_{3}(23,2 \%)$ e de silte $(61,6 \%)$. Este maior teor pode estar relacionado a uma maior contribuição fitoplanctônica na região.

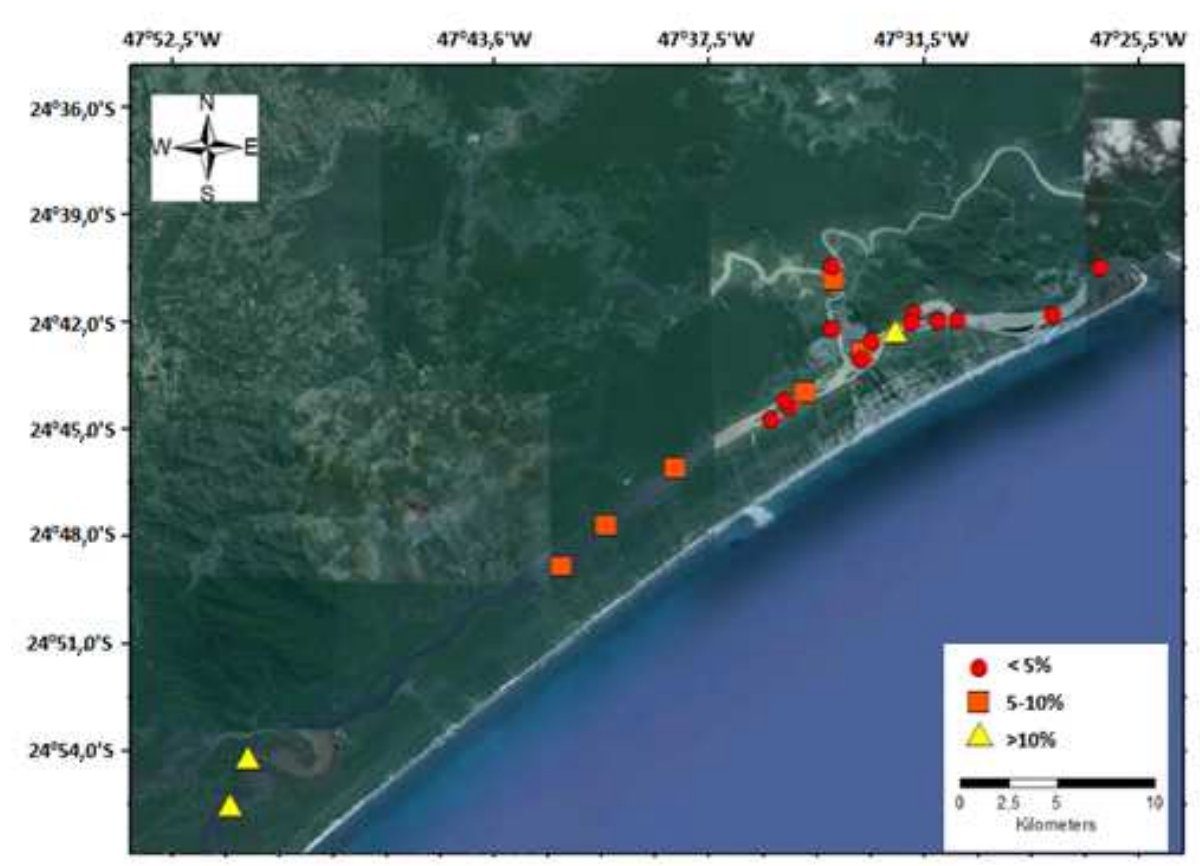

Figura 7: Distribuição espacial dos conteúdos de carbonato de cálcio $\left(\mathrm{CaCO}_{3}\right)$ encontrados nas amostras superficiais coletadas no Sistema Estuarino-Lagunar de Cananéia-Iguape. 
A parte sul do sistema apresenta conteúdos de $\mathrm{CaCO}_{3}$ relativamente mais altos (>10\%). Esta área está sob maior influência de aporte de material marinho (Barcellos et al., 2003). As amostras da região central, principalmente aquelas mais próximas à Pedra do Tombo, apresentaram níveis intermediários de $\mathrm{CaCO}_{3}$ (entre 5 e 10\%, Figura 7), provavelmente em função do encontro das marés que ocorre nesta região. Este gera condições hidrodinâmicas favoráveis à deposição deste material. Além disso, a maior deposição de sedimentos finos nesta área faz com que ocorra uma maior preservação do $\mathrm{CaCO}_{3}$.

Todas as amostras do presente estudo puderam ser classificadas como litoclásticas conforme proposto por Larssoneur et al. (1982) (valores abaixo de $30 \%$ ). Barcellos (2005), ao avaliar os teores de $\mathrm{CaCO}_{3}$ nos sedimentos superficiais do Sistema Estuarino-Lagunar de Cananéia-Iguape encontrou valores próximos aos encontrados no presente estudo (99\% das amostras apresentaram valores de $\mathrm{CaCO}_{3}$ inferiores a 30\%). Já Tessler (1982) encontrou esta característica na maioria de suas amostras, entretanto $30 \%$ delas obtiveram valores de $\mathrm{CaCO}_{3}$ superiores a $30 \%$. Esta diferença pode ter ocorrido devido ao período de coleta de cada trabalho. Diferentemente do presente estudo e do apresentado por Barcellos (2005), a coleta das amostras realizadas em Tessler (1982) ocorreu quando o canal do Valo Grande encontrava-se fechado (1979). A contribuição marinha relativa neste período foi maior, o que aumentou a contribuição de $\mathrm{CaCO}_{3}$ nos sedimentos depositados, indicando que o canal do Valo Grande aumenta o aporte de material terrígeno e/ou diminui o marinho para a região de estudo.

\subsubsection{Distribuição e fonte da matéria orgânica no sistema Estuarino-Lagunar de Cananéia-Iguape}

As concentrações de carbono orgânico total (TOC), nitrogênio total (TN) e $n$-alcanos totais (AlcTot) encontradas nas amostras de sedimentos superficiais variaram, respectivamente, de 0,15 a $6,37 \%$, abaixo do valor mínimo detectável pelo EA-IRMS a 0,74\%, e de 724 a 15932 ng g $^{-1}$ p.s. (Tabela 13). Menores concentrações de TOC, TN e AlcTot foram encontradas na parte 
norte do sistema. Maiores concentrações estiveram associadas à região central, principalmente nas proximidades da Pedra do Tombo (Tabela 13, Figura 8-B e C).

O teor da fração sedimentar mais fina, aparentemente, foi o principal fator que determinou o conteúdo da matéria orgânica do sedimento superficial da região estudada. Conteúdos de areia e silte apresentaram, respectivamente, correlações significativas negativas e positivas $(n=22)$ com as concentrações de TOC $(p<0,01, r=-0,53 ; p<0,01, r=0,56)$, TN $(p<0,001, r=-0,73 ; p<0,001$, $r=0,67)$ e AlcTot $(p<0,0001, r=-0,80 ; p<0,0001, r=0,77)$. Conteúdos de argila apresentaram correlações significativas positivas com os níveis de TN $(p<0,0001, r=0,78)$ e AlcTot $(p<0,001, r=0,70)$. Partículas sedimentares mais finas apresentam maior capacidade de adsorção da matéria orgânica (Cotano \& Villate, 2006; Ramaswamy et al., 2008). Assim, é comum que áreas com maior deposição de sedimentos finos também apresentem maiores conteúdos de TOC, TN e AlcTot (Ramaswamy et al., 2008; Gireeshkumar et al., 2013). 
Tabela 13: Conteúdo de carbono orgânico total (TOC, \%), conteúdo de nitrogênio total (TN, \%), razão entre carbono orgânico total e nitrogênio total $(\mathrm{C} / \mathrm{N}), \delta^{13} \mathrm{C}$ do carbono orgânico total, $\delta^{15} \mathrm{~N}$ do nitrogênio total (\%),contribuição de matéria orgânica terrestre $(F$, $\%$ ), concentração de $n$-alcanos totais (AlcTot, $\mathrm{ng} \mathrm{g}^{-1}$ de sedimento seco), índice preferencial de carbono (CPI), tamanho médio de cadeia $\left(\mathrm{ACL}_{23-33}\right)$, índice de produção aquática (Paq) e índice alcano ( $\mathrm{Al}$ ) calculados para o Sistema Estuarino-Lagunar de Cananéia-Iguape (n.d.= não detectado; $n . c .=$ não calculado).

\begin{tabular}{lccccccccccc}
\hline & TOC & TN & $\mathbf{C} / \mathbf{N}$ & $\mathbf{\delta}^{13} \mathbf{C}$ & $\mathbf{\delta}^{15} \mathbf{N}$ & $\mathbf{F}$ & AlcTot & $\mathbf{C P I}$ & $\mathbf{A C L}_{23-33}$ & Paq & Al \\
\hline S01 & 1,60 & 0,23 & 6,91 & $-27,6$ & 4,73 & 95,1 & 14994 & 5,96 & 29,4 & 0,12 & 0,46 \\
S02 & 1,93 & 0,14 & 13,3 & $-27,4$ & 4,69 & 93,0 & 5494 & 5,12 & 30,0 & 0,10 & 0,57 \\
S08 & 1,42 & 0,09 & 16,6 & $-27,6$ & 4,21 & 94,5 & 3439 & 5,49 & 29,7 & 0,13 & 0,54 \\
S12 & 1,05 & n.d. & n.c. & $-27,5$ & n.c. & 94,3 & 1434 & 4,87 & 30,1 & 0,06 & 0,56 \\
S15 & 2,63 & 0,05 & 48,2 & $-26,1$ & 4,83 & 76,5 & 4320 & 5,85 & 29,4 & 0,14 & 0,41 \\
S17 & 6,37 & 0,04 & 156 & $-23,0$ & 3,31 & 37,9 & 4157 & 5,62 & 29,7 & 0,11 & 0,52 \\
S19 & 1,95 & n.d. & n.c. & $-25,6$ & n.c. & 70,3 & 1486 & 5,30 & 29,0 & 0,25 & 0,47 \\
S23 & 3,95 & 0,26 & 15,0 & $-26,5$ & 5,86 & 81,1 & 5243 & 6,58 & 30,4 & 0,11 & 0,51 \\
S28 & 1,21 & 0,02 & 55,3 & $-26,7$ & 4,09 & 84,4 & 3928 & 5,85 & 29,7 & 0,11 & 0,52 \\
S31 & 0,44 & 0,02 & 19,2 & $-25,8$ & 1,94 & 72,1 & 724 & 4,16 & 29,6 & 0,13 & 0,51 \\
S33 & 0,15 & 0,08 & 2,00 & $-26,3$ & 3,29 & 78,6 & 1414 & 5,46 & 29,4 & 0,15 & 0,47 \\
S35 & 0,80 & 0,07 & 10,8 & $-27,1$ & 4,09 & 88,1 & 1894 & 6,34 & 29,6 & 0,13 & 0,51 \\
S38 & 2,98 & 0,57 & 5,22 & $-27,4$ & 4,77 & 92,8 & 10987 & 5,85 & 29,7 & 0,11 & 0,53 \\
S43 & 2,23 & 0,58 & 3,82 & $-27,1$ & 4,66 & 88,8 & 15932 & 5,10 & 29,9 & 0,09 & 0,54 \\
S45 & 1,15 & 0,31 & 3,71 & $-26,6$ & 4,57 & 83,0 & 11380 & 5,81 & 30,1 & 0,09 & 0,56 \\
S52 & 0,70 & 0,12 & 5,80 & $-27,3$ & 3,21 & 90,6 & 4238 & 6,24 & 29,8 & 0,10 & 0,54 \\
S54 & 1,97 & 0,36 & 5,49 & $-27,0$ & 4,18 & 87,9 & 4825 & 5,83 & 29,7 & 0,13 & 0,52 \\
S57 & 2,24 & 0,49 & 4,58 & $-27,1$ & 4,69 & 89,1 & 11644 & 5,21 & 29,8 & 0,11 & 0,53 \\
S60 & 2,29 & 0,52 & 4,39 & $-27,2$ & 4,29 & 89,4 & 12463 & 6,23 & 29,7 & 0,12 & 0,50 \\
S62 & 3,69 & 0,74 & 4,97 & $-26,6$ & 4,65 & 82,5 & 11027 & 5,54 & 29,0 & 0,17 & 0,39 \\
S74 & 0,27 & 0,04 & 6,19 & $-25,9$ & 2,58 & 73,4 & 1758 & 4,00 & 28,6 & 0,21 & 0,29 \\
S76 & 0,50 & 0,13 & 3,99 & $-26,1$ & 4,14 & 76,8 & 11674 & 5,82 & 28,8 & 0,15 & 0,27 \\
\hline & & & & & & & & & & & \\
\hline
\end{tabular}




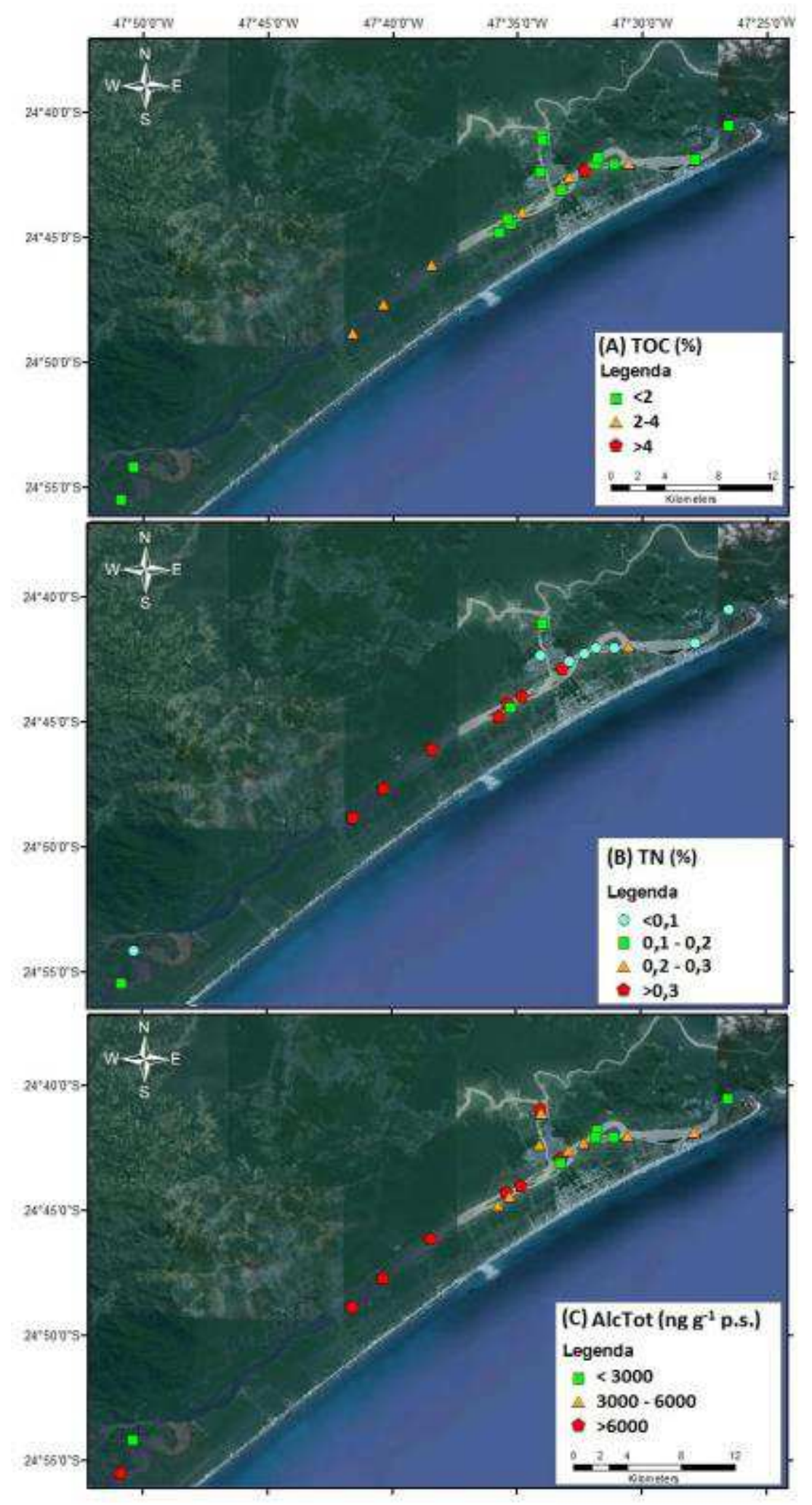

Figura 8: Distribuição espacial dos conteúdos de carbono orgânico total (TOC, A), nitrogênio total (TN, B) e $n$-alcanos totais (AlcTot, C) das amostras superficiais coletadas no Sistema Estuarino-Lagunar de Cananéia-Iguape. 
As variáveis TN e TOC não apresentaram correlação significativa (Figura 9-A, $p=0,15, r=0,34, n=22)$. Entretanto, esta situação muda quando a amostra S17 é excluída da análise (Figura 9-B, $p=0,001, r=0,69, n=21$ ). Nitrogênio inorgânico pode estar contribuindo com o conteúdo de TN desta amostra, aumentando a concentração deste parâmetro (Andrews et al., 1998). Esta amostra também apresentou maiores valores de $\mathrm{TOC}, \mathrm{CaCO}_{3}$ e silte. Pode ser que estas características estejam interligadas. A presença de nutrientes, por exemplo, aumenta a produção fitoplanctônica, que faz crescer a deposição de material orgânico na área (Barrera-Alba, 2004; Barcellos, 2005). Como o presente estudo está avaliando a distribuição de matéria orgânica no sistema em questão, o TN da amostra S17 não foi considerado na discussão a seguir.

A linha de regressão da correlação feita entre o TOC e o TNdas amostras restantes (onde se excluiu os valores da amostra S17) intercepta próximo do eixo de origem (Figura 9-B). Isto sugere que os teores de nitrogênio inorgânico foram insignificantes nas contribuições de TN dessas amostras. Consequentemente, pode-se assumir que esta variável é composta principalmente por nitrogênio orgânico (Rumolo et al., 2011), e a razão $\mathrm{C} / \mathrm{N}$ responde às fontes de matéria orgânica (Andrews et al., 1998; Tue et al., 2011; Gireeshkumar et al., 2013).

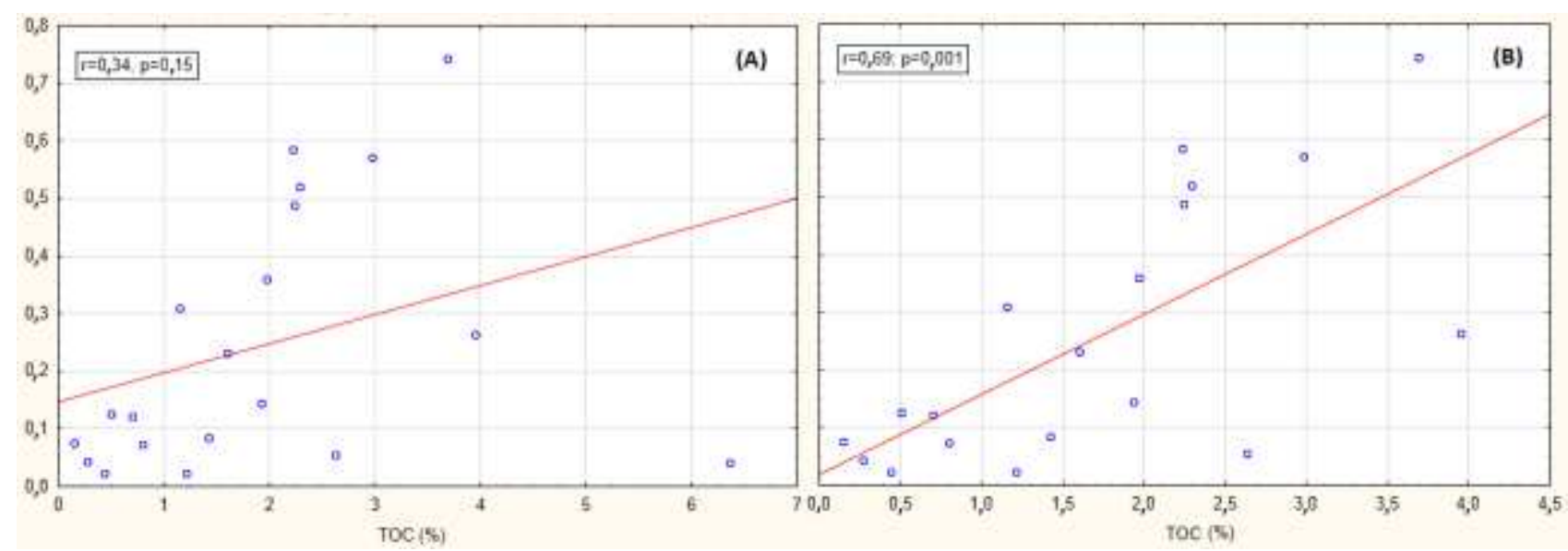

Figura 9: Correlação entre os conteúdos de TOC (\%) e TN (\%) em todas as amostras $(n=22)(A)$ e quando a amostra $S 17$ (com altos níveis de TOC) é excluída ( $n=21)(B)$. 
A razão $\mathrm{C} / \mathrm{N}$ tem sido usada há décadas na avaliação da influência do aporte da matéria orgânica marinha e terrígena (Bordovskiy, 1965). No presente estudo, esta razão variou de 1,96 a 55,3 (Tabela 13). Os valores encontrados na região central foram típicos de predominância de fontes de matéria orgânica marinha (C/N variando de 0 a 6; Barcellos, 2005;Figura 10). A área sul apresentou valores indicando mistura de fontes, mas com maior tendência marinha ( $\mathrm{C} / \mathrm{N}$ variando de 6 a 8; Barcellos, 2005;Figura 10). Valores entre 12 e 24 (que indica mistura de fontes com tendências terrígenas; Barcellos, 2005) e maiores que 24 (que indicam predominância de matéria orgânica de fontes terrígena; Barcellos, 2005) foram encontradas somente na região norte do sistema (Figura 10).

$\mathrm{O}$ uso da razão $\mathrm{C} / \mathrm{N}$ deve ser feita com cautela. Processos, como decomposição do nitrogênio, podem aumentar ou diminuir a concentração deste elemento nos sedimentos (Thornton \& McManus, 1994; Barcellos, 2005), mascarando o uso desta variável como marcador geoquímico de fontes de matéria orgânica. As amostras S12 e S19, por exemplo, não apresentaram conteúdos detectáveis de nitrogênio (Tabela 13). As amostras S15 e S28 apresentaram baixos valores de TN (Tabela 13), o que aumentou a razão C/N. Esses quatro exemplos tiveram predominância de areia na fração sedimentar (Tabela 12). A razão $\mathrm{C} / \mathrm{N}$ em regiões arenosas pode responder a processos de decomposição do nitrogênio, e não à fonte de matéria orgânica (Barcellos, 2005). O uso da razão $\mathrm{C} / \mathrm{N}$ como marcador de fonte de matéria orgânica deve ser feita sempre junto a outros marcadores. 


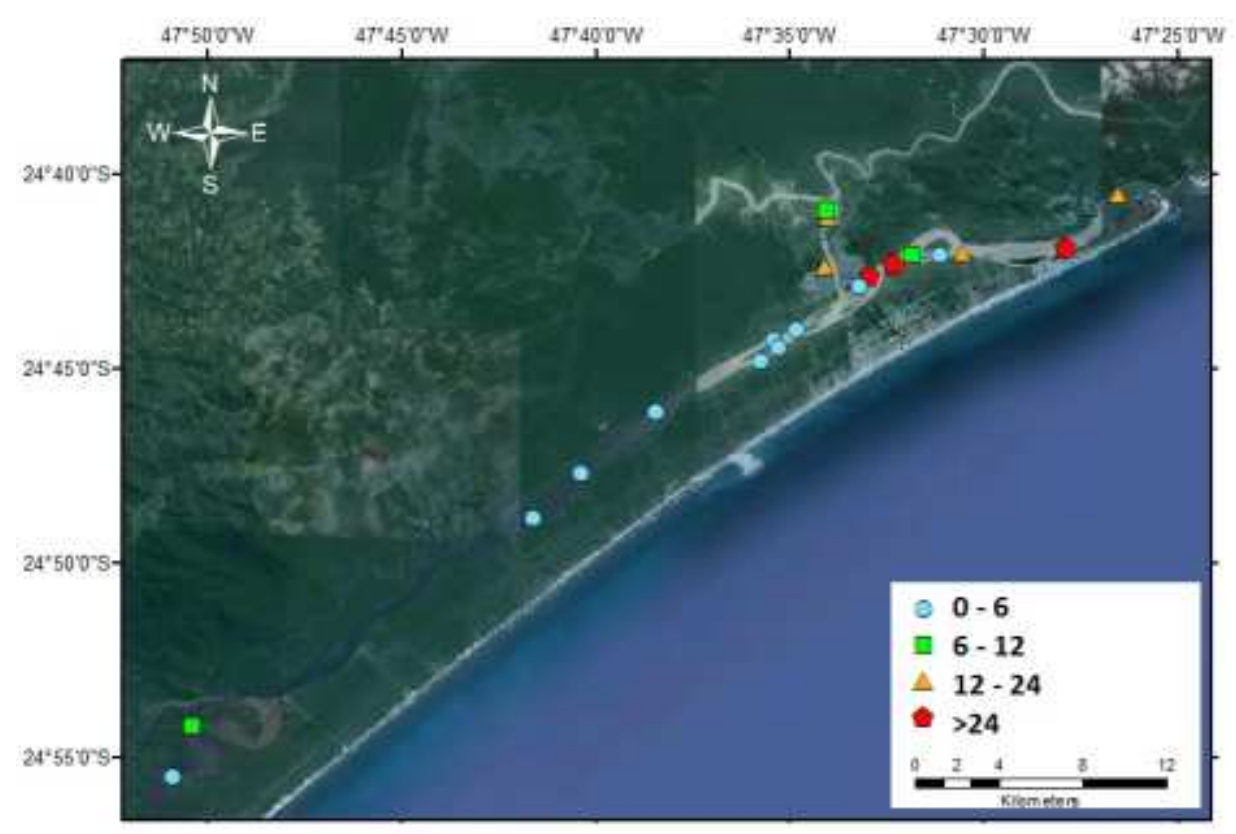

Figura 10: Distribuição especial da razão entre os teores de carbono orgânico total e de nitrogênio total $(\mathrm{C} / \mathrm{N})$ das amostras superficiais do Sistema Estuarino-Lagunar de Cananéia-Iguape.

$\mathrm{Na}$ Tabela 13, estão apresentados $\circ \delta^{13} \mathrm{C}$ e $\circ \delta^{15} \mathrm{~N}$ obtidos na matéria orgânica total dos sedimentos coletados. Estes variaram, respectivamente, de $-27,6$ a $-23,0 \%$; e de 1,94 a 5,86 \%. Os resultados indicaram predominância da contribuição terrígena à matéria orgânica do sistema $\left(\delta^{15} \mathrm{~N}\right.$ menor que $5 \%$, Gao et al., 2012). Com exceção da amostra S17 (Tabela 13), esta predominância se dá principalmente por plantas superiores com padrão fotossintético do tipo $C_{3}\left(\delta^{13} \mathrm{C}\right.$ variando de -30 a $-26 \%$, Pancost \& Boot, 2004).

A distribuição das cadeias de $n$-alcanos também foi típica de predominância terrígena, com preponderância de compostos ímpares, principalmente o $n-\mathrm{C}_{29}$ e/ou $n-\mathrm{C}_{31}$ (Figura 11). O tamanho médio de cadeia $\left(\mathrm{ACL}_{23-33}\right)$ variou de 28,6 a 30,4; e o $\mathrm{CPI}$, de 4,00 a 6,58 (Tabela 13). Estas razões, assim como a distribuição dos compostos, indicam que a principal fonte de matéria orgânica para a região são as plantas superiores (Brassell et al., 1978; Rieley et al., 1991).

Comparando os valores de Al encontrados nas amostras de vegetação estudada (Tabela 11) com os encontrados nas amostras superficiais (Tabela 13), observou-se que a predominância terrígena observada acima se deve 
principalmente à contribuição da vegetação de restinga. Barcellos (2005) e Barrera-Alba et al.(2007) propuseram que a principal fonte de matéria orgânica para o Sistema Estuarino-Lagunar de Cananéia-Iguape é a vegetação de mangue presente ao longo do sistema. Entretanto, os pressupostos feitos pelos trabalhos supracitados foram baseados em marcadores geoquímicos que indicaram que na região há uma predominância de matéria orgânica de plantas do tipo $\mathrm{C}_{3}$. Tanto a vegetação de mangue quanto a maioria das plantas da vegetação de restinga apresentam este padrão fotossintético. Embora a vegetação de mangue se encontre bem desenvolvida ao longo da área estudada (Schaeffer-Novelli \& Cintrón-Molero, 1990; Cunha-Lignon, 2001), a vegetação de restinga presente nos arredores dos rios que deságuam no sistema é bem preservada e desenvolvida. Sua contribuição para a matéria orgânica depositada no sistema estudado se faz significativa. Esta introdução ocorre principalmente através de duas bacias de drenagem: a de Itapitangui e a do Rio Ribeira de Iguape (Bérgamo, 2000).

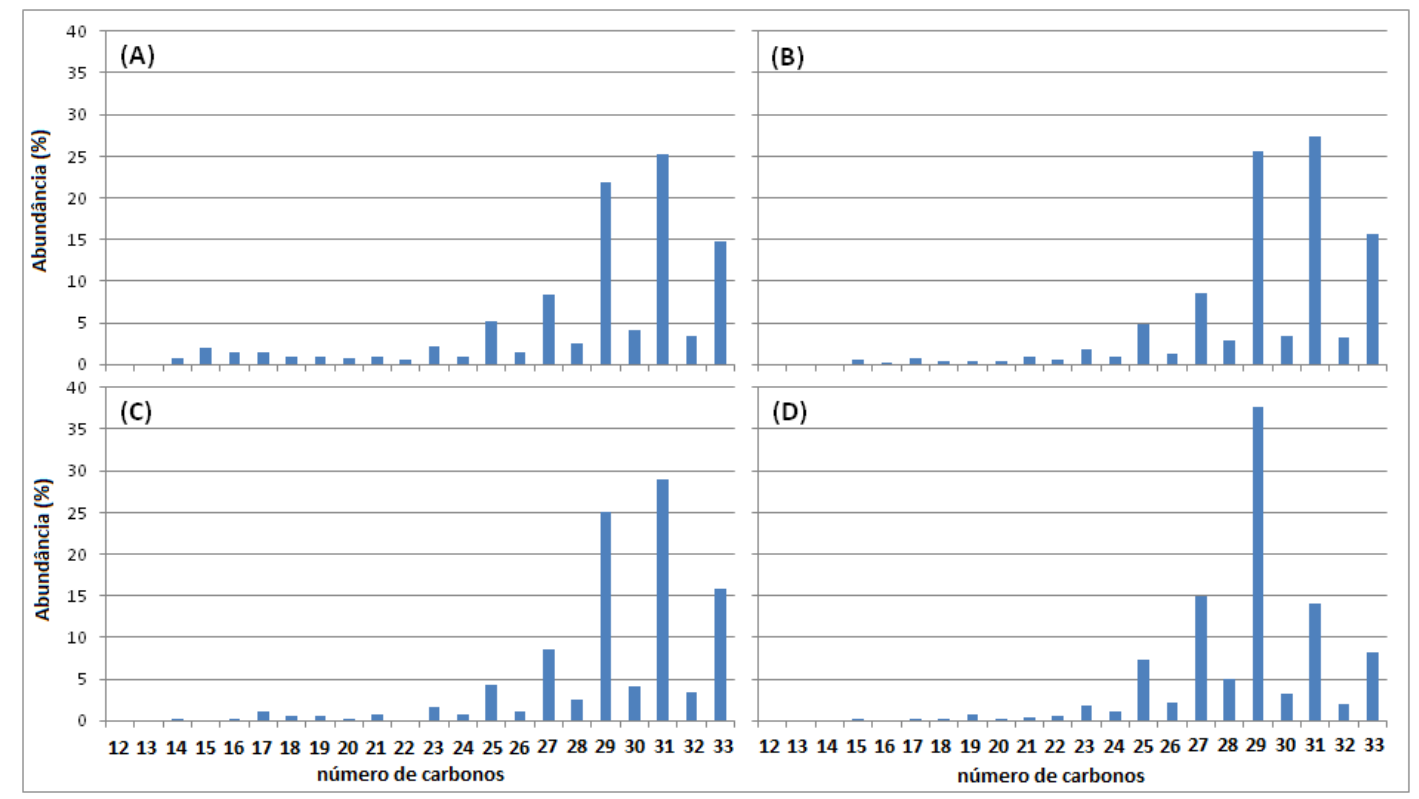

Figura 11: Exemplo de histogramas obtidos na distribuição molecular dos $n$-alcanos encontrados nas amostras de sedimentos superficiais coletados ao longo do Sistema

Estuarino-Lagunar de Cananéia-Iguape. Os histogramas são correspondentes às amostras S08 (A), S15 (B), S52(C) e S76 (D). 
Pode-se observar que os sedimentos da região norte, apresentaram maiores valores de Al quando comparados com os da região sul (Figura 12- $\mathrm{B}$ e D). Provavelmente isto indica que, embora haja um predomínio no aporte de matéria orgânica terrígena de restinga em todo o sistema, este é maior na região norte e menor na sul. Entre as duas principais bacias de drenagem presentes no sistema, a de Itapitangui está localizada mais ao sul e tem uma capacidade de drenagem menor $\left(1339 \mathrm{~km}^{2}\right)$, contribuindo com a introdução de $47 \mathrm{~m}^{3} \mathrm{~s}^{-1}$ de água doce (Bérgamo, 2000). A do Rio Ribeira de lguape está localizada mais ao norte, e apresenta a maior rota de drenagem do Estado de São Paulo $\left(23350 \mathrm{~km}^{2}\right)$. Com a construção do canal do Valo Grande, $70 \%$ do Rio Ribeira de Iguape começou a desaguar na região norte do Sistema Estuarino-Lagunar de Cananéia-Iguape, descarregando cerca de $1.000 .000 \mathrm{~m}^{3}$ $a^{-1} o^{-1}$ de sólidos. Este rio é o principal transportador de matéria orgânica para o sistema (Geobrás, 1966). Como a região norte está sobre maior influência do canal Valo Grande, há um maior aporte relativo de material da vegetação de restinga nesta área. Através deste canal, há a introdução do material trazido pelo Rio Ribeira de Iguape. Este material é transportado pelas correntes de maré ao longo do sistema, sendo depositados principalmente até a Pedra do Tombo, onde há a convergência das correntes de maré (Miyao et al., 1986). Como os rios que deságuam na região sul apresentam um menor aporte que o Rio Ribeira de Iguape, a quantidade de material de restinga introduzido é menor, o que faz com o que os valores de Al encontrados nesta área sejam menores. Há ainda outras rotas fluviais e gamboas que descarregam água doce no sistema, contribuindo com o material orgânico terrígeno sedimentado na região. Porém, as proporções desta contribuição são menores (Barcellos, 2005). A vegetação de mangue da região sul apresenta um maior desenvolvimento estrutural com maiores áreas de vegetação que a região norte (Cunha-Lignon \& Kampel, 2011), o que também contribui nos menores valores de Al. 


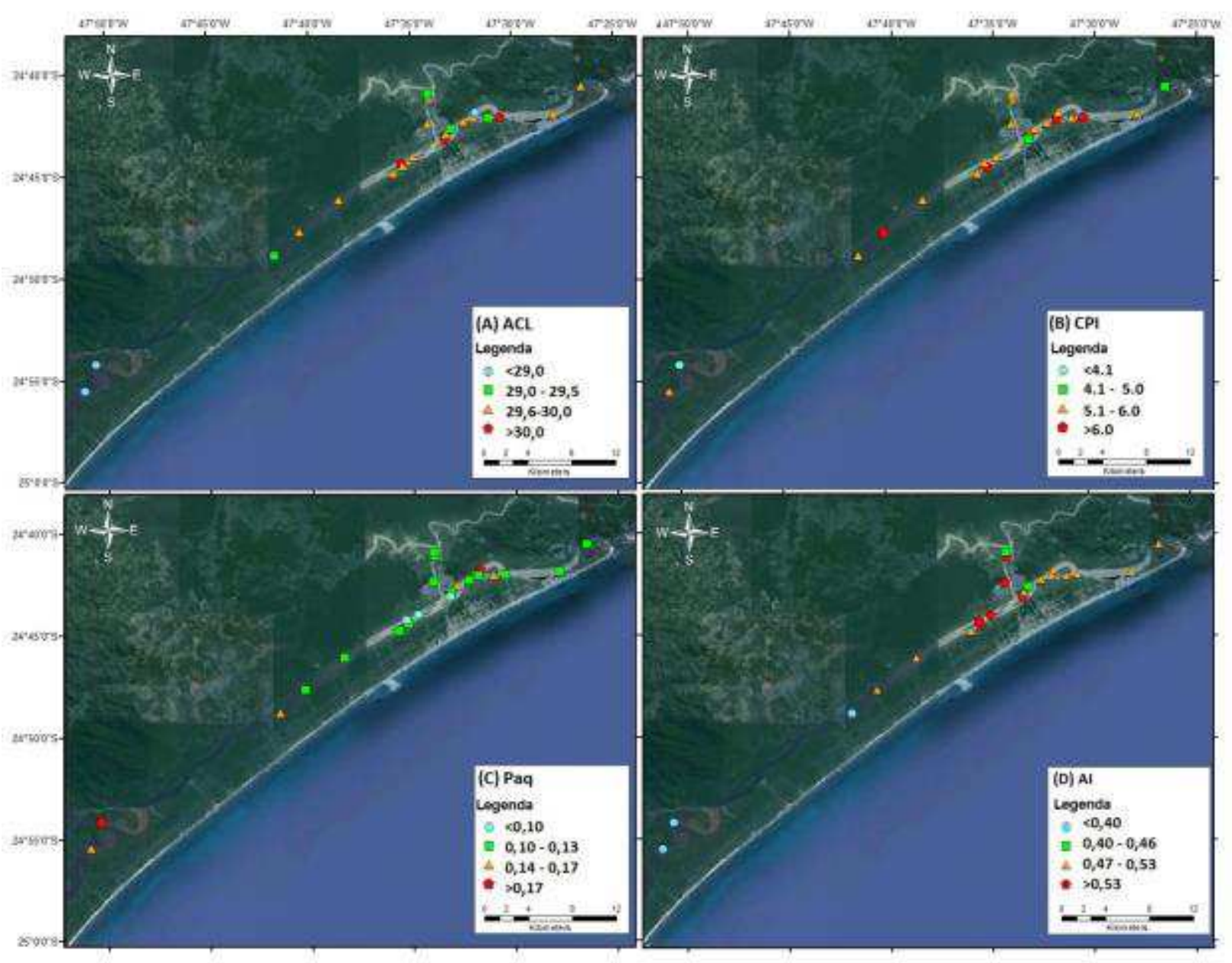

Figura 12: Distribuição espacial dos valores de tamanho médio de cadeia $\left(\mathrm{ACL}_{23-33}, \mathrm{~A}\right)$, índice preferencial de carbono (CPI, B), índice de produção aquática (Paq, C) e índice alcano ( $\mathrm{Al}, \mathrm{D})$ encontrados nas amostras de sedimento superficiais coletadas no Sistema Estuarino-Lagunar de Cananéia-Iguape. 
Embora não sejam predominantes, os compostosn $-C_{15}, n-C_{17}$ e $n-C_{19}$ foram detectados em todas as amostras (Figura 11). Isto indica que há uma contribuição de matéria orgânica autóctone à região de estudo. A fração da contribuição da matéria orgânica terrígena sobre a marinha $(F)$ pode ser estimada através do $\delta^{13} \mathrm{C}$ do TOC encontrado nos sedimentos $\left(\delta^{13} \mathrm{Cmedido}\right)$ através da Equação 10 (Schultze e Calder, 1976):

$$
\mathrm{F}=\frac{\left(\delta^{13} \mathrm{Cmar}-\delta^{13} \text { Cmedido }\right)}{\left(\delta^{13} \mathrm{Cmar}-\delta^{13} \mathrm{Cter}\right)}=100
$$

(Equação 10)

Segundo Barcellos (2005), pode-se assumir que $\circ \delta^{13} \mathrm{C}$ do material orgânico marinho $\left(\delta^{13} \mathrm{Cmar}\right)$ é $-20.0 \%$ o das plantas do tipo $\mathrm{C}_{3}\left(\delta^{13} \mathrm{Cter}\right)$ é $-28.0 \%$.

A contribuição da matéria orgânica terrestre para o sedimento superficial do presente estudo variou de $37,9 \%$ a $95,1 \%$ (Tabela 13). Com exceção do exemplar $\mathbf{S 1 7}$, todas as amostras apresentaram uma contribuição terrígena maior que $70 \%$. Valores mais altos foram encontrados nas amostras coletadas no Rio Ribeira de Iguape, no canal do Valo Grande e na desembocadura deste canal (S12). Na região sul, os valores de $\mathrm{F}$, embora altos, foram menores. Isto sugere, assim como proposto pelos índices de $\mathrm{CaCO}_{3}$ (Figura 7), que esta área tem um maior aporte relativo de material marinho quando comparado com à área central e à norte. A região sul está sobre influência da Bacia de Drenagem do Rio Itapitangui. Como sua capacidade de drenagem é menor quando comparada a do Ribeira de Iguape, localizada ao norte do sistema, a influência terrígena neste sistema será menor, aumentando o sinal marinho.

A presença de $n$-alcanos com 25 átomos de carbono (Figura 11) indica que as macrófitas também contribuem com o material orgânico da região de estudo. As amostras S19, S33, S62, S74 e S76 apresentaram valores de Paq típico de regiões com altas contribuições desta classe de plantas (Tabela 13, 
Figura 12-C). A espécie $S$. alterniflora, uma macrófita emersa, costuma colonizar franjas e bancos de areia, principalmente na região sul do sistema (Cunha-Lignon, 2009a). Na região norte, atualmente há um aumento da presença de macrófitas aquáticas flutuantes devido à influência do Rio Ribeira de Iguape (Cunha-Lignon \& Kampel, 2011), via canal do Valo Grande.

Sedimentos de regiões costeiras com influência de diferentes aportes de vegetação apresentam uma composição de matéria orgânica complexa, o que dificulta a determinação de suas principais fontes (Sikes et al., 2009; Maioli et al., 2012). O estudo da razão isotópica dos marcadores orgânicos moleculares presentes na matéria orgânica pode ser aplicado com a finalidade de confirmar a fonte apontada pelos marcadores geoquímicos, gerando dados mais precisos (Schefuß et al., 2003; Mailoi et al., 2012; Silva et al., 2012).

Schefuß et al. (2003) propuseram que $n$-alcanos com valores de $\delta^{13} \mathrm{C}$ entre -39 e $-31 \%$ estão associados ao material provindo de plantas com padrão fotossintético do tipo $C_{3}$. Valores entre -25 e $-18 \%$ estão associados ao material orgânico provindo de plantas tipo $\mathrm{C}_{4}$ (Schefuß et al., 2003). O presente estudo (Tabela 11) propôs que plantas monocotiledôneas apresentam $n$ alcanos com $\delta^{13} \mathrm{C}$ e $\delta \mathrm{D}$ maiores $(-28,5 \pm 3,9 \%$ e $-152 \pm 3 \%$, respectivamente) quando comparados às dicotiledôneas $(-35,2 \pm 3,5 \%$ e $\quad-171 \pm 17 \%$, respectivamente).

Os valores de $\delta^{13} \mathrm{C}$ e $\delta \mathrm{D}$ dos $n$-alcanos presentes nas amostras de sedimento superficial mostram que há uma predominância de plantas superiores dicotiledôneas ou do tipo $C_{3}$ na região estudada (Tabela 14). Este padrão confirma a importância da vegetação de restinga como exportadora de matéria orgânica para a região do Sistema Estuarino-Lagunar de CananéiaIguape. Entretanto, os valores apresentados do $n-\mathrm{C}_{23}$ ficaram dentro da escala proposta para plantas monocotiledôneas (variando de -30,9 a -28,6). O n- $\mathrm{C}_{31}$ também apresentou, em algumas amostras (S02, S15, S38, S45, S52, S54, $\mathrm{S} 57$ e S62), valores mais altos de $\delta^{13} \mathrm{C}$ do que aqueles estabelecidos para dicotiledôneas do tipo $\mathrm{C}_{3}$ (Tabela 14). Além disso, o $n$-alcano $n-C_{25}$, mesmo com valores de $\delta^{13} \mathrm{C}$ típicos de dicotiledôneas $(-32,6$ a $-31,3)$, esteve mais enriquecido em ${ }^{13} \mathrm{C}$ que $\circ n-\mathrm{C}_{27}$ e $\circ n-\mathrm{C}_{29}(-34,1$ a $-31,0$, e $-34,5$ a $-32,9$, respectivamente). Considerando que $n$-alcanos de cadeias distintas, mas 
provenientes de uma mesma fonte, não apresentam disparidades no enriquecimento de ${ }^{13} \mathrm{C}$, as diferenças aqui observadas podem ser causadas pelo aporte de distintas fontes. As macrófitas, como a monocotiledônea $S$. alterniflora e outras presentes na região de estudo, contêm maiores quantidades relativas de $n-C_{23}, n-C_{25}$ (Ficken et al., 2000) e $n-C_{31}$ quando comparadas às plantas superiores da vegetação de restinga e de mangue (Figura 4 e Figura 5). $O$ aporte significativo destas plantas aumenta o $\delta^{13} \mathrm{C}$ do $n-C_{23}, n-C_{25}$ e $n-C_{31}$ depositados. Assim, além da restinga, há também uma contribuição significativa das macrófitas na matéria orgânica presente nos sedimentos da área de estudo.

Tabela 14: $\delta^{13} \mathrm{C}$ dos $n$-alcanos $n-\mathrm{C}_{25}, n-\mathrm{C}_{29}, n-\mathrm{C}_{31}$ (\%॰) e $\delta \mathrm{D}$ dos $\mathrm{n}$-alcanos $n-\mathrm{C}_{29}, n-\mathrm{C}_{31}(\% \circ)$ detectados nas amostras de superfície coletadas no Sistema Estuarino-Lagunar de Cananéia-Iguape. (n.d. =não detectado)

\begin{tabular}{|c|c|c|c|c|c|c|c|}
\hline & $\delta \mathrm{C}_{13} n-\mathrm{C}_{23}$ & $\delta C_{13} n-C_{25}$ & $\delta C_{13} n-C_{27}$ & $\delta \mathrm{C}_{13} n-\mathrm{C}_{29}$ & $\delta C_{13} n-C_{31}$ & $\delta \mathrm{D} n-\mathrm{C}_{29}$ & $\delta \mathrm{D} n-\mathrm{C}_{31}$ \\
\hline S01 & $-29,3 \pm 0,1$ & $-31,6 \pm 0,5$ & $-32,9 \pm 0,5$ & $-33,5 \pm 0,0$ & $-35,9 \pm 0,1$ & $-165 \pm 1$ & $-167 \pm 0$ \\
\hline S02 & $-30,8 \pm 0,1$ & $-31,7 \pm 0,2$ & $-33,7 \pm 0,1$ & $-33,5 \pm 0,0$ & $-27,6 \pm 0,1$ & $-166 \pm 2$ & $-168 \pm 1$ \\
\hline S08 & $-29,64 \pm 0,1$ & $-32,6 \pm 0,1$ & $-33,4 \pm 1,1$ & $-34,0 \pm 0,5$ & $-33,7 \pm 0,1$ & $-160 \pm 2$ & $-161 \pm 1$ \\
\hline S12 & $-29,3 \pm 0,3$ & $-31,6 \pm 0,1$ & $-31,6 \pm 0,1$ & $-34,2 \pm 0,2$ & $-33,4 \pm 0,2$ & $-158 \pm 0$ & $-164 \pm 1$ \\
\hline S15 & $-29,6 \pm 0,5$ & $-31,3 \pm 0,3$ & $-33,6 \pm 0,1$ & $-33,3 \pm 0,1$ & $-27,7 \pm 0,4$ & $-165 \pm 0$ & $-163 \pm 0$ \\
\hline S17 & n.d. & n.d. & $-31,8 \pm 0,4$ & $-34,0 \pm 0,5$ & $-33,6 \pm 0,5$ & $-165 \pm 2$ & $-166 \pm 1$ \\
\hline S19 & n.d. & n.d. & $-31,0 \pm 0,1$ & $-33,5 \pm 0,2$ & $-33,6 \pm 0,1$ & $-163 \pm 3$ & $-167 \pm 0$ \\
\hline S23 & n.d. & n.d. & $-31,6 \pm 0,1$ & $-34,1 \pm 0,2$ & $-33,4 \pm 0,0$ & $-160 \pm 1$ & $-164 \pm 1$ \\
\hline S28 & n.d. & n.d. & $-32,6 \pm 2,1$ & $-33,9 \pm 0,2$ & $-33,9 \pm 0,2$ & $-160 \pm 1$ & $-162 \pm 0$ \\
\hline S31 & n.d. & n.d. & n.d. & $-33,1 \pm 0,5$ & $-33,2 \pm 0,5$ & n.d. & n.d. \\
\hline S33 & n.d. & n.d. & $-31,6 \pm 0,3$ & $-34,3 \pm 0,5$ & $-33,6 \pm 0,5$ & $-166 \pm 0$ & $-163 \pm 2$ \\
\hline S35 & n.d. & n.d. & n.d. & n.d. & n.d. & n.d. & n.d. \\
\hline S38 & $-30,2 \pm 1,3$ & $-31,6 \pm 0,1$ & $-34,1 \pm 0,1$ & $-34,2 \pm 0,2$ & $-27,2 \pm 0,1$ & $-167 \pm 2$ & $-167 \pm 2$ \\
\hline S43 & $-28,6 \pm 0,3$ & $-32,0 \pm 0,1$ & $-32,9 \pm 0,0$ & $-34,5 \pm 0,3$ & $-36,0 \pm 0,0$ & $-159 \pm 0$ & $-164 \pm 1$ \\
\hline S45 & $-30,9 \pm 0,5$ & $-31,9 \pm 0,2$ & $-33,9 \pm 0,1$ & $-32,9 \pm 0,1$ & $-24,8 \pm 0,3$ & $-164 \pm 2$ & $-170 \pm 2$ \\
\hline S52 & $-30,4 \pm 0,5$ & $-31,8 \pm 0,3$ & $-33,9 \pm 0,0$ & $-34,0 \pm 0,1$ & $-26,8 \pm 0,3$ & $-163 \pm 1$ & $-167 \pm 0$ \\
\hline S54 & $-30,1 \pm 0,2$ & $-31,4 \pm 0,1$ & $-33,6 \pm 0,1$ & $-33,9 \pm 0,0$ & $-28,6 \pm 0,2$ & $-168 \pm 0$ & $-166 \pm 2$ \\
\hline S57 & $-30,7 \pm 0,2$ & $-31,5 \pm 0,3$ & $-34,0 \pm 0,1$ & $-33,9 \pm 0,5$ & $-27,8 \pm 0,5$ & $-165 \pm 1$ & $-169 \pm 1$ \\
\hline S60 & n.d. & n.d. & $-33,1 \pm 0,4$ & $-34,0 \pm 0,0$ & $-34,7 \pm 0,3$ & $-171 \pm 1$ & $-170 \pm 0$ \\
\hline S62 & $-29,8 \pm 0,2$ & $-31,8 \pm 0,1$ & $-33,9 \pm 0,0$ & $-33,1 \pm 0,0$ & $-27,7 \pm 0,4$ & $-173 \pm 1$ & $-171 \pm 4$ \\
\hline S74 & n.d. & n.d. & n.d. & n.d. & n.d. & n.d. & n.d. \\
\hline S76 & $-29,9 \pm 0,3$ & $-31,8 \pm 0,5$ & $-33,5 \pm 0,1$ & $-33,7 \pm 0,0$ & $-34,4 \pm 0,5$ & $-163 \pm 0$ & $-163 \pm 2$ \\
\hline
\end{tabular}




\subsection{Matéria orgânica nos testemunhos}

Os resultados dos parâmetros avaliados nas amostras dos testemunhos estão apresentados no ANEXO 1 ao ANEXO 4. Na Tabela 15 e na Tabela 16, estão apresentados os valores mínimos, máximos e as médias de cada parâmetro avaliado nos quatro testemunhos analisados. Os perfis estão apresentados da Figura 14 à Figura 13.

Pode-se observar que diferentes períodos de deposição foram detectados nos quatro testemunhos. A seguir, cada testemunho será discutido separadamente. Os teores de silte e de argila serão exibidos somados, como teor de lama. Dentre os marcadores avaliados, serão apresentados somente aqueles que tiveram melhor resposta às mudanças da matéria orgânica e as escalas usadas não serão equivalentes entre os testemunhos. 
Tabela 15: Valores mínimos (mín.), máximos (máx.) e média dos teores de argila (\%), silte (\%), areia (\%), carbono orgânico total (TOC, \%), nitrogênio total (TN, \%) e $n$-alcanos totais (AlcTot, $\mu \mathrm{g} \mathrm{g-1} \mathrm{de} \mathrm{sedimento} \mathrm{seco)} \mathrm{encontrados} \mathrm{em} \mathrm{cada} \mathrm{testemunho} \mathrm{estudado} \mathrm{(Test.).}$ (n=número amostras).

\begin{tabular}{|c|c|c|c|c|c|}
\hline & Test. & $n$ & mín. & máx. & méd. \\
\hline & CAN02 & 72 & 2,23 & 9,55 & - \\
\hline Argila & CAN05 & 100 & 0,00 & 10,6 & - \\
\hline \multirow[t]{3}{*}{$(\%)$} & CAN07 & 63 & 0,75 & 4,87 & - \\
\hline & CAN10 & 40 & 9,74 & 68,0 & - \\
\hline & CAN02 & 72 & 17,6 & 64,2 & - \\
\hline Silte & CAN05 & 100 & 0,00 & 75,5 & - \\
\hline \multirow[t]{3}{*}{ (\%) } & CAN07 & 63 & 4,84 & 34,7 & - \\
\hline & CAN10 & 40 & 23,30 & 66,0 & - \\
\hline & CAN02 & 72 & 27,1 & 80,0 & - \\
\hline Areia & CAN05 & 100 & 15,7 & 100 & - \\
\hline \multirow[t]{3}{*}{$(\%)$} & CAN07 & 63 & 60,5 & 94,3 & - \\
\hline & CAN10 & 40 & 2,67 & 25,0 & - \\
\hline & CAN02 & 72 & 2,37 & 38,8 & $5,59 \pm 4,82$ \\
\hline Carbonato & CAN05 & 69 & 1,40 & 8,84 & $5,44 \pm 3,21$ \\
\hline \multirow[t]{3}{*}{$(\%)$} & CAN07 & 63 & 1,78 & 5,28 & $3,13 \pm 0,74$ \\
\hline & CAN10 & 75 & 0,45 & 17,34 & $11,4 \pm 2,6$ \\
\hline & CAN02 & 72 & 0,42 & 2,58 & $1,22 \pm 0,54$ \\
\hline TOC & CAN05 & 69 & 0,00 & 4,14 & $1,92 \pm 1,29$ \\
\hline \multirow[t]{3}{*}{ (\%) } & CAN07 & 63 & 0,23 & 2,49 & $0,65 \pm 0,39$ \\
\hline & CAN10 & 75 & 1,16 & 3,78 & $2,78 \pm 0,62$ \\
\hline & CAN02 & 72 & 0,02 & 0,23 & $0,10 \pm 0,05$ \\
\hline TN & CAN05 & 69 & 0,11 & 0,28 & $0,20 \pm 0,04$ \\
\hline \multirow[t]{3}{*}{ (\%) } & CAN07 & 63 & 0,04 & 0,21 & $0,11 \pm 0,06$ \\
\hline & CAN10 & 75 & 0,10 & 0,36 & $0,23 \pm 0,07$ \\
\hline & CAN02 & 72 & 3,60 & 14,3 & $7,72 \pm 2,84$ \\
\hline \multirow{3}{*}{$\begin{array}{l}\text { AlcTot } \\
\left(\mu g^{-1}\right)\end{array}$} & CAN05 & 69 & 1,93 & 17,7 & $8,66 \pm 4,14$ \\
\hline & CAN07 & 63 & 0,91 & 12,7 & $4,85 \pm 2,22$ \\
\hline & CAN10 & 75 & 6,24 & 31,9 & $17,9 \pm 8,6$ \\
\hline
\end{tabular}


Tabela 16: Valores mínimos (mín.), máximos (máx.) e média (méd.) das razões isotópicas de carbono $\left(\delta^{13} \mathrm{C}, \%\right.$ \% e nitrogênio $\left(\delta^{15} \mathrm{~N}\right.$,\%॰) da matéria orgânica total, razão entre o carbono orgânico total e o nitrogênio total (C/N); índice preferencial de carbono (CPI), tamanho médio de cadeia $\left(\mathrm{ACL}_{23-33}\right)$, índice de produção aquática (Paq), índice alcano (Al) e razões isotópicas de carbono dos $n$-alcanos $n$ - $\mathrm{C}_{25}\left(\delta^{13} \mathrm{C} n\right.$ - $\left.\mathrm{C}_{25}, \% \circ\right), n-\mathrm{C}_{29}\left(\delta^{13} \mathrm{C} n\right.$ $\mathrm{C}_{29}, \%$ \% e $n-\mathrm{C}_{31}\left(\delta^{13} \mathrm{C} n-\mathrm{C}_{31}, \%\right.$ ) encontrados em cada testemunho estudado (Test.). ( $\mathrm{n}=$ número amostras).

\begin{tabular}{|c|c|c|c|c|c|c|c|c|c|c|c|c|c|c|c|c|c|}
\hline & Test. & $\mathbf{n}$ & mín. & máx. & méd. & & Test. & $\mathbf{n}$ & mín. & máx. & méd. & & Test. & $\mathbf{n}$ & mín. & máx. & méd. \\
\hline \multirow{4}{*}{$\begin{array}{c}\delta^{13} \mathrm{C} \\
(\% \circ)\end{array}$} & CAN02 & 72 & $-27,9$ & $-26,2$ & $-27,2 \pm 0,4$ & \multirow{4}{*}{$A C L_{23-33}$} & CAN02 & 72 & 28,5 & 29,6 & $29,1 \pm 0,2$ & \multirow{4}{*}{$\begin{array}{c}\delta^{13} \mathrm{C} n- \\
\mathrm{C}_{29} \\
(\% \circ)\end{array}$} & CANO2 & 27 & $-34,6$ & $-33,6$ & $-33,6 \pm 0,4$ \\
\hline & CAN05 & 69 & $-28,0$ & $-23,5$ & $-26,6 \pm 1,2$ & & CAN05 & 69 & 27,6 & 29,0 & $28,5 \pm 0,3$ & & CAN05 & 55 & $-34,6$ & $-31,7$ & $-33,4 \pm 0,8$ \\
\hline & CAN07 & 63 & $-27,4$ & $-24,6$ & $-25,8 \pm 0,7$ & & CAN07 & 63 & 27,2 & 29,7 & $28,6 \pm 0,4$ & & CAN07 & 13 & $-34,4$ & $-32,2$ & $-33,1 \pm 0,7$ \\
\hline & CAN10 & 75 & $-26,1$ & $-24,5$ & $-25,5 \pm 0,4$ & & CAN10 & 75 & 27,7 & 29,3 & $28,5 \pm 0,3$ & & CAN10 & 13 & $-35,7$ & $-31,9$ & $-33,1 \pm 0,9$ \\
\hline \multirow{4}{*}{$\begin{array}{c}\delta^{15} \mathbf{N} \\
(\% \circ)\end{array}$} & CAN02 & 72 & $-0,25$ & 3,41 & $2,21 \pm 0,82$ & \multirow{4}{*}{ Paq } & CAN02 & 72 & 0,14 & 0,40 & $0,21 \pm 0,05$ & \multirow{4}{*}{$\begin{array}{c}\delta^{13} \mathrm{C} n- \\
\mathrm{C}_{31} \\
(\% \circ)\end{array}$} & CANO2 & 28 & $-36,5$ & $-33,9$ & $-33,7 \pm 1,6$ \\
\hline & CAN05 & 69 & $-2,64$ & 2,39 & $-0,93 \pm 1,34$ & & CAN05 & 69 & 0,15 & 0,36 & $0,23 \pm 0,04$ & & CAN05 & 46 & $-35,5$ & $-28,0$ & $-32,4 \pm 2,0$ \\
\hline & CAN07 & 63 & $-3,69$ & 4,71 & $1,24 \pm 2,06$ & & CAN07 & 63 & 0,12 & 0,21 & $0,22 \pm 0,06$ & & CAN07 & 11 & $-33,2$ & $-31,1$ & $-31,8 \pm 0,7$ \\
\hline & CAN10 & 75 & 4,77 & 7,52 & $6,73 \pm 0,38$ & & CAN10 & 75 & 0,18 & 0,37 & $0,23 \pm 0,03$ & & CAN10 & 10 & $-32,7$ & $-29,9$ & $-30,4 \pm 1,3$ \\
\hline \multirow{4}{*}{$\mathrm{C} / \mathrm{N}$} & CANO2 & 72 & 4,70 & 26,8 & $13,3 \pm 5,0$ & \multirow{4}{*}{ Al } & CAN02 & 72 & 0,44 & 0,54 & $0,53 \pm 0,04$ & & & & & & \\
\hline & CAN05 & 69 & 0,74 & 28,6 & $9,45 \pm 7,23$ & & CAN05 & 69 & 0,01 & 0,45 & $0,18 \pm 0,09$ & & & & & & \\
\hline & CAN07 & 63 & 1,35 & 24,4 & $7,47 \pm 5,87$ & & CAN07 & 63 & 0,13 & 0,63 & $0,34 \pm 0,07$ & & & & & & \\
\hline & CAN10 & 75 & 3,56 & 6,98 & $12,9 \pm 3,6$ & & CAN10 & 75 & 0,23 & 0,41 & $0,31 \pm 0,03$ & & & & & & \\
\hline \multirow{4}{*}{ CPI } & CANO2 & 72 & 2,20 & 7,24 & $5,23 \pm 0,84$ & \multirow{4}{*}{$\begin{array}{c}\delta^{13} \mathrm{C} \text { n- } \\
\mathrm{C}_{25} \\
(\% \circ)\end{array}$} & CAN02 & 26 & $-32,0$ & $-30,8$ & $-30,6 \pm 0,8$ & & & & & & \\
\hline & CAN05 & 69 & 2,61 & 7,94 & $4,88 \pm 1,29$ & & CAN05 & 53 & $-32,4$ & $-29,4$ & $-31,0 \pm 0,7$ & & & & & & \\
\hline & CAN07 & 63 & 2,70 & 7,13 & $4,61 \pm 1,05$ & & CAN07 & 24 & $-32,1$ & $-28,1$ & $-30,1 \pm 1,3$ & & & & & & \\
\hline & CAN10 & 75 & 2,17 & 6,85 & $4,26 \pm 1,03$ & & CAN10 & 20 & $-31,7$ & $-28,2$ & $-30,1 \pm 1,2$ & & & & & & \\
\hline
\end{tabular}




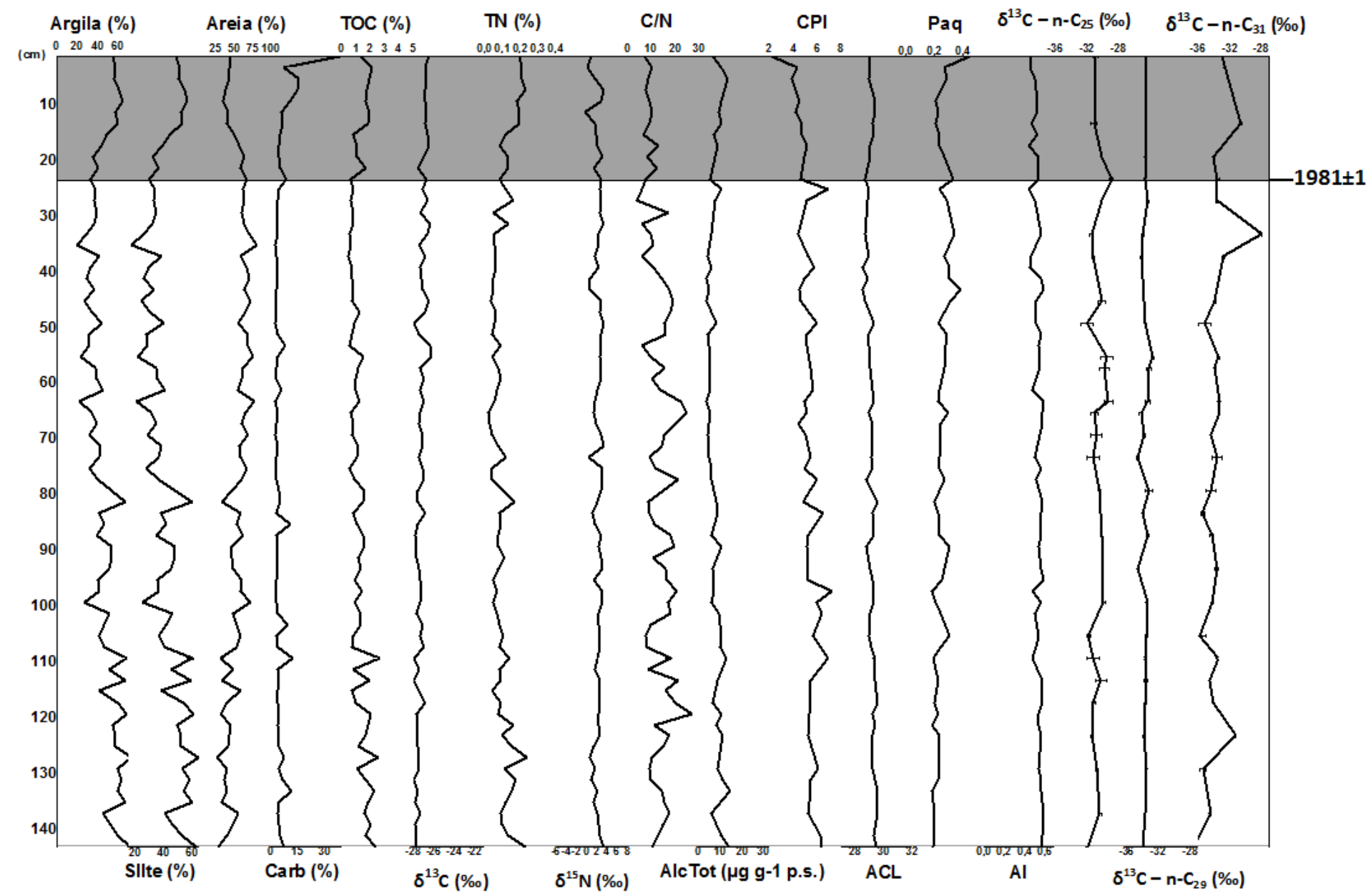

Figura 13: Perfil dos teores de argila (arg, \%), silte (\%) e areia (\%); conteúdo de carbonato de cálcio (Carb., \%); concentração de carbono orgânico total (TOC,\%) e nitrogênio total (TN,\%); $\delta^{13} \mathrm{C}(\% \circ)$ e $\delta^{15} \mathrm{~N}(\% \circ)$ da matéria orgânica total; razão entre TOC e TN (C/N); concentração de $n$-alcanos totais (AlcTot, $\mu \mathrm{g} \mathrm{g}^{-1}$ p.s.), índice preferencial do carbono (CPI), tamanho médio de cadeia $\left(\mathrm{ACL}_{23-33}\right.$ ), índice de produção aquática (Paq), índice alcano (Al) e $\delta^{13} \mathrm{C}$ dos $n$-alcanos $n-\mathrm{C}_{25}, n-\mathrm{C}_{29}, n-\mathrm{C}_{31}(\% \circ)$ encontrados no testemunho CAN02. As diferentes cores representam os diferentes períodos de deposição de carbono orgânico. 


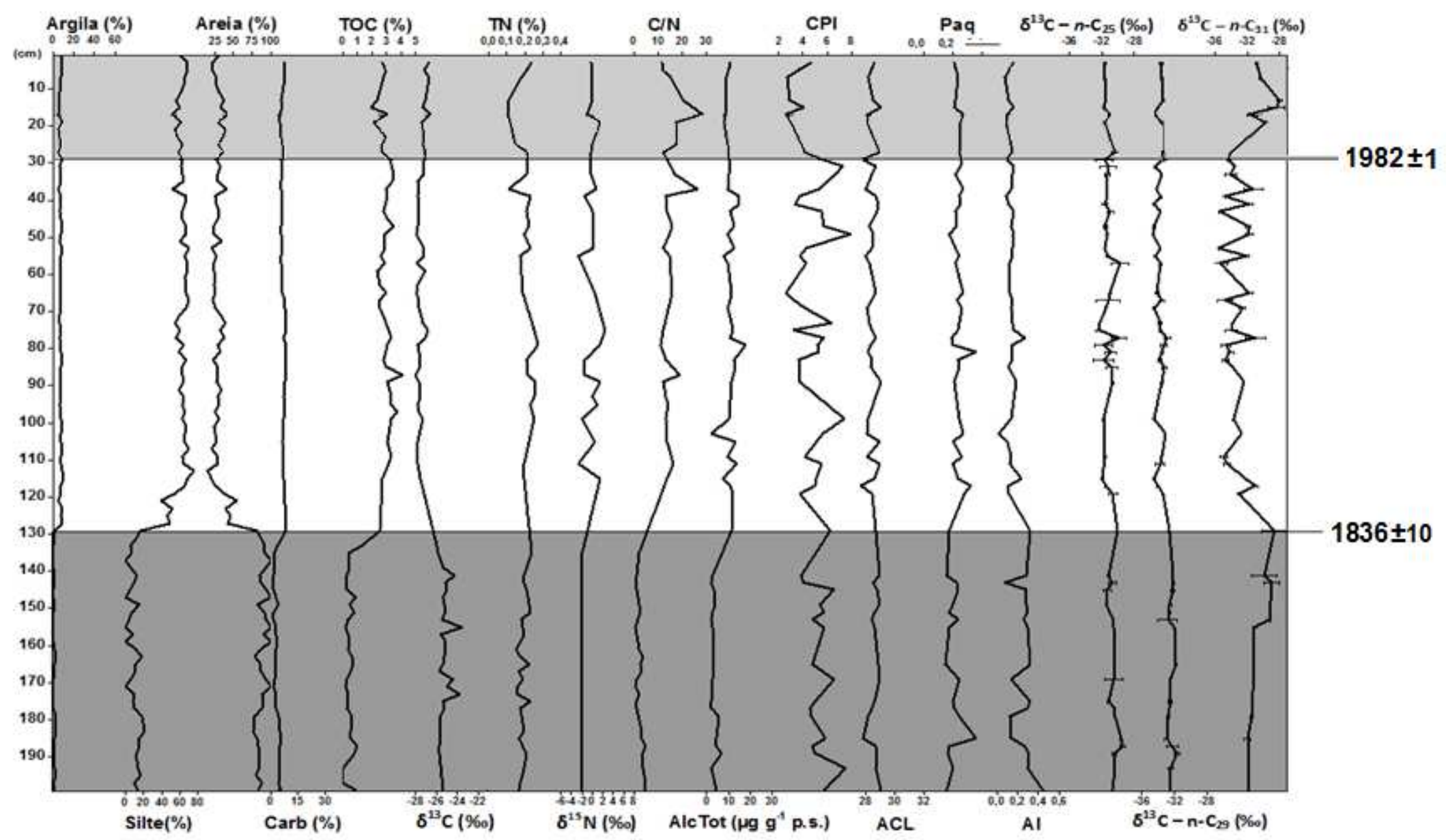

Figura 14: Perfil dos teores de argila (arg, \%), silte (\%) e areia (\%); conteúdo de carbonato de cálcio (Carb., \%); concentração de carbono orgânico total (TOC,\%) e nitrogênio total (TN,\%); $\delta^{13} \mathrm{C}(\%)$ e $\delta^{15} \mathrm{~N}(\%)$ da matéria orgânica total; razão entre TOC e TN (C/N); concentração de $n$-alcanos totais (AlcTot, $\mu \mathrm{g} \mathrm{g}^{-1}$ p.s.), índice preferencial do carbono (CPI), tamanho médio de cadeia $\left(\mathrm{ACL}_{23-33}\right.$ ), índice de produção aquática (Paq), índice alcano ( $\mathrm{Al}$ ) e $\delta^{13} \mathrm{C}$ dos $n$-alcanos $n-\mathrm{C}_{25}, n-\mathrm{C}_{29,}, \mathrm{C}_{31}(\%)$ encontrados no testemunho $\mathrm{CAN} 05$. As diferentes cores representam os diferentes períodos de deposição de carbono orgânico. 


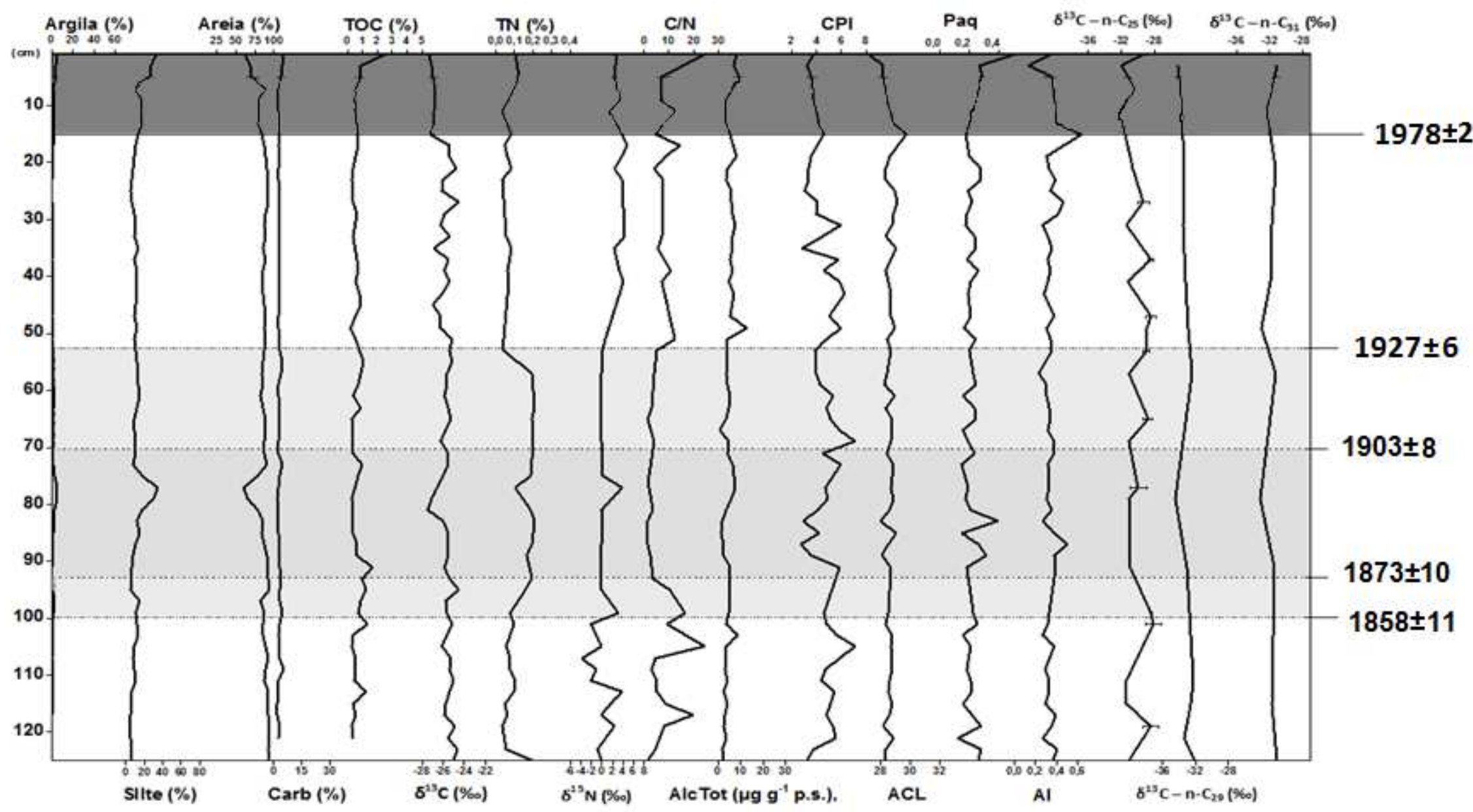

Figura 15: Perfil dos teores de argila (arg, \%), silte (\%) e areia (\%); conteúdo de carbonato de cálcio (Carb., \%); concentração de carbono orgânico total (TOC,\%) e nitrogênio total (TN,\%); $\delta^{13} \mathrm{C}(\% \circ)$ e $\delta^{15} \mathrm{~N}(\%)$ da matéria orgânica total; razão entre TOC e TN (C/N); concentração de $n$-alcanos totais (AlcTot, $\mu \mathrm{g} \mathrm{g}^{-1}$ p.s.); índice preferencial do carbono (CPI); tamanho médio de cadeia $\left(\mathrm{ACL}_{23-33}\right.$ ); índice de produção aquática (Paq); índice alcano (Al) e $\delta^{13} \mathrm{C}$ dos $n$-alcanos $n-C_{25}, n-C_{29}, n-C_{31}(\%)$ encontrados no testemunho CAN07. As diferentes cores representam os diferentes períodos de deposição de carbono orgânico. 


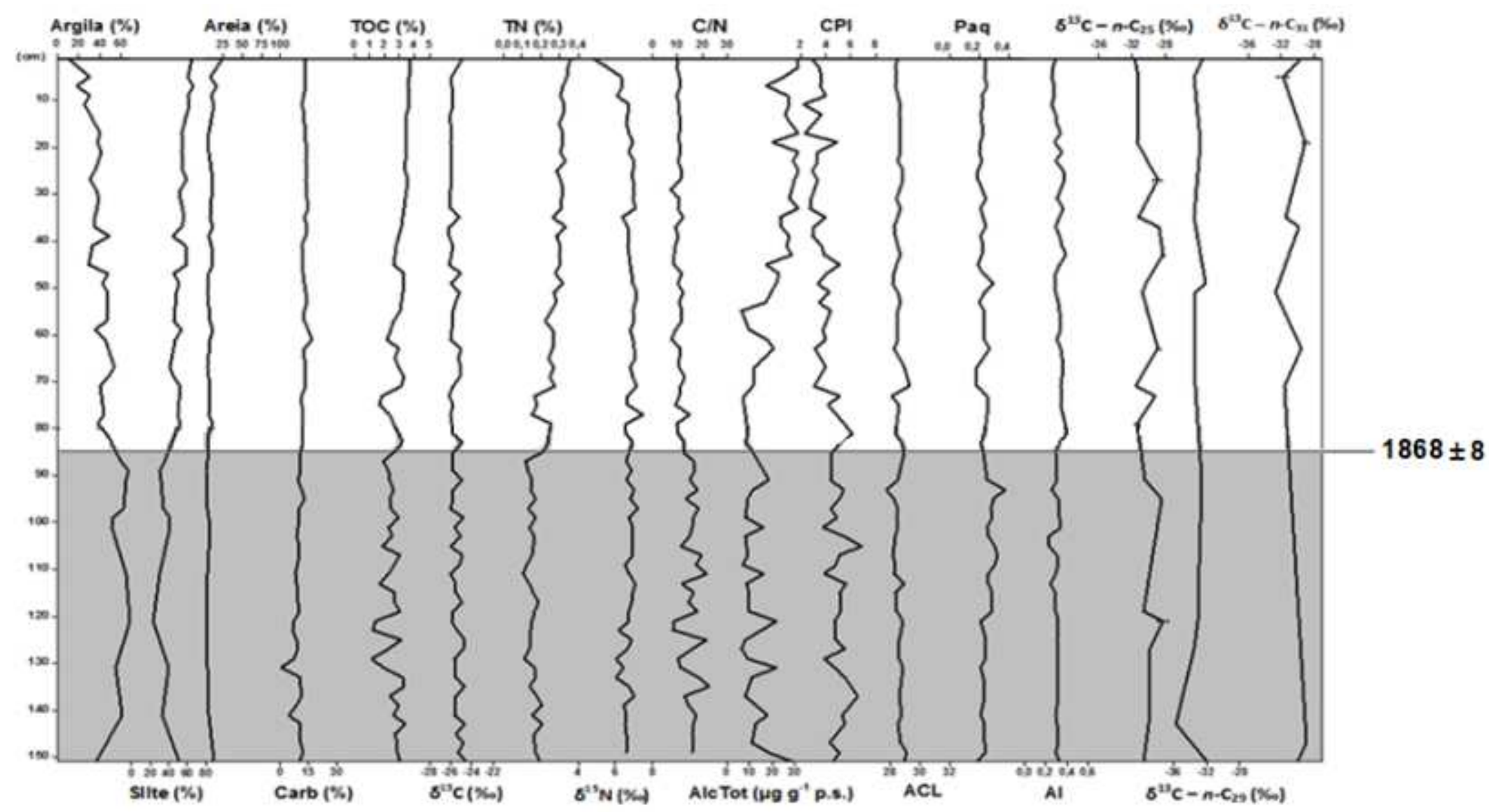

Figura 16: Perfil dos teores de argila (arg, \%), silte (\%) e areia (\%); conteúdo de carbonato de cálcio (Carb., \%); concentração de carbono orgânico total (TOC,\%) e nitrogênio total (TN,\%); $\delta^{13} \mathrm{C}(\%)$ e $\delta^{15} \mathrm{~N}(\%)$ da matéria orgânica total; razão entre TOC e TN (C/N); concentração de $n$-alcanos totais (AlcTot, $\mu \mathrm{g} \mathrm{g}^{-1}$ p.s.), índice preferencial do carbono (CPI), tamanho médio de cadeia $\left(\mathrm{ACL}_{23-33}\right.$ ), índice de produção aquática (Paq), índice alcano (Al) e $\delta^{13} \mathrm{C}$ dos $n$-alcanos $n-\mathrm{C}_{25}, n-\mathrm{C}_{29}, n-\mathrm{C}_{31}(\%)$ encontrados no testemunho $\mathrm{CAN10}$. As diferentes cores representam os diferentes períodos de deposição de carbono orgânico. 


\subsubsection{CANO2}

O CAN02 $(142 \mathrm{~cm})$ foi amostrado a aproximadamente $2 \mathrm{~km}$ ao norte da desembocadura do Valo Grande (Figura 2) e exibiu uma taxa de sedimentação

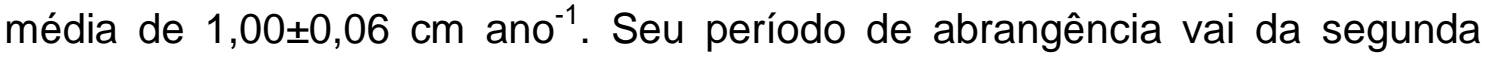
metade do século XIX $(1866 \pm 8)$ até 2008 , sendo posterior à abertura do canal artificial do Valo Grande (entre 1827 e 1852; Geobrás, 1966). Através dos resultados dos marcadores encontrados para o CAN02, observou-se que este testemunho apresentou dois períodos de deposição distintos (Figura $17 \mathrm{e}$ Figura 18). Durante o primeiro período (108-24 cm), a concentração da matéria orgânica (TOC, TN e AlcTot) era menor, apresentando uma queda ao longo do tempo. Os teores de lama eram maiores, aumentando ao longo do tempo. Os valores de $\mathrm{CPI}, \mathrm{Al}$, e de $\mathrm{ACL}_{23-33}$ eram maiores e os de $\mathrm{Paq}$ e $\delta^{13} \mathrm{C}$, menores.

O segundo período vai de $24 \mathrm{~cm}$ a base, e tem como características uma queda no teor de lama, e um aumento no de TOC, TN e AlcTot. Os teores de $\mathrm{CaCO}_{3}$ aumentaram, assim como os de $\mathrm{ACL}_{23-33}$. Este último pode estar associado à queda na contribuição de macrófitas emersas à matéria orgânica depositada, que também foi observada através dos menores valores de Paq neste período (Ficken et al., 2000). Segundo o modelo de idade usado este

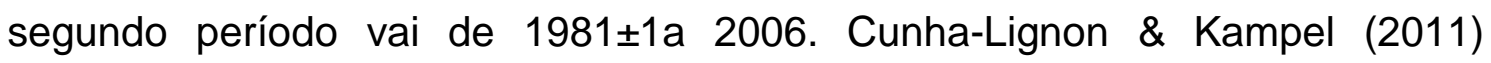
verificaram diminuição no estabelecimento de $S$. alterniflora na região norte do Sistema Estuarino-Lagunar de Cananéia-Iguape entre 1997 e 2011, sendo esta vegetação substituída por macrófitas aquáticas flutuantes. Este fato esteve associado à presença do canal do Valo Grande, que introduziu novas espécies de macrófitas aquáticas e diminuiu a presença de $S$. alterniflora. 


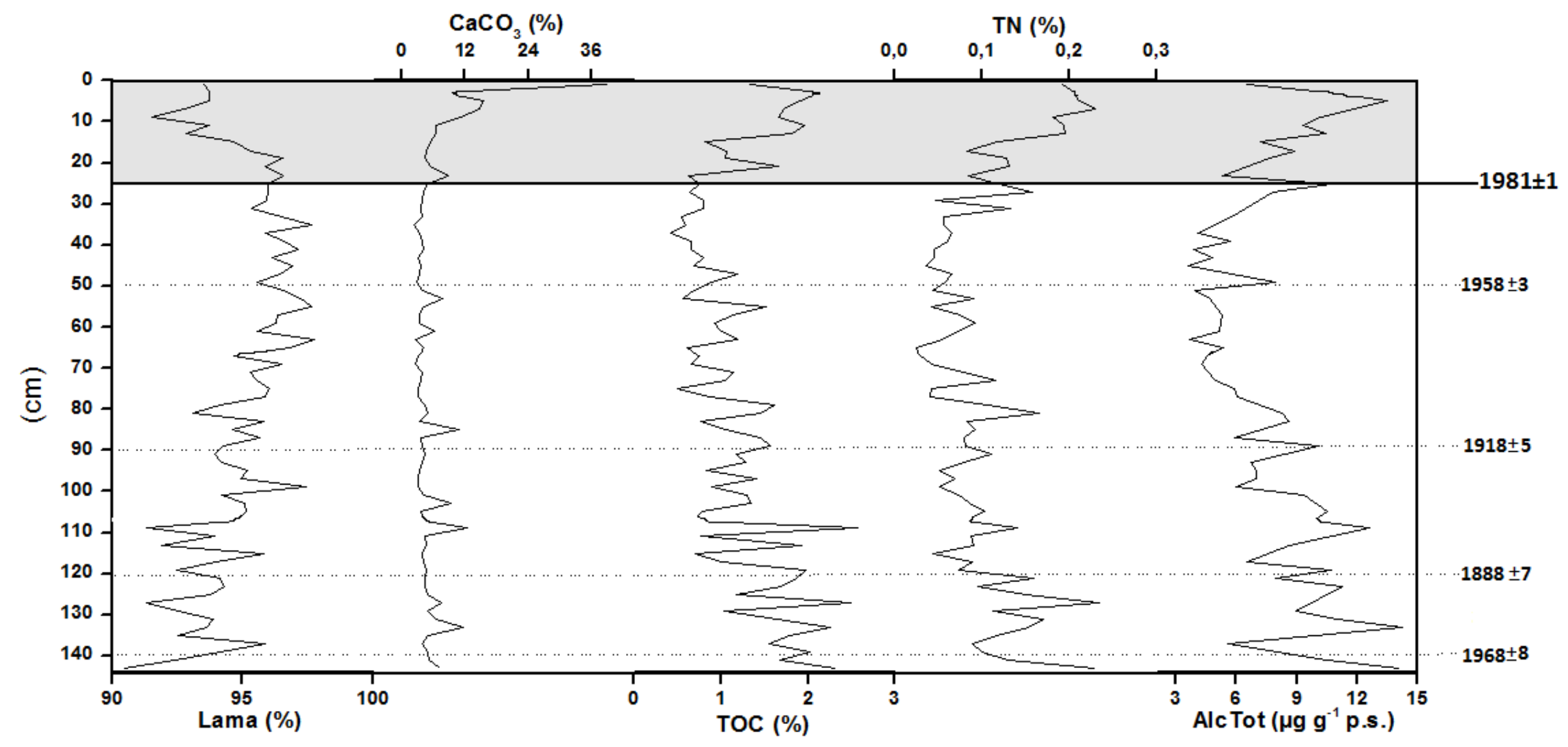

Figura 17: Perfil dos teores de lama (\%), carbonato de cálcio $\left(\mathrm{CaCO}_{3}, \%\right)$, carbono orgânico total (TOC,\%), nitrogênio total (TN, \%) e $n$-alcanos totais (AlcTot, $\mu \mathrm{g} \mathrm{g} \mathrm{g}^{-1}$ p.s.) do testemunho CAN02. As diferentes cores representam os diferentes períodos de deposição de carbono orgânico. 


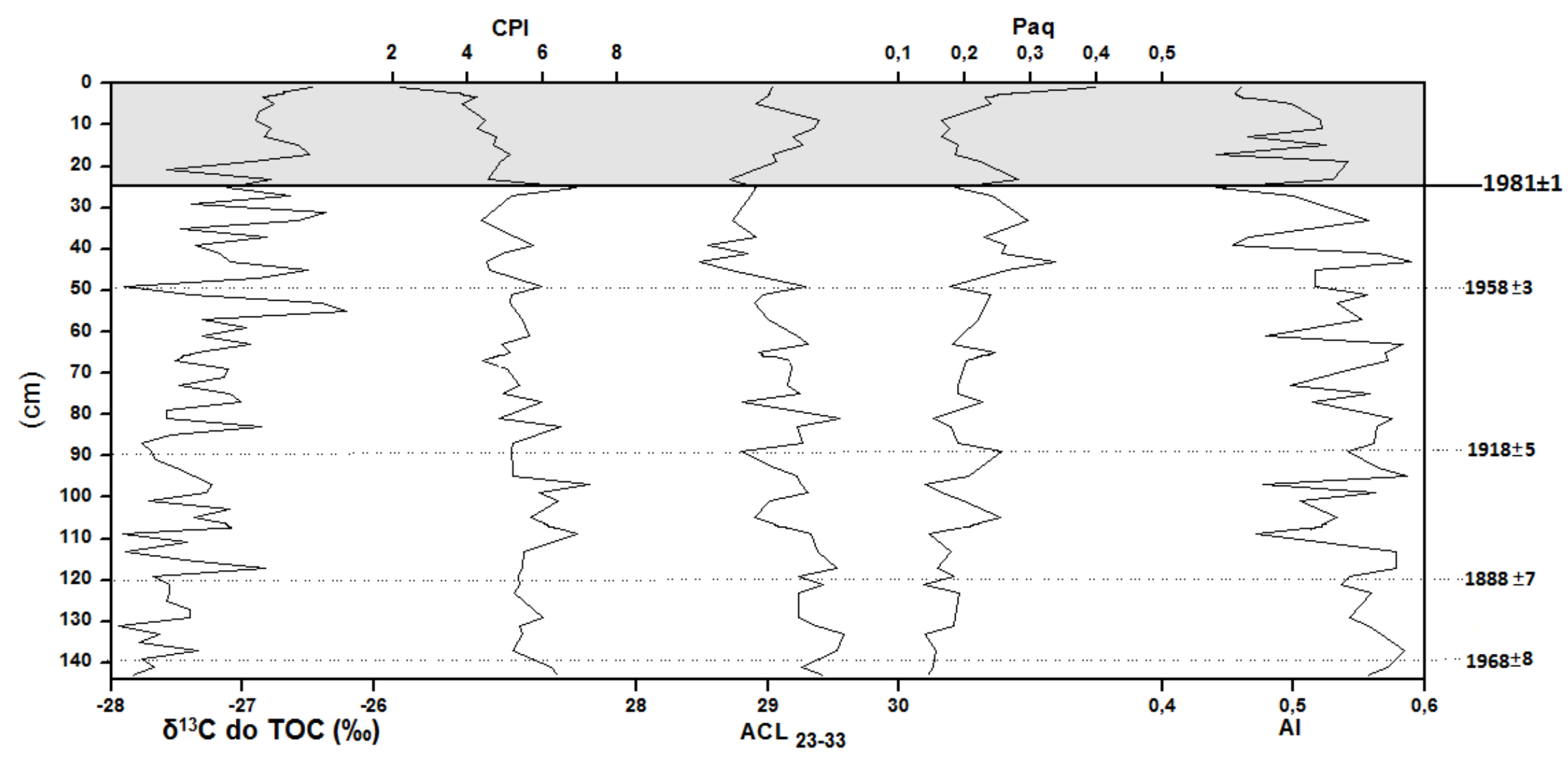

Figura 18: Perfil dos valores de $\delta^{13} \mathrm{C}$ do carbono orgânico total $\left(\delta^{13} \mathrm{C}\right.$ do TOC, \%o), do índice preferencial de carbono (CPI), tamanho médio de cadeia $\left(\mathrm{ACL}_{23-33}\right)$, índice de produção aquática (Paq) e do índice alcano (Al) encontrados no testemunho CAN02. As diferentes cores representam os diferentes períodos de deposição de carbono orgânico. 
Observa-se que no final deste segundo período, houve um aumento acentuado na quantidade de $\mathrm{CaCO}_{3}$ depositado e nos valores de Paq. Houve também um leve aumento nos resultados de $\delta^{13} \mathrm{C}$ do TOC e uma queda nos valores de $\mathrm{CPI}$. Este pode estar relacionado com um novo aumento recente da contribuição relativa de macrófitas flutuantes (Ficken et al., 2000)e do fitoplâncton na matéria orgânica depositada na região (Zhou et al., 2006). Barrera-Alba et al. (2007) observaram que, durante o período de 2001 a 2006, houve um aumento nas concentrações de fósforo inorgânico dissolvido devido aos efluentes lançados por adubações de plantas nos afluentes do Rio Ribeira de Iguape. O aumento na concentração deste nutriente pode ser o responsável pela maior produtividade primária observada no presente estudo nas amostras mais superficiais do CAN02. Os autores também encontraram que o aumento na concentração de fósforo inorgânico ocasionou o afloramento das macrófitas flutuantes Echornia crassipes. Este afloramento teria ocasionado o aumento observado nos valores do Paq e queda nos de CPI durante o período em questão (Ficken et al., 2000).

\subsubsection{CAN05}

O testemunho CAN05 $(198 \mathrm{~cm})$ foi amostrado no Mar Pequeno a aproximadamente $8 \mathrm{~km}$ ao sul da desembocadura do Valo Grande (Figura 2). Sua taxa de sedimentação pode ser dividida em duas. Da base do testemunho até $70 \mathrm{~cm}$, ela foi de $0,55 \pm 0,04 \mathrm{~cm}^{a n o^{-1}}$. A partir de $70 \mathrm{~cm}$ até 0 topo, houve um aumento para $1,52 \pm 0,04 \mathrm{~cm}^{2 n o^{-1}}$. Segundo o modelo de idade, a mudança na taxa de sedimentação ocorreu em 1959 \pm 5 . Baseando-se na datação feita através do ${ }^{210} \mathrm{~Pb}$, o período de abrangência do CAN05 vai da primeira metade do século XVIII (aproximadamente 1723 \pm 15 ) até 2008. As diferentes predominâncias das fontes de matéria orgânica causadas pela abertura do canal Valo Grande (1827 a 1852, Geobrás, 1966), bem como pelo seu fechamento e reabertura (1978 e 1983, respectivamente; Mahiques et al., 2009), podem ser avaliadas através deste testemunho. Conforme a variação observada nos valores dos marcadores, principalmente no teor de lama, TOC, AlcTot, $\delta^{13} \mathrm{C}$ do TOC, $\mathrm{Al}$ e $\delta^{13} \mathrm{C}$ do $n-\mathrm{C}_{31}$, o CAN05 apresentou três fases com 
características deposicionais bem marcadas e distintas (Figura 19 e na Figura 20).

A primeira fase se inicia na base e vai até $138 \mathrm{~cm}$. Durante este período, o sedimento apresentou menores teores de lama. Uma vez que partículas sedimentares mais finas têm maior capacidade de adsorção da matéria orgânica (Ramaswamy et al., 2008), a quantidade de TOC e de AlcTot depositada também foi menor. Os valores de $\delta^{13} \mathrm{C}$ do $n-\mathrm{C}_{31}$ foram típicos de monocotiledôneas (Tabela 9). Os valores de Al foram maiores, indicando que houve um maior aporte relativo de $n-C_{31}$ durante este período. Este composto é preponderante tanto na vegetação de restinga quanto em $S$. alterniflora, que tem maiores valores de $\delta^{13} \mathrm{C}$ em seu $n$-alcanos. Assim, houve uma maior contribuição relativa de macrófitas emersas durante este período. Os valores de $\delta^{13} \mathrm{C}$ do TOC, embora típicos de predominância terrígena, também foram relativamente maiores, indicando possivelmente uma maior contribuição de material fitoplanctônico (Zhou et al., 2006).

O segundo período ocorreu entre 138 e $38 \mathrm{~cm}$. Neste, os teores de lama, bem como a quantidade de matéria orgânica depositada (AlcTot e TOC), foram maiores. Os valores de $\delta^{13} \mathrm{C}$ do TOC e do $n-\mathrm{C}_{31}$ foram menores, sugerindo que a quantidade relativa de matéria terrígena provinda de plantas do tipo $\mathrm{C}_{3}$ e de dicotiledôneas, respectivamente, aumentou (Zhou et al., 2006). Os valores de Al também foram menores, o que pode indicar uma maior contribuição relativa de plantas lenhosas do mangue à matéria orgânica depositada. 


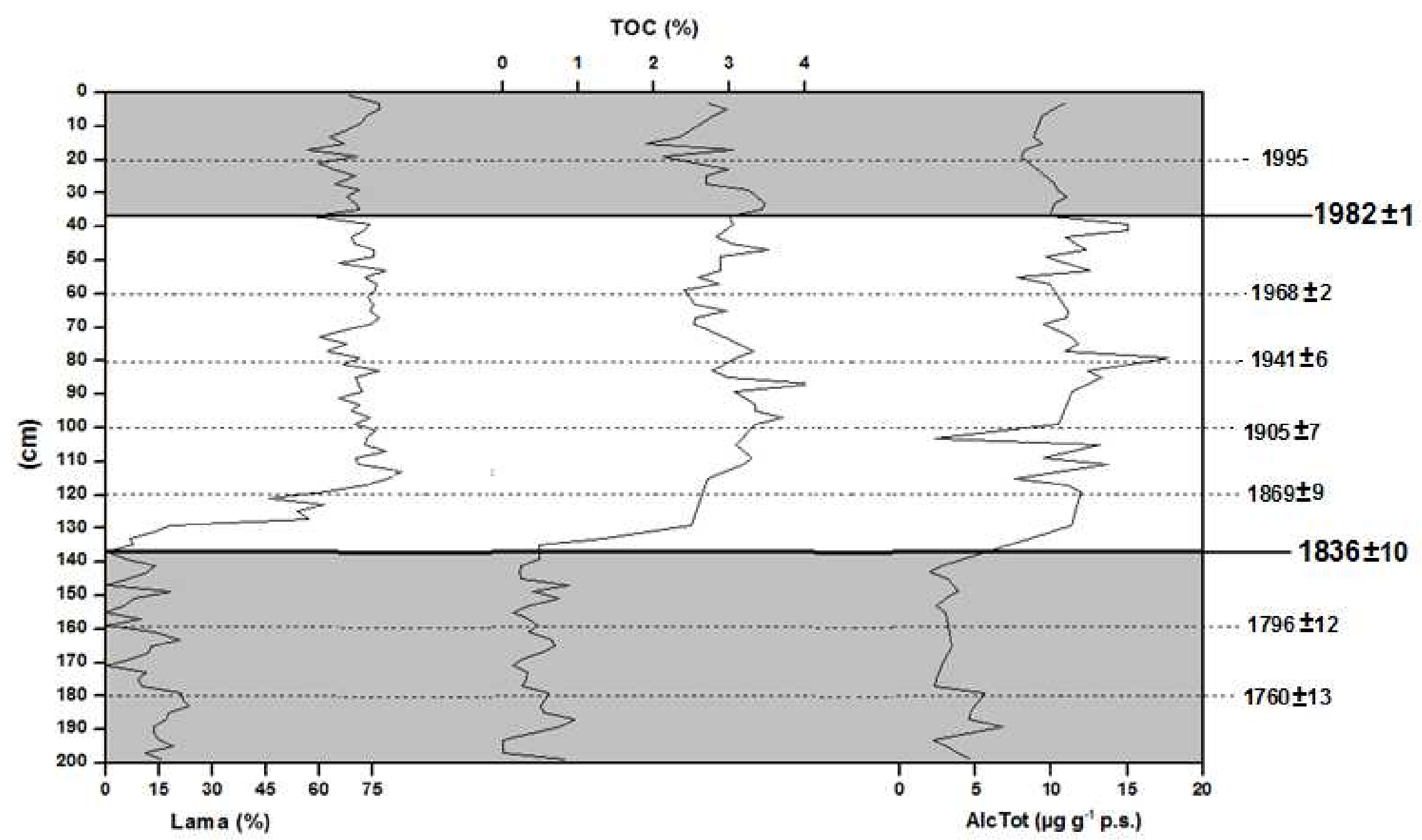

Figura 19: Perfil dos teores de lama (\%), carbono orgânico total (TOC,\%) e $n$-alcanos totais (AlcTot, $\mu \mathrm{g} \mathrm{g}^{-1}$ p.s.) do testemunho CAN05. As diferentes cores representam os diferentes períodos de deposição de carbono orgânico. 


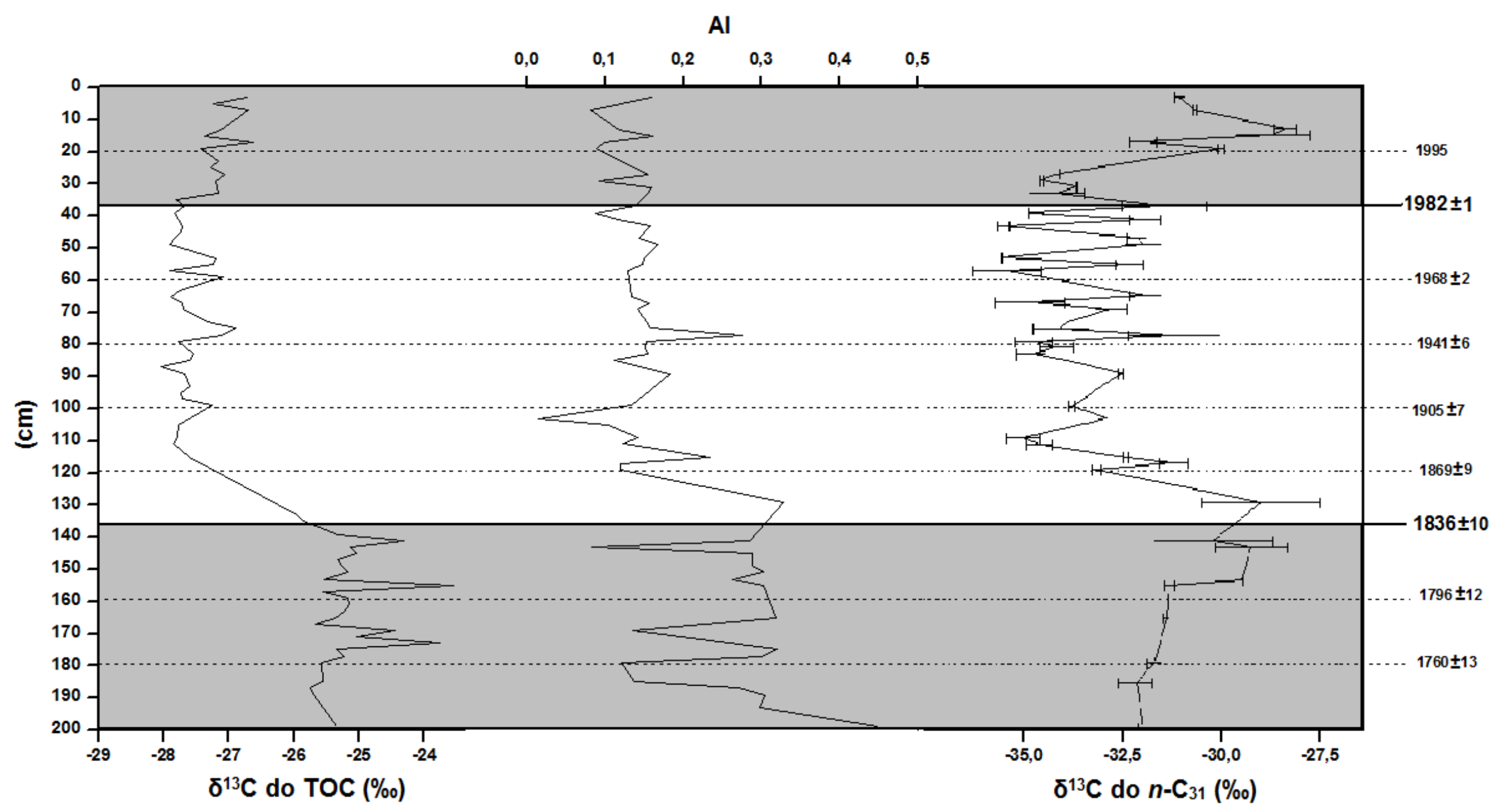

Figura 20: Perfil dos valores de $\delta^{13} \mathrm{C}$ do carbono orgânico total $\left(\delta^{13} \mathrm{C}\right.$ do TOC, \%), do índice alcano (Al) e do $\delta^{13} \mathrm{C}$ do $n$ - $\mathrm{C}_{31}(\% \circ)$ encontrados no testemunho CAN05. As diferentes cores representam os diferentes períodos de deposição de carbono orgânico. 
A mudança entre a primeira e a segunda fase pode estar relacionada à abertura do Valo Grande (1827 a 1852, Geobrás, 1966), confirmando a influência deste canal na deposição da matéria orgânica da região amostrada. Sedimentos pelíticos são principalmente introduzidos no Sistema EstuarinoLagunar de Cananéia-Iguape pelo Rio Ribeira de lguape através do Valo Grande (Barcellos, 2005). Durante a primeira fase, quando este canal encontrava-se fechado, a quantidade de lama e, por consequência, de matéria orgânica depositada, era menor. Segundo Cunha-Lignon \& Kampel (2011), S. alterniflora tende a se estabelecer em regiões mais salinas e sem influência de macrófitas aquáticas. Durante o primeiro período, não havia a presença da contribuição do Rio Ribeira de Iguape, então S. alterniflora encontrava-se mais bem desenvolvida, influenciando no tipo de matéria orgânica predominante da região. O menor fluxo de água doce proveniente deste rio, também permitiu a maior produtividade primária marinha fitoplanctônica, diminuindo o sinal da matéria orgânica terrígena nos valores de $\delta^{13} \mathrm{C}$ do TOC.

Com a abertura do canal, houve um aumento da influência do Rio Ribeira de Iguape, aumentando a quantidade de macrófitas aquáticas nos arredores do canal do Valo Grande (Cunha-Lignon \& Kampel, 2011). Estas macrófitas competem com $S$. alterniflora, diminuindo a presença desta espécie na região amostrada (Cunha-Lignon, comunicação pessoal*). Como $S$. alterniflora foi substituída por outras macrófitas, não houve mudanças significativas no Paq (Figura 14). Uma vez que ela apresenta concentrações significativas de $n$ - $C_{31}$, houve uma diminuição nos valores de Al.

A terceira fase encontrada no CAN05 se inicia em $38 \mathrm{~cm}$ e vai até o topo. Nela, observa-se um aumento nos valores de $\delta^{13} \mathrm{C}$ do TOC e no $\delta^{13} \mathrm{C}$ do $n$ - $\mathrm{C}_{31}$. A datação usada no presente estudo indica que este período vai de $1982 \pm 1$ até o ano da coleta (2008). Considerando o comportamento dos valores dos marcadores usados, esta fase corresponderia àquela em que 0 canal do Valo Grande foi fechado. Isto ocorreu em 1978, quando, atendendo a

\footnotetext{
* Correspondência com a Prof ${ }^{\mathrm{a}}$. Dr ${ }^{\mathrm{a}}$. Marília Cunha-Lignon, professora da Universidade Federal de São Paulo, pesquisadora associada da Université Libre de Bruxelles e do Instituto BiomaBrasil, realizada em 28/07/2013
} 
constantes reivindicações da população local, o Departamento de Água e Energia Elétrica do Estado de São Paulo (DAEE) obstruiu o canal do Valo Grande através de uma barragem de blocos de rocha capeados por lama (Pisetta, 2006). A entrada de água doce para o sistema diminuiu, aumentando a produtividade primária fitoplanctônica na região (Barcellos, 2005). Assim, houve um aumento do aporte de matéria orgânica de origem marinha para os sedimentos, acarretando em um aumento dos valores de $\delta^{13} \mathrm{C}$ do TOC. Os maiores valores de $\delta^{13} \mathrm{C}$ encontrados no $n$ - $C_{31}$ podem ser um indício de uma diminuição na quantidade de matéria orgânica introduzida pela vegetação de restinga.

O fechamento do Valo Grande (1978) protegeria as margens deste canal, evitando sua erosão e diminuindo o aporte de água doce e de sedimentos mais finos para o sistema estuarino-lagunar (Geobrás, 1966). Entretanto, em 1979, inundações nas áreas baixas do Rio Ribeira de Iguape já puderam ser observadas. A partir daí, ocorreram transposições de água doce e galgamentos foram observados na barragem. Estas permitiam, mesmo que em menor escala, a descarga fluvial e de sedimentos em suspensão ao sistema (DAEE, 2013). Em 1983, em decorrência das fortes chuvas, a barragem rompeu-se em definitivo e o canal do Valo Grande tornou-se ativo novamente (Mahiques et al., 2009).

Os marcadores avaliados neste testemunho não apresentaram variações relativas à abertura do canal do Valo Grande.

\subsubsection{CAN07}

O testemunho CAN07 $(124 \mathrm{~cm})$, amostrado a aproximadamente $20 \mathrm{~km}$ ao sul da desembocadura do Valo Grande, apresentou uma taxa de sedimentação média de $0,67 \pm 0,05 \mathrm{~cm}^{2} \mathrm{ano}^{-1}$. Baseando-se na datação feita através do ${ }^{210} \mathrm{~Pb}$, seu período de abrangência se inicia na primeira metade do século XIX (1823 \pm 14$)$ e vai até 2008 , abrangendo o período que vai desde a obra de abertura do Valo Grande (1827 a 1852, Geobrás, 1966). Considerando a variação dos valores dos marcadores, principalmente do teor de lama, TOC, 
TN e AlcTot, $\delta^{13} \mathrm{C}$ do TOC, CPI, Paq e Al, o CAN07 pôde ser divido em duas fases com características deposicionais distintas (Figura 21e Figura 22).

A primeira fase vai da base até $20 \mathrm{~cm}$. Nela, os teores de lama foram menores e houve uma tendência de aumento nas concentrações de AlcTot. $O$ $\delta^{13} \mathrm{C}$ do TOC durante esta época, embora com valores típicos de plantas terrígenas do tipo $C_{3}$ (Zhou et al., 2006), foi maior, indicando que houve uma contribuição fitoplanctônica relativa mais intensa nesta fase que na seguinte.

A segunda fase encontrada vai de 20 ao topo $\mathrm{cm}$. Nela, há um aumento no teor de lama e uma diminuição nos valores de $\delta^{13} \mathrm{C}$ do TOC, que provavelmente está associada a uma menor contribuição relativa da matéria orgânica marinha (Zhou et al., 2006). Os valores do Paq também tiveram uma tendência de aumento, o que pode um indício de uma maior contribuição de macrófitas emersas monocotiledôneas.

De acordo com o modelo de idade usado, a primeira e a segunda fase de deposição vão, respectivamente, de $1823 \pm 14$ a $1978 \pm 2$, e de $1978 \pm 2$ a 2008. Baseando-se nos marcadores apresentados acima, a primeira fase seria correspondente àquela ocorrida enquanto o Valo Grande já se encontrava aberto (de 1827-1852 a 1978); e a segunda fase, àquela ocorrida quando houve o fechamento deste canal (de 1978 a 1983, Mahiques et al., 2009). 


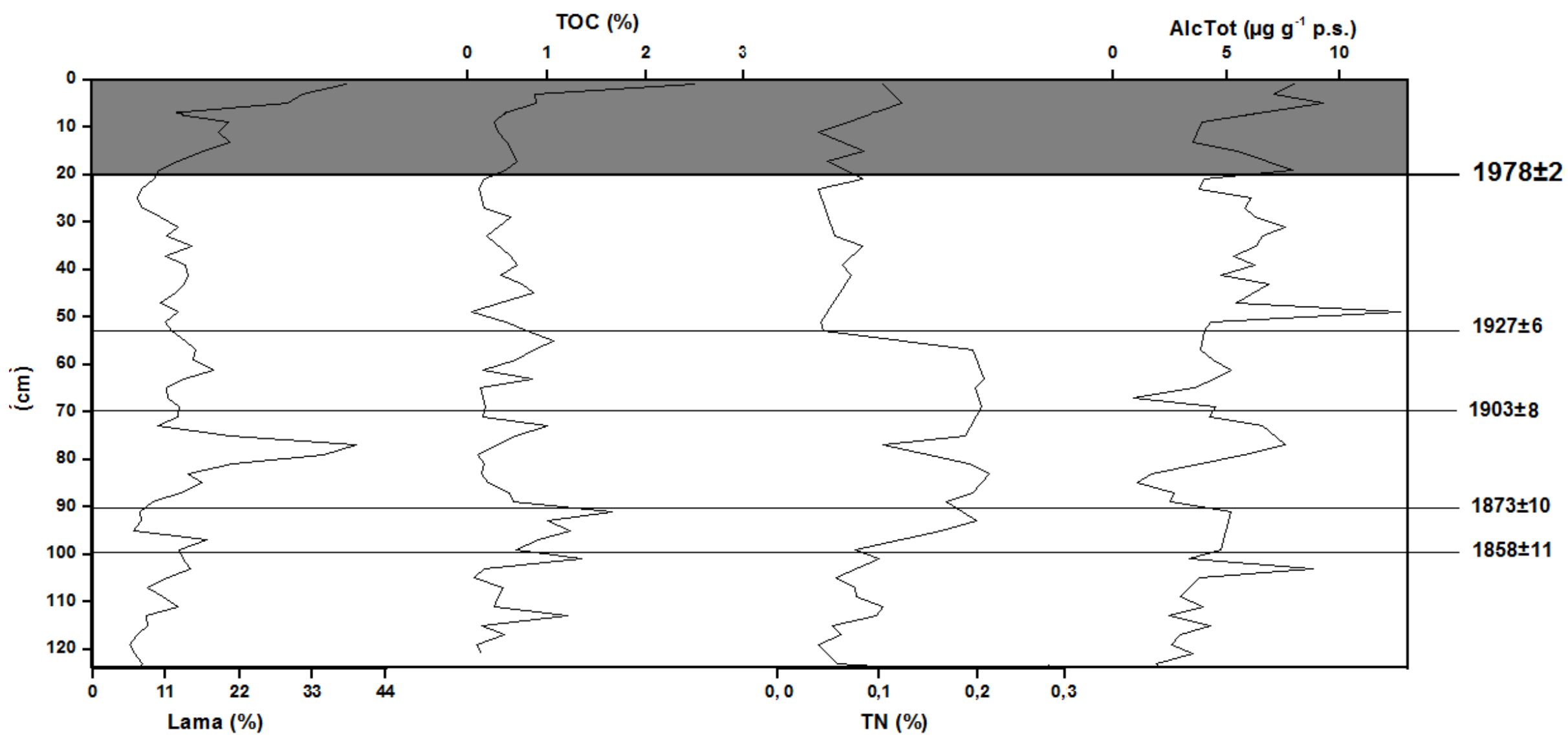

Figura 21: Perfil dos teores de lama (\%), carbono orgânico total (TOC,\%), nitrogênio total (TN, \%) e $n$-alcanos totais (AlcTot, $\mu$ g g ${ }^{-1}$ p.s.) do testemunho CAN07. As diferentes cores representam os diferentes períodos de deposição de carbono orgânico. 


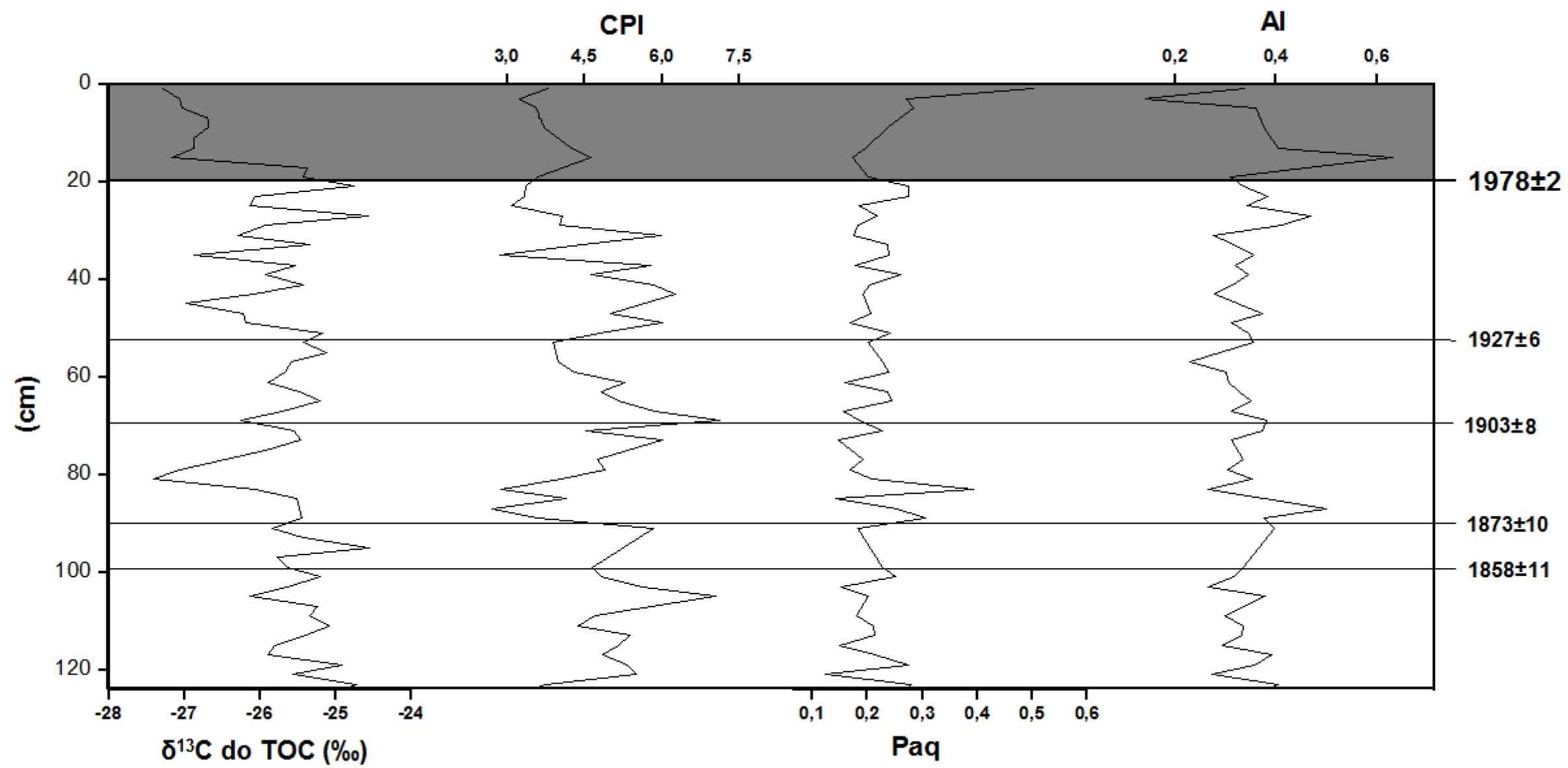

Figura 22: Perfil dos valores de $\delta^{13} \mathrm{C}$ do carbono orgânico total $\left(\delta^{13} \mathrm{C}\right.$ do TOC, \%), do índice preferencial de carbono (CPI), do índice de produção aquática (Paq) e do índice alcano (Al) encontrados no testemunho CAN07. As diferentes cores representam os diferentes períodos de deposição do carbono orgânico. 
O CAN07, embora esteja mais afastado que o CAN05 do Valo Grande, está localizado em uma área sobre influência deste canal (Mahiques et al., 2013). A principal fonte de pelitos para o sistema é o Rio Ribeira de Iguape. As correntes de maré existentes na região transportam efetivamente os sedimentos ao longo de toda área de estudo (Miyao et al., 1986). Durante a maré enchente, as ondas entram pelas barras de Cananéia e de Icapara, e se encontram nas proximidades da Pedra do Tombo, onde está localizado o CAN07. Este encontro das ondas de maré é conhecido como "tombo das águas", e gera condições hidrodinâmicas favoráveis para deposição dos materiais mais finos provindos do Rio Ribeira de Iguape. Com o Valo Grande aberto, o fenômeno do "tombo" é mais acentuado. O volume de água marinha que penetra no Mar Pequeno pela desembocadura de Icapara é acrescido das águas continentais que afluem através deste canal (Tessler, 2001 apud Tessler et al., 1987). Pode ser que isto tenha deslocado mais para sul a região do "tombo das águas". Assim, quando o canal do Valo Grande estava aberto, o este fenômeno ocorria um pouco mais afastado da região do CAN07, diminuindo a quantidade de pelitos depositados. Quando ele foi fechado, este processo ocorreu mais próximo ao local do testemunho, aumentando a quantidade de material fino depositado.

Observa-se que a concentração de AlcTot do CAN07 sofreu um leve aumento ao longo do primeiro período. Isso também pode estar relacionado à mudança gradativa do local onde havia o "tombo das águas". Segundo Tessler (comunicação pessoal*), a região onde há o encontro das marés tende a se mover em direção ao norte. Isso ocorre porque a região da Barra de Icapara está tendo um aumento gradativo para o norte (Tessler \& Mahiques, 1993; Kawakubo, 2008; Nascimento-Filho et al., 2008). Assim, provavelmente, ao longo do primeiro período, a região do "tombo das águas" foi se aproximando do local onde o CAN07 foi coletado, aumentando gradativamente a deposição de matéria orgânica neste testemunho.

\footnotetext{
* Correspondência com o Prof. Dr. Moysés Tessler, professor do Instituto Oceanográfico da Universidade de São Paulo, realizada em 10/02/2012.
} 
Enquanto o canal do Valo Grande esteve aberto, observou-se também o aumento na produtividade primária marinha na região do CAN07. Este pode estar relacionado a um aumento na quantidade de nutrientes do sistema. Entre 100 e $54 \mathrm{~cm}$, pode-se observar que o TN foi mais alto. Este parâmetro não obteve correlação significativa com os níveis de TOC $(p=0,48 ; r=0.12 ; n=63)$, mostrando que houve contribuição de nitrogênio inorgânico neste parâmetro. Entre 90 e $70 \mathrm{~cm}(1873 \pm 10$ a 1903 \pm 8$)$ houve um aumento no teor de lama e de TOC (Figura 22). Mahiques et al. (2013), ao estudarem o aporte de metais no sistema, avaliaram este mesmo testemunho e também encontraram este aumento. Este fato pode estar relacionado à influência do Valo Grande e das chuvas ocorridas na região durante este período.

\subsubsection{CAN10}

O testemunho CAN10 $(153 \mathrm{~cm})$ foi amostrado a aproximadamente $40 \mathrm{~km}$ ao sul da desembocadura do Valo Grande. Sua taxa de sedimentação média foi $0,60 \pm 0,06 \mathrm{~cm}^{a n o-1}$. Baseando-se na datação feita através do ${ }^{210} \mathrm{~Pb}, 0$ período de abrangência do CAN10 é correspondente à metade do século XVIII $(1753 \pm 15)$ até 2008 . Analisando os resultados dos marcadores estudados no presente estudo, principalmente do teor de lama, TOC, TN, AlcTot, $\mathrm{CaCO}_{3}$, Paq e Al, pôde-se observar que o testemunho CAN10 apresentou dois períodos com características deposicionais distintas (Figura 23 e Figura 24).

O primeiro vai da base até $80 \mathrm{~cm}$. Neste, mesmo não havendo mudanças no teor de lama, as concentrações de TOC, TN e AlcTot foram menores. Os valores de Paq foram maiores e os de $\mathrm{Al}$, menores. O segundo período de deposição encontrado no CAN10 vai de $80 \mathrm{~cm}$ ao topo. Neste, os níveis de TOC, TN e AlcTot subiram. Os valores de Paq, mesmo sendo típicos de macrófitas emersas, diminuíram e os de Al aumentaram. Estes resultados mostram que, aparentemente, houve aumento na contribuição relativa da matéria orgânica terrígena provinda da vegetação de restinga durante o período em questão. Houve também um leve aumento na produtividade primária na região, observado através do aumento nos teores de carbonato. 
Sabe-se que a influência do canal do Valo Grande pode afetar as porções mais ao sul do Sistema Estuarino-Lagunar de Cananéia-Iguape (Barcellos, 2005). Valores de salinidade 0 e a presença de aguapés, cuja principal fonte é o Rio Ribeira de Iguape, já foram observados nas proximidades da cidade de Cananéia (Figura 1) (Mahiques et al., 2009; Pisetta, 2010). Assim, a região do CAN10 está sob influência do canal do Valo Grande, ainda que de maneira mais restrita que os demais testemunhos coletados.

Aparentemente, a mudança entre a primeira e a segunda fase do testemunho em questão está relacionada à abertura deste canal (1827-1852, Geobrás, 1966). De acordo com a datação, ela ocorreu em 1868ะ8. Baseandose nos marcadores apresentados acima, o primeiro período de deposição seria correspondente àquele anterior à abertura do Valo Grande; e a segunda fase seria correspondente àquela ocorrida posteriormente à abertura deste canal.

A vegetação lenhosa de mangue e $S$. alterniflora encontram-se mais bem desenvolvidas na região sul que na região norte do Sistema EstuarinoLagunar de Cananéia-Iguape (Cunha-Lignon et al., 2009a). A presença destas plantas é influenciada pelas características hidrodinâmicas e geomorfológicas ocorridas em cada área (Cunha-Lignon et al., 2009b). Sabe-se que a abertura do canal do Valo Grande diminuiu a quantidade de $S$. alterniflora na região norte do sistema devido ao maior aporte de água doce na região (Cunha \& Kampel, 2011). Como há indícios de que o Rio Ribeira de Iguape influenciou a região sul do sistema, após a abertura do canal do Valo Grande, sua ação pode ter ocasionado uma diminuição na contribuição destas vegetações na matéria orgânica depositada na região do CAN10. Segundo os marcadores estudados no presente estudo, durante o período no qual o Valo Grande esteve fechado, havia nas proximidades deste testemunho uma vegetação de mangue bem desenvolvida. A abertura do canal do Valo Grande teria diminuiu a presença destas vegetações na região do CAN10. 


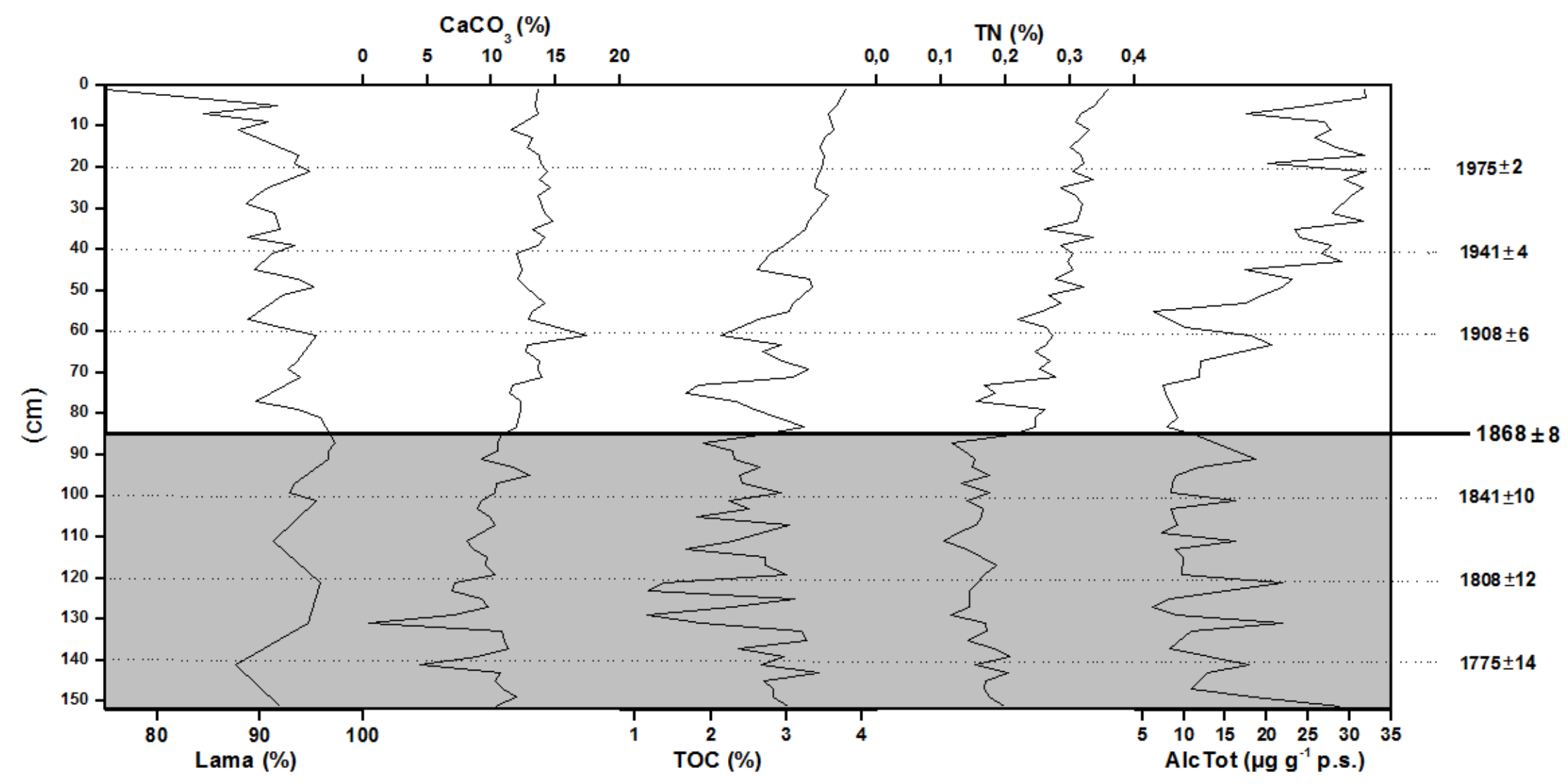

Figura 23: Perfil dos teores de lama (\%), carbonato de cálcio $\left(\mathrm{CaCO}_{3}, \%\right)$, carbono orgânico total (TOC,\%), nitrogênio total (TN, \%) e n-alcanos totais (AlcTot, $\mu \mathrm{g} \mathrm{g}^{-1}$ P.s.) do testemunho CAN10. As diferentes cores representam os diferentes períodos de deposição de carbono orgânico. 


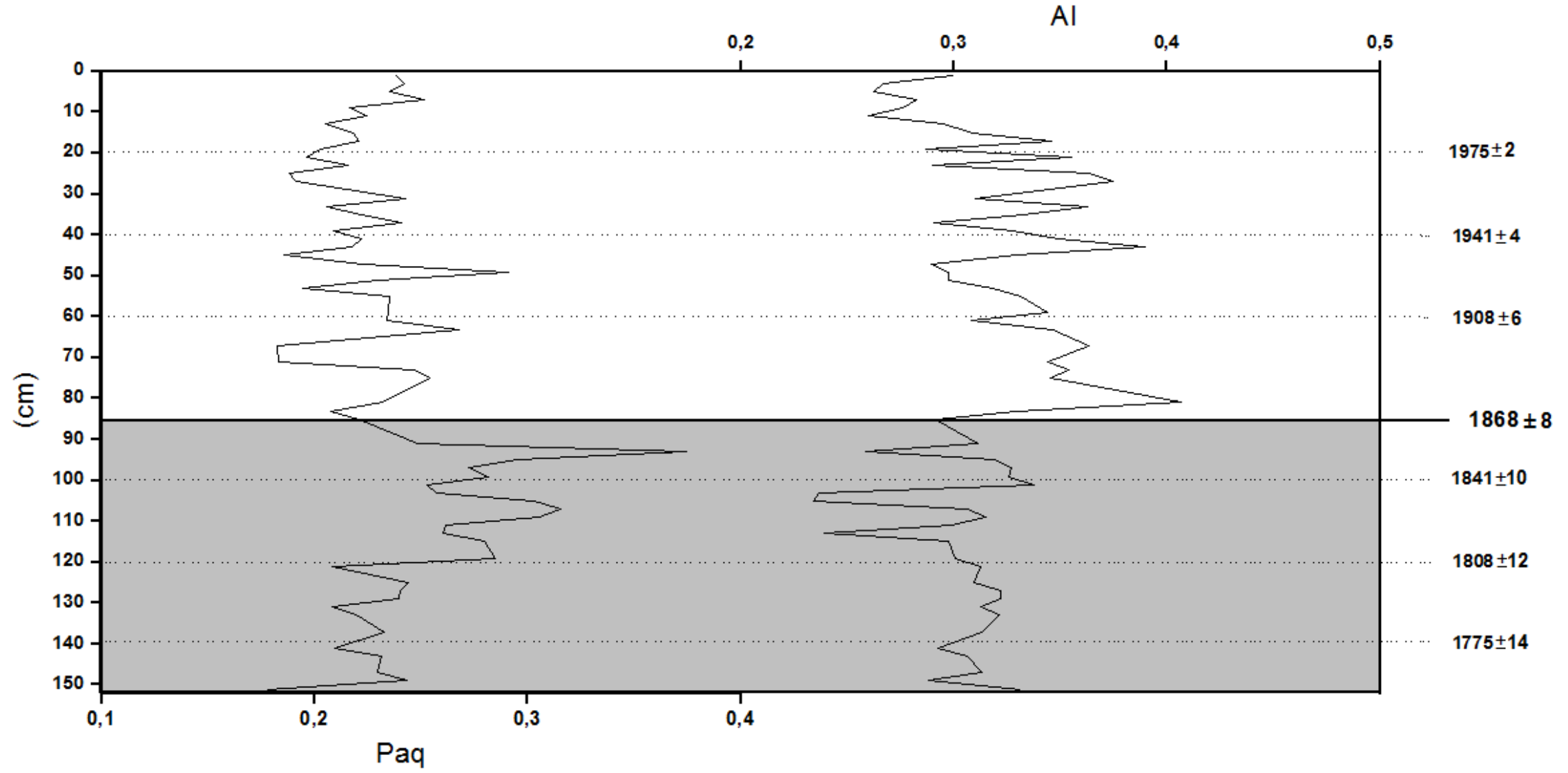

Figura 24: Perfil dos valores do índice de produção aquática (Paq) e do índice alcano (Al) encontrados no testemunho CAN10. As diferentes cores representam os diferentes períodos de deposição de carbono orgânico. 
A influência do Rio Ribeira de Iguape após a abertura do Valo Grande aumentou a contribuição relativa da vegetação de restinga na região do CAN10, mudando o sinal do Al durante este período. Este aumento pode ser o responsável pela maior deposição de matéria orgânica observada no local em questão durante segundo período.

\subsubsection{Comparação entre os testemunhos amostrados}

Os quatro testemunhos apresentaram diferenças na variação da matéria orgânica que puderam ser associadas ao canal do Valo Grande. Estas estão resumidas na Figura 25.

Dentre os testemunhos avaliados, o CAN05 e o CAN10 mostraram diferenças causadas pela abertura deste canal ocorrida entre 1827 e 1852 (Geobrás, 1966). Através deles, observa-se que, antes da abertura do Valo Grande, a influência marinha na região de estudo era maior. O CAN05 tinha uma maior produtividade fitoplanctônica e presença de macrófitas emersas, e 0 CAN10, um maior estabelecimento da vegetação lenhosa do mangue. Ambos os testemunhos apresentaram maior presença de macrófitas emersas, como $S$. alterniflora. Com a abertura do canal do Valo Grande, houve um aumento da contribuição da vegetação de restinga, através do Rio Ribeira de Iguape. $\mathrm{Na}$ região mais ao norte do sistema, houve um aumento no desenvolvimento de macrófitas aquáticas flutuantes e da vegetação de mangue. Cunha-Lignon \& Kampel (2011) encontraram que, de 1997 a 2011, houve um aumento em área da vegetação de mangue (por causa do aumento das áreas de deposição) e, principalmente, de macrófitas aquáticas na região norte do sistema devido à maior influência do Rio Ribeira de Iguape. Segundo os dados observados no presente estudo, esta mudança tem ocorrido desde que o canal do Valo Grande foi aberto pela primeira vez. As mudanças foram observadas na área de estudo como um todo. A matéria orgânica da região sul, após a abertura deste canal, apresentou maior contribuição de material marinho de origem fitoplanctônica. Como esta região está mais afastada da desembocadura do Valo Grande, sua salinidade é maior. Isto favorece o desenvolvimento de organismos fitoplanctônicos. Uma vez que houve maior introdução de 
nutrientes no sistema após a abertura do canal do Valo Grande, esta região se tornou mais propicia para o desenvolvimento do fitoplâncton marinho. Esta maior produtividade marinha pode ser observada também no CAN07.
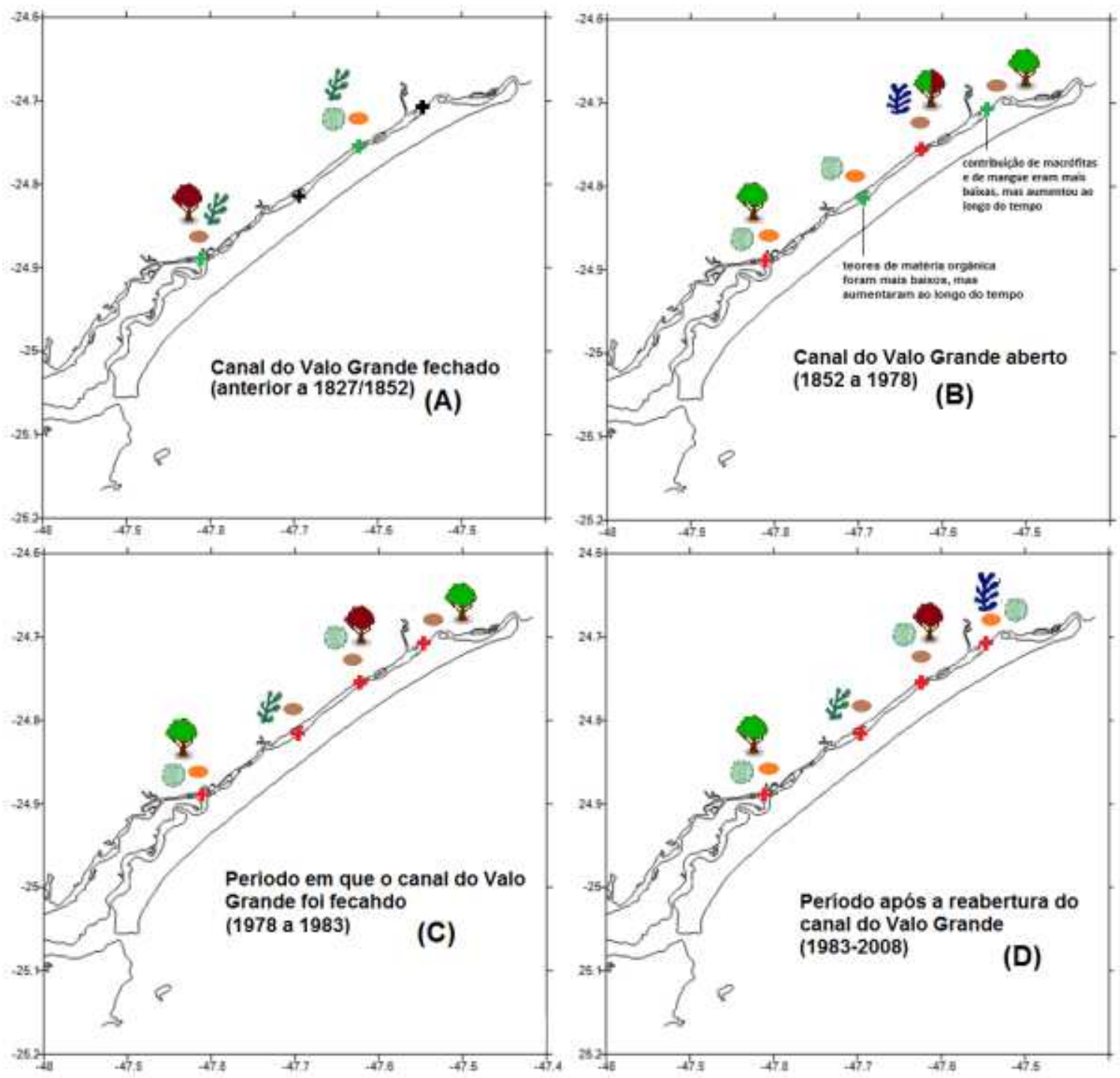

Legonda
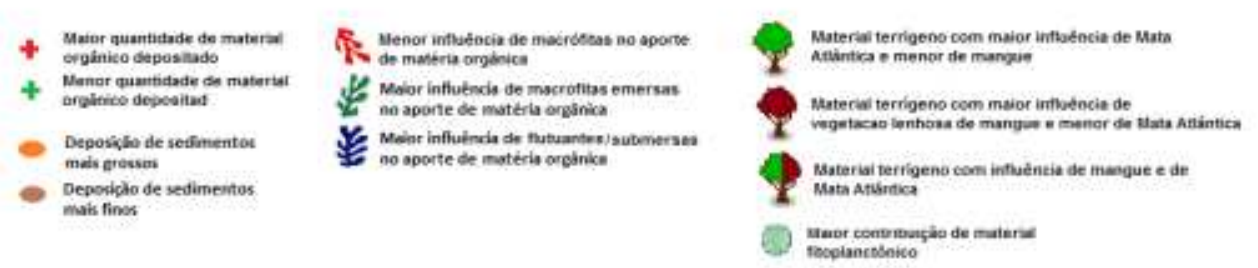

Figura 25: Resumo das mudanças observadas ao longo do Sistema Estuarino-Lagunar de Cananéia-lguape relacionadas à abertura do canal do Valo Grande. (A) período anterior à abertura do canal do Valo Grande; (B) período após a construção deste canal; (C) período posterior ao seu fechamento; (D) período posterior à sua reabertura. 


\section{CONCLUSÕES}

Através dos dados obtidos no presente estudo, foi possível caracterizar as principais fontes de matéria orgânica do Sistema Estuarino-Lagunar de Cananéia-Iguape, verificando as mudanças causadas pela abertura do canal do Valo Grande na composição molecular e isotópica dessa matéria orgânica.

Os marcadores avaliados nas espécies de plantas amostradas permitiram separar a vegetação em grupos. Através dos índices de $n$-alcanos calculados, pode-se dividir as espécies estudadas em monocotiledôneas e dicotiledôneas, e em vegetação lenhosa de mangue e de restinga. Propõem-se valores dos seguintes índices relacionados aos $n$-alcanos em monocotiledôneas como: produção aquática (Paq) maior que 0,1 , o índice preferencial do carbono (CPI) menor que $5, \circ \delta^{13} \mathrm{C}$ do $n$-alcanos igual a $-28,5 \pm 3,9 \%$ e $\delta \mathrm{D}$ dos $n$-alcanos igual a $-154 \pm 3 \%$. Para as dicotiledônias, os valores propostos foram: Paq menor que 0,$1 ; \mathrm{CPI}$ maior que $5 ; \delta^{13} \mathrm{C}$ do $n$-alcanos igual $-35,2 \pm 3,5 \%$ e $\delta D$ dos $n$-alcanos igual a $-174 \pm 16 \%$. Para 0 $\mathrm{ACL}_{23-33}$ (tamanho médio de cadeia de $n$-alcanos) e o Al (índice alcano) da vegetação lenhosa de mangue, os valores propostos são respectivamente, menores que 29,0 e menores que 0,1 . Para a vegetação de restinga estes valores foram, respectivamente, maiores que 29,0 e maiores que 0,2. Os parâmetros propostos acima, principalmente $\mathrm{Al}$ e o Paq, foram muito úteis na identificação das fontes de matéria orgânica do Sistema Estuarino-Lagunar de Cananéia-lguape.

O teor de matéria orgânica das amostras superficiais esteve associado à deposição de sedimentos finos. Mesmo tendo sido avaliado um número restrito de amostras superficiais, pôde-se verificar quais são as fontes atuais de matéria orgânica para o Sistema Estuarino-Lagunar de Cananéia-Iguape. As principais são as terrígenas provindas da vegetação da vegetação de restinga. Estas são introduzidas na região de estudo através dos rios que lá deságuam. Uma vez que a área norte encontra-se sobre maior influência do Rio Ribeira de Iguape, a influência relativa da vegetação de restinga nesta região é maior. $\mathrm{Na}$ região central e sul, embora também seja observada a predominância da vegetação de restinga no aporte de matéria orgânica, há uma influência relativamente maior da vegetação de mangue. Esta região também apresenta 
uma contribuição marinha mais acentuada que as demais regiões. Outras fontes de matéria orgânica para o Sistema Estuarino-Lagunar de CananéiaIguape são as macrófitas. A influência das macrófitas emersas é maior na região sul e das macrófitas aquáticas flutuantes é maior na região norte.

Os resultados obtidos nos testemunhos mostraram que o canal do Valo Grande influenciou na qualidade e na quantidade de matéria orgânica da região de estudo ao longo do tempo. Antes da abertura deste canal, a contribuição marinha e das macrófitas emersas ao longo da região de estudo era maior. A região norte tinha uma produtividade marinha mais acentuada e a contribuição da vegetação lenhosa do mangue na região sul era maior. Quando o Valo Grande foi aberto pela primeira vez, houve um aumento na deposição de sedimentos mais finos na região norte e de sedimentos mais grossos no sul da área de estudo. Houve um aumento da contribuição da vegetação de restinga na matéria orgânica depositada ao longo de todo sistema.

Devido à abertura do canal do Valo Grande, houve um aumento na quantidade de nutrientes provindos do Rio Ribeira de Iguape o que fez com que aumentasse a contribuição da vegetação do mangue no norte do sistema e da produtividade fitoplanctônica no sul.

Com o fechamento do canal, houve um aumento da contribuição da vegetação lenhosa de mangue e de macrófitas emersas na região da Pedra do Tombo. Quando o Valo Grande foi aberto pela segunda vez, a contribuição das macrófitas aquáticas na região norte aumentou novamente, indo em direção à Barra de Icapara. 


\section{REFERÊNCIAS BIBLIOGRÁFICAS}

ABOUL-KASSIM, T. A. T.; SIMONEIT, B. R. T. Lipid geochemistry of surficial sediments from the coastal environment of Egypt 1. Aliphatic hydrocarbons: characterization and sources. Marine Chemistry, v.54, n. 1/2, p. 135-158, 1996.

AFONSO, C. M. Uso e ocupação do solo na zona costeira do Estado de São Paulo: uma análise ambiental. São Paulo: Annablume, 1999. $180 \mathrm{p}$.

ALBAIGÉS, J., ALGABA, J., GRIMALT, J.O., (1984) Extractable and bound neutral lipids in some lacustrine sediments. Organic Geochemistry, 6, 223-236.

ANDREWS, J. E.; A. M., GREENWAY; DENNIS.P. F. Combined carbon isotope and $\mathrm{C} / \mathrm{N}$ ratios as indicators of source and fate of organic matter in a poorly flushed, tropical estuary. Hunts Bay, KingstonHarbour, Jamaica. Estuarine, Coastal and Shelf Science, v. 46, p. 743-456, 1998.

APPLEBY, P. G.; OLDFIELD, F. The calculation of Lead-210 dates assuming constant rate of supply ${ }^{210} \mathrm{~Pb}$ to sediment, Catena, v. 5, p. $1-8$, 1978.

BARCELlos, R. L.; CAMARGo, P. B.; GALVÃO, A.; WeBER, R. R. Sedimentary organic matter in cores of the Cananéia-Iguape Lagoonal-Estuarine System, São Paulo State, baril. Journal of Coastal Research, n. 56, p. 1335-1339. Special issue, 2009.

BARCELLOS, R. L.; JAWORSKI, K. S.; PEREIRA, E. R. M. CARDOSO, P. B. P. K; EICHLER, B. B. FURTADO, V. V. 2003. Caracterização ambiental e comparação entre as desembocaduras de Icapara e Cananéia, Sistema Estuarino-Lagunar de Cananéia-Iguape estado 
de São Paulo. Congresso sobre Planejamento e Gestão das Zonas Costeiras dos Países de Expressão Portuguesa, 2., 2003, Recife. Anais do II Congresso da Associação Brasileira de Estudos do Quaternário, 2003.

BARCELLOSS, R. L. Distribuição da matéria orgânica sedimentar e o processo sedimentar atual no Sistema Estuarino-Lagunar de Cananéia-Iguape (SP). 2005. 89 f. Tese (Doutorado) - Instituto Oceanográfico, Universidade de São Paulo.

BARRERA-ALBA, J. J. Dinâmica metabólica e transporte de propriedades no Sistema estuarino-Lagunar de Cananéia-Iguape. 2004. 2 v. Tese (Doutorado) - Instituto Oceanográfico, Universidade de São Paulo.

BARRERA-ALBA, J. J.; GIANESELLA, S. M. F.; SALDANHA-CORRÊA, F. M. P.; MOSER, G. A. O. Influence of an artificial channel in a wellpreserved sub-tropical estuary. Journal of Coastal Research, $n$. 50, p. 1137-1141, 2007. Speciallssue.

BÉRGAMO, A. L. Características da hidrografia, circulação e transporte de sal: Barra de Cananéia, sul do mar de Cananéia e Baía do Trapandé. 2000. 254 f. Dissertação (Mestrado) - Instituto Oceanográfico, Universidade de São Paulo.

BESNARD, W. Considerações gerais em torno da região lagunar de Cananéia e Iguape I. Boletim do Instituto Paulista de Oceanografia, São Paulo, v. 1, n. 1, p. 9-26, 1950.

BI, X.; SHENG, G.; LIU, X.; LI, C.; FU, J. Molecular and carbon and hydrogen isotopic composition of $n$-alkanes in plant leaf waxes. Organic Geochemistry, v. 36, n. 10, p. 1405-1417, 2005.

BIRD, M. I.; SUMMONS, R. E.; GAGAN, M. K.; ROKSANDIC, Z.; DOWLING, L.; HEAD, J.; FIFIELD, L. K.; CRESSWELL, R. G.; JOHNSON, D. 
P. Terrestrial vegetation changed inferred from $n$-alkanes $\delta^{13} \mathrm{C}$ analyses in the marine environment. Geochimica et Cosmochimica Acta, v. 59, n. 13, p. 2853-2857, 1995.

BLUMER, M.; GUILARD, R. R. L.; CHASE, T. Hydrocarbons of marine phytoplankton. Marine Biology, v. 8, p. 183-189, 1971.

BONETTI FILHO, J. Transporte de Sedimentos por suspensão nas proximidades da Barra de Cananéia (SP). 1995. 2 v. Dissertação (Mestrado) - Instituto Oceanográfico, Universidade de São Paulo.

BONETTI FILHO, J.; CONTI, L. A.; FURTADO, V. V. Suspended sediment concentration variability and its relation to tidal currents in microtidal system. Anais da Academia Brasileira de Ciências, v. 68, n. 3, p. 485-494, 1996.

BONETTI FILHO, J.; MIRANDA, L. B. Estimativa da descarga de água doce no sistema estuarino-lagunar de Cananéia-Iguape. Revista Brasileira de Oceanografia, v. 45, n. 112, p. 89-94, 1997.

BORDOVSKIY, O. K. Accumulation of organic matter in bottom sediments. Marine Geology, v. 3, p 33-82, 1965

BOUTTON, T. W. Stable carbon isotope ratios of natural materials: II. Atmospheric, terrestrial, marine, and freshwater environments. In: COLEMAN, D. C.; FRY, B.(Ed.). Carbonisotopetechniques. San Diego: Academic, 1991. p. 173-185.

BRAGA, E. S. Nutrientes dissolvidos e produção primária do fitoplâncton em dois sistemas costeiros do Estado de São Paulo. 1995. 2 v. Tese (Doutorado) - Instituto Oceanográfico, Universidade de São Paulo.

BRASSEL, S. C. Application of biomarkers for delineating marine paleoclimatic fluctuations during the Pleistocene. In: ENGEL, M. H.; MACKO, S. 
A. Organic Geochemistry: principles and applications. New York: Plenum, 1993. p. 699-738.

BRASSEL, S. C.; EGLINTON, G.; MAXWELL, J. R.; PHILIP, R. P. Natural background of alkalines in the aquatic environmental. In: HUNTZINGER, O.; LELYVELD, L. H.; ZOETMAN, B. C. J. (Ed.). Aquatic pollutants: transformations and biological effects. Oxford: Pergamon, 1978. p. 69-86

BREUGEL, Y. Causes for negative carbon isotope anomalies in Mesozoic marine sediments: Constraints from modern and ancient anoxic settings. 2006. $79 \mathrm{f}$. Thesis (PhD.) - Utrecht University.

CANET, A.; JACQUEMIN, R. Methods for measuring radium isotopes: Gamma spectrometry. In Environmental Behaviour of Radium, IAEA Technical Reports Series 310, Viena, vol.1C-4.

CARVALHO, J. P. O. Visões do LAGAMAR. São Paulo: Hammer, 2001.

CHIKARAISHI, Y.; NARAOKA, H. Organic hydrogen-carbon isotope signatures of terrestrial higher plants during biosynthesis for distinctive photosynthetic pathways. Geochemical Journal, v.35, p. 451-458, 2001.

CHIKARAISHI, Y.; NARAOKA, $H . \delta^{13} \mathrm{C}$ and $\delta \mathrm{D}$ relationships among three $\mathrm{n}$-alkyl compound classes (n-alkanoic acid, n-alkane and n-alkanol) of terrestrial higher plants. Organic Geochemistry, v. 38, p. 198-215, 2007.

CHIKARAISHI, Y.; SUZUKI, Y.; NARAOKA, H. Hydrogen isotopic fractionations during desaturation and elongation associated with polyunsaturated fatty acid biosynthesis in marine macroalgae. Phytochemistry, v. 65, n. 3, p. 2293-2300, 2004.

CITAC; EURACHEM. Guide to quality in analytical chemistry.United Kingdom, 2002. 
CLARK, J. R.; BLUMER, M. Distribution of $n$-paraffins in marine organisms and sediments.Limnology and Oceanography, v. 12, n. 1, p. 79-87, 1967.

COLLISTER, J. W.; LICHTFOUSE, E.; HIESHIMA, G.; HAYES, J. M. Partial resolution of sources of $n$-alkanes in the saline portion of the Parachute Creek Member, Green River Formation (Piceance Creek Basin, Colorado). Organic Geochemistry, v. 21, n. 6/7, p. 645659, 1994.

COLOMBO, J. C.; PELLETIER, E.; BROCHU, C.; KHALIL, M. Determination of hydrocarbon sources using $n$-alkane and potyaromatic hydrocarbon distribution indexes. Case Study:Rio de La Plata Estuary, Argentina. Environmental Science and Technology, v. 23, n. 7, p. 888-894, 1989.

CÔRTES, C.; DAMASCENO, C.; PAINE, R. C.; FUKUMOTO, N. M.; RÊGO, F. C. A.; CECATO, U. Uso de $n$-alcanos na estimativa da composição botânica em amostras com diferentes proporções de Brachiariabrizantha e Arachispintoi. RevistaBrasileira de Zootecnologia, v. 34, n.5, p. 1468-1474, 2005.

CORTES, J.E.; RINCON, J.M.; JARAMILLO, J.M.; PHILIP, R.P.; ALLEN, J. Biomarkers and compound-specific stable carbon isotope of $n$-alkanes in crude oils from Eastern Llanos Basin, Colombia. Journal of South American Earth Sciences, v. 29, n. 2, p. 198-213, 2010.

COTANO, U.; VILLATE, F. Anthropogenic influence on the organic fraction of sediments in two contrasting estuaries: A Biochemical approach. Marine Pollution Bulletin, v. 52, n. 4, p.404-414, 2006.

CRANWELL, P. A. Chain-length distribution of $n$-alkanes from lake sediments in relation to post-glacial environmental change. Freshwater Biology, v. 3 , n. 3, p. $259-265,1973$ 
CRANWELL, P. A.; EGLINTON, G.; ROBINSON, N. Lipids of aquatic organisms as potential contributors to lacustrine sediments-II. OrganicGeochemistry, v. 11, n. 6, p. 513-527, 1987.

CUNHA-LIGNON, M. Dinâmica do manguezal no Sistema de CananéiaIguape, Estado de São Paulo -Brasil. 2001. 105 f. Dissertação (Mestrado) - Instituto Oceanográfico, Universidade de São Paulo.

CUNHA-LIGNON, M.; KAMPEL, M. Análise multitemporal de imagens Landsat para monitoramento de áreas de manguezal: subsídio à gestão costeira de litoral sul do Estado de São Paulo. In: Anais de XV Simpósio Brasileiro de Sensoriamento Remoto, 2011, Curitiba, Paraná. Resumoexpandido: p. 5032-5038.

CUNHA-LIGNON, M.; KAMPEL, M.; MENGHINI, R. P.; SCHAEFFERNOVELLI, Y.; CINTRÓN, G.; DAHDOUH-GUEBAS, F. Mangrove Forest submitted to depositional processes and salinity variations investigated using satellite images and vegetation structure surveys. Journal of Coastal Research, v. 64, p. 344-348, 2009a.

CUNHA-LIGNON, M.; COELHO-JR., C.; ALMEIDA, R.; MENGHINI, R. P.; SCHAEFFER-NOVELLI, Y.; CINTRÓN, G.; DAHDOU-GUEBAS, F. Characterization of mangrove forest types in view of conservation and management: a review of mangals at Cananéia region, São Paulo, Brazil. JournalofCoastalResearch, v. 64, p. 349-353, 2009b.

DAEE - Departamento de Água e Energia Elétrica do Estado de São Paulo. Online. Disponível em: <http://www.daee.sp.gov.br> . Acesso em: 24 mai. 2013

DAMSTÉ, J. S. S.; RIJPSTRA, W. I. C.; HOPMANS, E. C.; WEIJERS, J. W. H.; FOESEL, B. U.; OVERMANN, J.; DEDYSH, S. N. 13,16-Dimethyl octacosanedioic (iso-diabolic acid): a common membrane-spanning 
lipid of Acidobacteria subdivision 1 and 3. Applied Environmental Microbiology, v. 77, n. 12, p. 4147-4154, 2011.

DUAN, Y; HEN, J. 2011. Distribution and isotopic composition of $n$-alkanes from grass, reed and tree leaves along a latitudinal gradient in China, Geochemical Journal, Vol. 45, pp. 199 to 207, 2011

DUAN, Y.; MA, L. H. Lipid geochemistry in a sediment core from Ruoergai Marsh deposit (Eastern Qinghai- Tibet plateau, China).OrganicGeochemistry, v. 32, n. 12, p. 1429-1442, 2001.

DULEBA, W. Variações nas associações de tecamebas, foraminíferos e ostracodessub-recentes da região lagunar de CananéiaIguape. 1997. 237 f. Tese (Doutorado) - Instituto Oceanográfico, Universidade de São Paulo.

EGLINTON G.; HAMILTON, R. J. The distributionof $n$-alkanes. In: SWAIN, T. Chemical plant taxonomy. London: Academic, 1963. p. 187-208.

EGLINTON, G.; GONZALEZ, A. G.; HAMILTON, R. J.; RAPHAEL, R. A. Hydrocarbon constituents of the wax coatings of plant leaves: a taxonomic survey. Phytochemistry, v. 1, n. 2, p. 89-102, 1962.

EGLINTON, G.; HAMILTON, R. J. Leaf epicuticular waxes.Science, v.156, n. 3780, p. 1322-1335, 1967.

EKPO, B. O.; FUBARA, E. P.; EKPA, O. D.; MARYNOWSKI, H. L. Determination of hydrocarbon source using $n$-alkane and $\mathrm{PAH}$ distribution indices in sediments form coastal areas of Bonny River in Niger Delta, Nigeria. Asian Research Publishing Network Journal of Earth Sciences, v. 1, n. 1, p. 9-20, 2012.

FEAKINS, S. J.; SESSIONS, A. L. Controls on the D/H ratios of plant leaf waxes from an arid ecosystem.GeochimicaetCosmochimicaActa, v. 74, n. 7, p. 2128-2141, 2010. 
FERNANDES, H. L. Iguape: a história de um desastre natural. Ecologia e desenvolvimento, v. 3, n. 41, p. 2-4, 1994. Suplemento.

FERNANDEZ, B. B. Variações do conteúdo de carbonato em estudos paleoceanográficos: um exemplo na Bacia de Campo. 2010. $79 \mathrm{f}$. Dissertação (Mestrado) - Instituto Oceanográfico, Universidade de São Paulo.

FICKEN, K. J., LI, B., SWAIN, D. L., EGLINTON, G. An n-alkane proxy for the sedimentary input of submerged/floating fresh water aquatic macrophytes. Organic Geochemistry, v. 31, n. 7/8, p. 745-749, 2000.

FIGUEIRA, R. C. L.; TESSLER, M. G.; MAHIQUES, M. M.; FUKUMOTO, M. M. Is there a technique for teh determination of sedimentation rates based on calcium carbonate content? A comparative study on the southeasthrn Brazilian shelf. Soil and Foundations, v. 47, n. 4, p. 649-656, 2007.

FRAGA, C. N.; PEIXOTO, A. L. Florística e ecologia das Orchidaceae das restingas do estado do Espírito Santo. Rodriguésia, v. 55, n. 84, p. 5-20. 2004.

FREITAS, A. F. N.; COGLIATTI-CARVALHO, L.; SLUYS, M. V. ROCHA, C. F. Distribuição espacial de bromélias na restinga de Jurubatam, Macaé, RJ, Acta bol. bras., v.14, n. 1, p. 175-180, 2000.

FRY, B. Stable isotope ecology.New York: Springer, 2006.

FUNDAÇÃO SOS MATA ATLÂNTICA. Portal sos Mata Atlântica. Online. Disponível em:<http://www.sosmataatlantica.org.br> .Acessoem: 23 jan. 2004.

GAGOSIAN R. B.; PELTZER E. T.The importance of atmospheric input of terrestrial organic material to deep sea sediments.Organic Geochemistry, v. 10, n. 4-6, p. 661-669, 1986. 
GAO, H.; MATYKA, M.; LIU, B.; KHALILI, A.; KOSTKA, J. E.; COLLINS, G.; JANSEN, S.; HOLTAPPELS, M.; JENSEN, M. M.; BADEWIEN, T. H.; BECK, M.; GRUNWALD, M.; DE BEER, D.; LAVIK, G.; KUYPERS, M. M. M.I ntensive and extensive nitrogen loss from intertidal permeable sediments of the Wadden Sea, Limnology and Oceanography, v. 57, n. 1, p. 185-198, 2012.

GASPER, A. L.; SALINO, A.; VIBRANS, A. C.; SEVEGNANI, L.; VERDI, M.; KORTE, A.; SANTOS, A. S.; SUSANA, D.; CADORIN, T. J.; SCHIMITT, J. L.; CAGLIONI, E. Pterid[ofitas de Santa Catarina: um olhar sobre os dados do inventário florístico florestal de Santa Catarina, Brasil. Acta Botanica Brasilica, v. 26, n. 2, p-421-434, 2012.

GEOBRÁS. Complexo Valo Grande, Mar Pequeno e Rio Ribeira de Iguape. São Paulo: DAEE, 1966.

GIREESHKUMAR, T. R.; DEEPULAL, P. M.; CHANDRAMOHANAKUMAR, N. Distribution and sources of sedimentary organic matter in a tropical estuary, south west coast of India (Cochin estuary): a baseline study. Marine Pollution Bulletin, v. 66, n. 1/2, p. 239-245, 2013.

GIULIANI, S.; CAPOTONDI, L.; MAFFIOLO, P.; LANGONE, L.; GIGLIO, F.; YAM, R.; FRIGNANI, M.; RAVAIOLI, M. Paleoenvironmental changes in the Pacific sector of the Southern Ocean (Antarctica) during the past 2.6 Ma. Global and Planetary Change, v. 77, n. 1/2, p. 34-48, 2011.

GODOY J. M.; MOREIRA I.; BRAGANÇA M. J.; WANDERLEY C.; MENDES L. B.A study of Guanabara Bay sedimentations rates.Journal of Radioanalytical and Nuclear Chemistry, v. 227, n. 1/2, p. 157160, 1998. 
HAYES, J. M. Factors controlling ${ }^{13} \mathrm{C}$ contents of sedimentary organic compounds: Principles and evidence. Marine Geology, v. 113, n. 1/2, p. 111-125, 1993.

HU, L.; GUA, Z.; FENG, J.; YANG, Z.; FANG, M. Distributions and sources of bulk organic matter and aliphatic hydrocarbons in surface sediments of the Bohai Sea, China.Marine Chemistry, v. 113, n. 3/4, p. 197-211, 2009.

ISHIWATARI, R.; UZAKI, M.; YAMADA, K. Carbon isotope composition of individual $n$-alkanes in recent sediments.Organic Geochemistry, v. 21, n. 6/7, p. 801-808, 1994.

IZART, A.; PALHOL, F.; GLEIXNER, G.; ELIE, M.; BLAISE, T.; SUAREZ-RUIZ, I.; SACHSENHOFER, R. F.; PRIVALOV, V. A.; PANOVA, E. A. Palaeoclimate reconstruction from biomarker geochemistry and stable isotopesof $n$-alkanes from Carboniferous and Early Permian humic coals and limnic sediments in western and eastern Europe.

Organic Geochemistry, v. 43, p. 125-149, 2012.

JENG, W. L. Higher plant $n$-alkane average chain length as an indicator of petrogenic hydrocarbon contamination in marine sediments.Marine Chemistry, v. 102, n. 3/4, p. 242-251, 2006.

KAHMEN A., SACHSE D., ARNDT S. K., FARRINGTON H., VITOUSEK P. M.; DAWSON T. E. Cellulose $\delta 180$ is an index of leaf to air vapor pressure difference (VPD) in tropical plants. Proceedings of the National Academy of Sciences of the United States of America, v. 108, n. 5, p. 1981-1986, 2011.

KAHMEN, A. Schefuß, E.; SACHSE, D. Leaf water deuterium enrichment shapes leaf wax $n$-alkane $\delta D$ values of angiosperm plants I: Experimental evidence and mechanisticsinsights.GeochimicaetCosmochimicaActa, v. 111, p. 39-49, 2013a. 
KAHMEN, A.; HOFFMANN, B.; SCHEFUß, E.; ARNDT, S. K.; CERNUSAK, L. A. WEST,J. B.; SACHSE, D. Leaf water deuterium enrichment shapes leaf wax $n$-alkane $\delta D$ values of angiosperm plants II: Observational evidence and global implications. GeochimicaetCosmochimicaActa, v. 111, p. 50-63, 2013b.

KATO, K. Chemical Investigations on the hidrographical System of Cananéia Lagoon.Boletim do InstitutoOceanográfico, São Paulo, v. 15, n. 1, p. 1-20, 1966.

KAWAKUBO, F. S. Avaliação das mudanças na linha de costa na foz do rio Ribeira de Iguape/desembocadura lagunar da Barra do Icapara (litoral sul de São Paulo - Brasil) utilizando dados Landsat MSS, TM e ETM+. Investigaciones Geográficas, Boletindel Instituto de Geografia, UNAM, n. 68, p. 41-49, 2009.

KENNICUTT II, M. C.; COMET, P. A. Resolution of sediment hydrocarbon sources: multiparameter approaches. In: WHELAN, J. K.; FARRINGTON, J. W. Organic Matter:productivity, accumulation, and preservation in recent and ancient sediments. New York: Columbia University Press, 1992. p. 308-339.

KHIM, B. K.; PARK, Y. H.; BAHK, J. J.;JIN, J. H.; LEE, G. H. Spatial and temporal variation of geochemical properties and paleoceanographic implications in the South Korea Plateau (East Sea) during the late Quaternary. Quaternary International, v. 176/177, p. 46-61, 2008.

KILLOPS, S. D.; KILLOPS, V. Introduction to organic geochemistry. 2nd ed. Malden: Blackwell, 2005.

KOZLOWSKI, T. T.; PALLARDY, S. G. Physiology of Woody Plants, 2nd ed. San Diego: Academic, 1997. 
LARSSONEUR, C.; BOUYSSE, P.; AUFRET, J. P. The superficial sediments of the English Channel and its western approaches. Sedimentology, v. 29, n. 6, p. 851-864, 1982.

LACERDA, L.D.; ARAÚJO , D. S. D.; MACIEL, N.C. Restingas: origem, estrutura, processos. UFF - Rio de Janeiro: UFF. 1984.

LEHNINGER, A. L. Principles of biochemistry. New York: Worth, 1982.

LICHTFOUSE E. Compound-specific isotope analysis.Application to archaeology, biomedical sciences, biosynthesis, environment, extraterrestrial chemistry, food science, forensic science, humic substances, microbiology, organic geochemistry, soil science and sport.Rapid Communications in Mass Spectrometry, v. 14, n. 15, p. 1337-1344, 2000.

LIU, Z. X.; XIA, D. X., BERNE S.; WANG, K. Y.; MARSSET, T.; TANG, Y. X.; BOURRLLET, J. F. Tidal deposition systems of continental shelf, with special reference to the eastern Bohai Sea. Marine Geology, v. 145 , p. $225-253,1998$;

LIU, W.; YANG, H. Multiple controls for the variability of hydrogen isotopiccompositions in higher plant $n$-alkanes from modern ecosystems. Global Change Biology, v. 14, n. 9, p. 2166-2177, 2008.

LOURENÇO, R.A. 2007. Aplicação de Marcadores Orgânicos Moleculares em estudos oceanográficos e paleoceanográficos: Estudo de caso na Margem Continental Superior do Sudeste do Brasil. Tese de Doutorado. Instituto Oceanográfico da Universidade de São Paulo, 158 p.

MAHIQUES, M. M; TASSINARI, C. C. G.; MARCOLINI, S.; VIOLANTE, R. A.; FIGUEIRA, R. C. L.; SILVEIRA, I. C. A.; BURONE, L.; SOUSA S. $\mathrm{H}$. M. $\mathrm{Nd}$ and $\mathrm{Pb}$ isotope signatures on the southeastern South 
American Upper Margin: Implications for sediment transport and source rocks. Marine Geology, v. 250, p. 51-63, 2008.

MAHIQUES, M. M.; BURONE, L.; FIGUEIRA, R. C. L.; LAVENÉREWANDERLEY, A. A. O.; CAPELLARI, B.; ROGACHESKI, C. E.; BARROSO, C. P.; SAMARITANO, L. A.; CORDERO, L. A.; CUSSIOLI, M. C. Anthropogenic influences in a lagoonal environment: a multiproxy approach at the Valo Grande mouth, Cananéia-Iguape System (SE) Brazil. Brazilian Journal of Oceanography, v. 57, n. 4, p. 325-337, 2009

MAHIQUES, M. M.; FIGUEIRA, R. C. L.; SALAROLI, A. B.; PAVANI, D. V. A. 150 years of anthropogenic metal input in a Biosphere Reserve: the case study of the Cananéia-Iguape coastal system, Southeastern Brazil. Environmental Earth Sciences, v. 68, n. 4, 2013.

MAIOLI, O. L. G.; OLIVEIRA, C. R.; DAL SASSO, M. A.; MADUREIRA, L. A. S.; AZEVEDO, D. A.; AQUINO-NETO, F. R. Evaluation of the organic matter sources using the $\mathrm{d} 13 \mathrm{C}$ composition of individual $n$-alkanes in sediments from Brazilian estuarine systems by $\mathrm{GC} / \mathrm{C} / \mathrm{IRMS}$. Estuarine, CoastalandShelf Science, v. 114, p. 140-147, 2012.

MALUF, J. C. C. Estudo dos metais traço (zinco, cádmio e chumbo) em duas regiões do complexo Estuarino-Lagunar de CananéiaIguape (SP) sob diferentes pressões antrópicas. 2009. $145 \mathrm{f}$. Dissertacao (Mestrado) - Instituto Oceanográfico, Universidade de São Paulo.

MEAD, R.; XU, Y.; CHONG, J.; JAFFÉ, R. Sediment and soil organic matter source assessment as revealed by the molecular distribution and carbon isotopic composition of $n$-alkanes. Organic Geochemistry, v. 36, n. 3, p. 363-370, 2005. 
MEIER-AUGESTEIN, W. Applied gas chromatography coupled to isotope mass spectrometry. JournalofChromatography A, v. 892, n. 1/2, p. 351$371,1999$.

MENDONÇA, J. T. Gestão dos Recursos Pesqueiros do Complexo Estuariano-Lagunar de Cananéia - Iguape - Ilha Comprida, Litoral Sul de São Paulo, Brasil. 2007. 383 f. Tese (Doutorado) Universidade Federal de São Carlos.

MERINO, E. F.; MAESTRI, D. M.; PLANCHUELO, A. P.Chemotaxonomic evaluation of leaf alkanes in species of Lupinus (Leguminosae). Biochemical Systematics and Ecology, v. 27, n. 3, p. 297-301, 1999.

MEYERS, P. A. Organic geochemical proxies of paleoceanographic, paleolimnologic, and paleoclimatic processes. Organic Geochemistry, v. 27, n. 5/6, p. 213-250, 1997.

MILES, J. A. Illustrate glossary of petroleum geochemistry. Oxford: Claredon, 1994.

MINIUSSI, I. C. Propagação da onda de maré em torno da llha de Cananéia. Contribuições avulsas do Instituto Oceanográfico. Oceanografia física, n. 2, p. 1-8, 1959.

MIRANDA, L. B.; MESQUITA, A. R.; FRANÇA, C. A. S. Estudo da circulação e dos processos de mistura no extremo sul do mar de Cananéia: condições de dezembro de 1991. Boletim do Instituto Oceanográfico, São Paulo, v. 43, n. 2, p. 101-113, 1995.

MISHIMA, M.; YAMANAKA, N.; PEREIRA, O. M.; SOARES, F. C.; SINQUE, C.; AKABOSHI, S.; JACOBSEN, O. Hidrografia do complexo estuarinolagunar de Cananéia ( $25^{\circ} \mathrm{S}, 48^{\circ} \mathrm{W}$ ), São Paulo, Brasil I. Boletim do Instituto de Pesca, São Paulo, v. 12, n. 3, p. 109-121, 1985. 
MIYAO, S. Y. Contribuição ao estudo da oceanografia física da região de cananéia (lat. $2^{\circ} \mathrm{S}$ long. $4^{\circ} \mathrm{W}$ ). 1977.87 f. Dissertação (Mestrado) - Instituto Oceanográfico, Universidade de São Paulo.

MIYAO, S. Y.; HARARI, J. Estudo preliminar da maré e das correntes de maré da região estuarina de Cananéia $\left(25^{\circ} S-48^{\circ} \mathrm{W}\right)$. Boletim do Instituto Oceanográfico, São Paulo, v. 37, n. 2, p. 107-123, 1989.

MIYAO, S. Y.; NISHIHARA, L.; SARTI, C. C. Características físicas e químicas do sistema estuarino-lagunar de Cananéia-Iguape. Boletim do Instituto Oceanográfico, São Paulo, v. 34, p. 23-36, 1986.

MORAES, R.P. 1997. Transporte de chumbo e metais associados no Rio Ribeira de Iguape, São Paulo, Brasil. 1997. f. 94. Dissertação (Mestrado) - Instituto de Geociências, Universidade Estadual de Campinas.

MUDGE, S. M.; NORRIS, C. E. Lipid biomarkers in the Conwy Estuary (North Wales, U.K): a comparison between fatty alcohols and sterols. Marine Chemistry, v. 57, n. 1/2, p. 61-84, 1997.

NASCIMENTO-JUNIOR, D. R.; GIANNINI, P. C. F; TANAKA, A. P. B.; GUEDES, C. C. F. Mudanças morfológicas da extremidade NE da Ilha Comprida (SP) nos últimos dois séculos. Geologia USP: Série Científica, v. 8, n. 1, p. 25-39, 2008.

OLIVEIRA, D. E.; PRATES, E. R. Utilização dos componentes da cera das plantas em especial os n-alcanos, em estudos de nutrição de ruminantes. Ciências Rural, v. 30, n. 3, p. 549-557, 2000.

PANCOST, R. D.; BOOT, C. S. The palaeoclimatic utility of terrestrial biomarkers in marine sediments. Marine Chemistry, v. 92, n. 1-4, p. 239-261, 2004.

PANCOST, R. D.; PAGANI, M. Controls on the carbon isotopic compositions of lipids in marine environments. In: VOLKMAN, J. K. (Ed.). Marine 
organic matter: biomarkers, isotopes and DNA. New York: Springer, 2006. p. 209-49. (Handbook of environmental chemistry, v. 2).

PEARSON, A.; EGLINTON, T. I. The origen of $n$-alkanes in Santa Monica Basin surface sediment: a model based on compound specific $\Delta^{14} \mathrm{C}$ and $\delta^{13} \mathrm{C}$ data. Organic Geochemistry, v. 31 , n. 11 , p. 1103-1116, 2000.

PEDENTCHOUK, N.; SUMNER, W.; TIPPLE, B.; PAGANI, M. $\delta^{13} \mathrm{C}$ and $\delta \mathrm{D}$ compositions of $n$-alkanes from modern angiosperms and conifers: an experimental set up in central Washington State, USA. Organic Geochemistry, v. 39, n. 8, p. 1066-1071, 2008.

PEREIRA, M. L. M.; SOUZA, K. I. S.; VIEIRA, C.V. Restinga: Ser ou não ser, eis a questão... XIII ABEQUA Congress - The South American Quaternary: Challenges and Perspectives.

PHILIP, R. P. Biological markers in fossil fuel production. Mass Spectrometry Reviews, v.4, n. 1, p.1-54, 1985.

PIETROGRANDE, M. C.; MERCURIALI M. Distribution of $n$-alkanes in the Northern Italy aerossol: data handling of GC-MS signals for homologus series characterization. Environmental Science anstechnology, v. 44, n. 11, p. 4232-4240, 2010

PISETTA, M. Análise do processo de distribuição do material particulado em suspensão e metais associados no sistema CananéiaIguape. 2010. 199 f. Tese (Doutorado) - Instituto Oceanográfico; Universidade de São Paulo.

PISETTA, M. Transporte de sedimentos por suspensão no sistema estuarino-lagunar de Cananéia-Iguape (SP). 2006. $179 \mathrm{f}$. Dissertação (Mestrado) - Instituto Oceanográfico, Universidade de São Paulo. 
PISETTA, M.; BARCELLOS, R. L.; FURTADO, V. V. Circulação de material particulado em suspensão no Mar Pequeno - Sistema CananéiaIguape. In: SIMPOSIO BRASILEIRO DE OCEANOGRAFIA, 5., 2011, Santos. Resumos ... São Paulo: IOUSP, 2011. 1 CD-ROM.

PONÇANO, W. L. Mapa geomorfológico do Estado de São Paulo. São Paulo: Instituto de Pesquisas Tecnológicas, 1981.

POYNTER, J. G., FARRIMOND, P., ROBINSON, N.; EGLINTON, G. Aeolianderived higher plant lipids in the marine sedimentary record: links with paleoclimate. In: LEINEN, M.; SARNTHEIN, M. Paleoclimatology and paleometeorology: modern and past patterns of global atmospheric transport. Dordrecht: Kluwer Academic, 1989. p. 435-462.

POYNTER, J. G.; EGLINTON, G. Molecular composition of three sediments from hole 717C: The Bengal Fan. Proceedings of the Ocean Drilling Program Scientific Results, v. 116, p. 155-161, 1990.

RAMASWAMY, V.; GAYE, B.; SHIRODKAR, P. V.; RAO, P. S.; CHIVAS, A. R. Distribution and sources of organic carbon, nitrogen and their isotopic signatures in sediments from the Ayeyarwady (Irrawaddy) continental shelf, northern Andaman Sea. Marine Chemistry, v. 111, n. 3/4, p. 137-150, 2008.

RAMOS, E. B.; GALLO, J.; VERRONE, V. M. A. Áreas da região lagunar Cananéia-Iguape suscetíveis de exploração pesqueira segundo diversos tipos de tecnologia I-Pesca com cerco-fixo. Boletim do Instituto Oceanográfico, São Paulo,v. 29, n. 2, p. 329-335, 1980.

REDDY, C. M.; EGLINTON, T. I.; PALIC, R.; BENITEZ-NELSON, B. C.; STOJANOVIC, G.; PALIC, I.; STANSKOVIC, S.; EGLINTON, G. Even carbono number predominance of plant wax n-alkanes: a correction. Organic Geochemistry, v. 31, p. 331-336, 1999. 
RIELEY, G.; COLLIER , R. J.; JONES, D. M.; EGLINTON, G.; EAKIN, P. A.; FALLICK, A. E. Sources of sedimentary lipids deduced from stable carbon-isotope analyses of individual compounds. Nature, v. 352, n. 6334, p. 425-426, 1991.

ROMMERSKIRCHEN, F.; EGLINTON, G.; DUPONT, L.; GÜNTNER, U.; WENZEL, C.; RULLKÖTTER, J. A north to south transect of southeast Atlantic continental margin sediments: relationship between aerosol transport and compound-specific $\delta 13 \mathrm{C}$ plant biomarker and pollen records. Geochemistry, Geophysics, Geosystems, v. 4, n. 12, 2003.

ROMMERSKIRCHEN, F.; EGLINTON, G.; DUPONT, L.; RULLKOTTER, J. Glacial/interglacial changes in southern Africa: Compound-specific $\delta^{13} \mathrm{C}$ land plant biomarker and pollen records from southeast Atlantic continental margin sediments. Geochemistry, Geophysics, Geosystems, v. 7, n. 8, 2006.

RUMOLO, P; BARRA, M.; GHERARDI, S.; MARSELLA, E.; SPROVIERI, M. Stable isotopes and $\mathrm{C} / \mathrm{N}$ ratios in marine sediments as a tool for discriminating anthropogenic impact. Journal of Environmental Monitoring, v. 13, p. 3399-3408, 2011.

SACHSE, D.; BILLAULT, I.; BOWEN, G. J.; CHIKARAISHI, Y.; DAWSON, T. E.; FEAKINS, S. J.; FREEMAN, K. H.; MAGILL, C. R.; MCINERNEY, F. A.; VAN DER MEER, T. J.; POLISSAR, P.; ROBINS, R. J.; SACHS, J. P.; SCHMIDT, H. L.; SESSIONS, A. L.; WHITE, J. W. C.; WEST, J. B.; KAHMEN, A. Molecular paleohydrology: interpreting the hydrogen-isotopic composition of lipid biomarkers from photosynthesizing organisms. Annual Review of Earth and Planetary Sciences, v. 40, p. 221-49, 2012.

SACHSE, D.; RADKE, J.; GLEIXNER, G. $\delta D$ values of individual $n$-alkanes from terrestrial plants along a climatic gradient-implications for the 
sedimentary biomarker record. OrganicGeochemistry, v. 37, n. 4, p. 469-483, 2006.

SAITO, R. T. Radionuclídeos $\left({ }^{210} \mathrm{~Pb},{ }^{226} \mathrm{Ra},{ }^{210} \mathrm{Po}\right.$ e $\left.{ }^{137} \mathrm{Cs}\right)$ no sistema costeiro Cananéia-Iguape: estudos ambientais. 2002. 163 f. Tese (Doutorado) - Instituto de Pesquisas Energéticas e Nucleares; Universidade de São Paulo.

SAITO, R. T.; FIGUEIRA, R; TESSLER, M. G.; CUNHA, I. I. L. Geochronology of sediments in the Cananéia-Iguape estuary and in southern continental shelf of São Paulo State, Brazil. Journal of Radioanalytical and Nuclear Chemistry, v. 250, n. 1, p. 109-115, 2001.

SAMPAIO, D.; SOUZA, V. C.; OLIVEIRA, A. A.; RODRIGUES, R. R.; SOUZA, J. P. Árvores de Restinga. Ed. Neotrópica, São Paulo, Brasil, 280 p., 2010.

SCHAEFFER-NOVELLI, Y.; CINTRÓN-MOLERO, G.; ADAIME, R. R.; CAMARGO, T. M. Variability of mangrove ecosystems along Brazilian coast. Estuaries, v. 13, n. 2, p. 204-2019, 1990.

SCHAEFFER-NOVELLI, Y.; CINTRÖN-MOLERO, G. The Cananéia-Iguape lagoon estuarine system. São Paulo, Brazil. Estuaries, v. 13, n. 2, p. $193-203,1990$

SCHEFUß, E.; SCHOUTEN, S.; JANSEN, J. H. F.; DAMSTÉ, J. S. African vegetation controlled by tropical sea surface temperatures in the mid-Pleistocene period. Nature, v. 422, n. 6930, p. 418-421, 2003.

SCHUBERT, C. J.; CALVERT, S. E. Nitrogen and carbon istopic composition of marine and terrestrial organic matter in Arctic Ocean sediments: implications for nutrient utilization and organic matter composition. Deep-Sea Research: I, v. 48, n. 3, p. 789-810, 2001. 
SCHULTZE, D. J.; CALDER, J. A. Organic carbon ${ }^{13} \mathrm{C} /{ }^{12} \mathrm{C}$ variations in estuarine sediments.GeochimicaetCosmochimicaActa, v. 40, n. 4, p. 381-385, 1976.

SCHWARK, L.; ZINK, K.; LECHTERBECK, J. Reconstruction of postglacial to early Holocene vegetation history in terrestrial Central Europe via cuticular lipid biomarkers and pollen records from lake sediments.Geology v. 30, n. 5, p. 463-466, 2002.

SEKI, O.; YOSHIKAWA, C.; NAKATSUKA, T.; KAWAMURA, K.; WAKATSUCHI, M. Fluxes, sources, and transport of organic matter in the western Sea of Okhotsk: Stable isotopic ratios of $n$-alkanes and total organic carbon. Deep-SeaResearch: I, v. 53, n. 2, p. 253270, 2006.

SENATORE, D. B. Uso de marcadores orgânicos moleculares na determinação da origem da matéria orgânica em sedimentos do Sistemas estuarino-Lagunar de Cananéia-Iguape - SP - Brasil. 2010. 139 f. Dissertação (Mestrado) - Instituto Oceanográfico, Universidade de São Paulo.

SESSIONS, A. L.; JAHNKE, L. L.; SCHIMMELMANN, A.; HAYES, J. M. Hydrogen isotope fractionation in lipids of the methane-oxidizing bacterium Methylococcuscapsulalus. GeochimicaetCosmochimica Acts, v. 66, n. 22, p. 3955-3969, 2002.

SESSIONS, A. L.; BURGOYNE, T. W; SCHIMMELMANN, A.; HAYES, J. M. Fractionation of hydrogen isotopes in lipid biosynthesis. Organic Geochemistry, v. 30, n. 9, p. 1193-1200, 1999.

SHEPHERD, T. Wax pathways. In: THOMAS, B.; MURPHY, D. J. Encyclopedia of applied plant sciences. Oxford: Elsevier, 2003. p. 1204-1225. 
SIKES, E. L.; UHLE, M. E.; NODDER, S. D.; HOWARD, M. E. Sources of organic matter in a coastal marine environment: evidence from $n$ alkanes and their $\delta 13 \mathrm{C}$ distributions in the Hauraki Gulf, New Zealand. Marine Chemistry, v. 113, n. 3/4, p. 149-163, 2009.

SILVA, J. F.; HERZ, R. Estudo de microclimas em ambientes de manguezais na região do complexo estuarino-lagunar de Cananéia. In: SIMPÓSIO SOBRE ECOSSISTEMAS DA COSTA SUL E SUDESTE BRASILEIRA, 1., 1987, Cananéia. Síntese dos conhecimentos. São Paulo:ACIESP, 1987. v. 2, p. 127-131.

SILVA, T. R.; LOPES, S. R. P.; SPÖRL, G.; KNOPPERS, B. A.; AZEVEDO, D. A. Source characterization using molecular distribution and stable carbon isotopic composition of $n$-alkanes in sediment cores from the tropical Mundaú-Manguaba estuarine-lagoon system, Brazil. OrganicGeochemistry, v. 53, p. 25-33, 2012.

SLEIMAN, M.; VENTURINI-FILHO, W.G.; DUCATTI, C.; NOJIMOTO, T. Utilização de isótopos estáveis do carbono e do nitrogênio para determinar o percentual de malte em cervejas tipo Pilsen. Brazilian Journal of Food Technology, v. 11, n. 2, p.95-102, 2008.

SMITH, F. A.; FREEMAN, K. H. Influence of physiology and climate on $\delta D$ of leaf wax $n$-alkanes from $\mathrm{C} 3$ and $\mathrm{C} 4$ grasses.GeochimestryandCosmochimicalActa, v. 70, n. 5, p. 1172-1187, 2006.

SOUZA, L. A. P.; TESSLER, M. G.; GALLI, V. L. O gráben de Cananéia. RevistaBrasileira de Geociências, v. 26, n. 3, p. 139-150, 1996.

STERNBERG, R., BERHANE, I.; OGSTON, A. Measurement of size and settling velocity of suspended aggregates on the Northern California continental shelf. Marine Geology, v. 154, n. 1-4, p. 43-53, 1999. 
SUDELPA. Plano básico de desenvolvimento auto-sustentado para a região lagunar de Iguape e Cananéia. São Paulo: Sudelpa, 1987.

SUGUIO, K.; MARTIN, L. Formações quaternárias marinhas do litoral paulista e sul-fluminense. In: INTERNATIONAL SYMPOSIUM ON COASTAL EVOLUTION IN THE QUATERNARY, 1978, São Paulo. Abstracts... São Paulo, Instituto de Geociências da Universidade de São Paulo, 1978. v. 1, p. 1-5.

SZTUTMAN, M.; RODRIGUES, R. R. O mosaico vegetacional numa área de floresta contínua da planície litorânea, Parque Estadual da Campina do Encantado, Pariquera - Açu, SP. RevistaBrasileira de Botânica, v. 25, n. 2, p. 61-176, 2002.

TAKADA, H.; EGANHOUSE, R. P. Molecular markers of anthropogenic waste.InMEYERS, R. A. Encyclopedia of environmental analysis and remediation.New York: John Wiley, 1998. p. 2883-2940.

TEIXEIRA, C. Estudo sobre algumas características do fitoplâncton da região de Cananéia e o seu potencial fotossintético. 1969. 82 f. Tese (Doutorado) - Faculdade de Filosofia, Ciências e Letras, Universidade de São Paulo.

TELES, A. P. S. S. A Evolução Geológica Quaternária e a Influência do Valo Grande na Dinâmica Dedimentar da Área de Iguape, São Paulo. 1997. 1 v. Dissertação (Mestrado) - Instituto Oceanográfico, Universidade de São Paulo.

TERWILLIGER, V. J.; DENIRO, M. J.Hydrogenisotopefractionation in woodproducing avocado seedlings: biologicalconstraintstopaleoclimaticinterpretationsof $\delta \mathrm{D}$ values in treeringcellulosenitrate. GeochimestryandCosmochimical Acta, v. 59, n. 24, p. 5199-5207, 1995. 
TESSLER, M. G. Taxas de sedimentação holocênica na plataforma continental sul do estado de São Paulo. 2001. 163 f. Tese de livre docência - Instituto Oceanográfico. Universidade de São Paulo.

TESSLER, M. G.; FURTADO, V. V. Dinâmica de sedimentação das feições de assoreamento da região lagunar Cananéia -Iguape, Estado de São Paulo. Boletim do Instituto Oceanográfico, São Paulo, v. 32, n. 2, p. 117-124, 1983.

TESSLER, M. G.; MAHIQUES, M. M.. Utilization of coastal geomorphic features as indicators of longs-hore transport: examples of the Southern Coastal region of the state of São Paulo, Brazil", Journal of Coastal Research, v. 9, n. 3, p. 823-830, 1993.

TESSLER, M. G.; SOUZA, L. A. P. Dinâmica sedimentar e feições sedimentares identificadas na superfície de fundo do sistema Cananéia-Iguape, SP. Revista Brasileira de Oceanografia, v. 46, n. 1, p. 69-83, 1998.

TESSLER, M. G. Sedimentação atual na região lagunar de CananéiaIguape, Estado de São Paulo. 1982. 2 v. Dissertação (Mestrado) Instituto de Geociências, Universidade de São Paulo.

TESSLER, M. G.; SUGUIU, K.; ROBILOTTA, P. R. 1987. Teores de alguns elementos traços metálicos em sedimentos pelíticos da superfície de fundo da região lagunar de Cananéia-Iguape. In: Simpósio sobre ecossistemas da costa sul e sudeste brasileira: síntese dos conhecimentos, 1987, Cananéia. Anais: São Paulo, ACIESP 2255-263.

THORNTON, S.; MCMANUS, J. Application of organic carbon and nitrogen stable isotope and $\mathrm{C} / \mathrm{N}$ ratios as source indicators of organic matter provenance in estuarine systems: Evidence from the Tay Estuary, 
Scotland. Estuarine, Coastal and Shelf Science, v. 38, n. 3, p. 219-233, 1994.

TULLOCH, A. P. Chemistry of waxes of higher plants. In: KOLATTUKUDY, P.

E. Chemistry and biochemistry of natural waxes. New York: Elsevier, 1976. p. 235-287.

UNESCO.World heritage nomination - IUCN technical evaluation Atlantic Forests (Southeast). Brasília, DF: UNESCO, 1999. p. 1-8.

UNESCO.World network of biosphere reserves - SC/EES. Paris: The MAB Program, 2005. $19 \mathrm{p}$.

VELOSO, H. P.; RANGEL FILHO, A. L. R.; LIMA, J. C. A. Classificação da vegetação brasileira, adaptada a um sistema universal. Rio de Janeiro. IBGE, 1991.

VOGTS, A.; MOOSSEN, H.; ROMMERSKIRCHEN, F.; RULLKÖTTER, J. Distribution patterns and stable carbon isotopic composition of alkanes and alkan-1-ols from plant waxes of African rain forest and savanna C3 species. Organic Geochemistry, v. 40, n. 10, p. 1037-1054, 2009.

VOLKMAN, J. K.; HOLDSWORTH, G. D.; NEILL, G. P.; BAVOR Jr., J. H. Identification of natural, anthrogene and petroleum hydrocarbons in aquatic sediments. Science of the Total Environment, v.112, n. 2/3, p. 203-219, 1992.

WADE, T. L.; CANTILLO, Y. A. Use of standards and reference material in the measurement of chlorinated hydrocarbon residues. NOAA Technical Memorandus NOS ORCA, n. 77, p. 1-59, 1994.

WANG, Y. V.; LARSEN, T.; LEDUC, G.; ANDERSEN, N.; BLANZ, T.; SCHNEIDER, R. R. What does leaf wax dD from a mixed C3/C4 vegetation region tell us?.GeochimicaetCosmochimicaActa, v. 111, p. 128-139, 2013. 
XING, L.; ZHANG, H.; YUAN, Z.; SUN, Y.; ZHAO, M. Terrestrial and marine biomarker estimates of organic matter sources and distribution $s$ in surface sediments from the East China Sea shelf. Continental Shelf Research, v. 31, n. 10, p. 1106-1115, 2011.

ZHANG, Z.; ZHAO, M.; EGLINTON, G.; LU, H.; HUANG, C-Y.Leaf wax lipids as paleovegetational and paleoenvironmental proxies for the Chinese Loess Plateau over the last 170 kyr.Quaternary Science Reviews, v. 25, n 5/6, p. 575-594, 2006.

ZHOU, J.; WU, Y.; ZHANG, J.; KANG, Q.; LIU, Z. Carbon and nitrogen composition and stable isotopes as potential indicators of source and fate of organic matter in the salt marsh of the Changjiang Estuary, China.Chemosphere, v. 65, p. 310-317, 2006. 
ANEXOS 
ANEXO 1: Valores dos parâmetros calculados com os $n$-alcanos detectados no CAN05.

\begin{tabular}{|c|c|c|c|c|c|c|c|c|c|c|c|c|c|c|c|c|}
\hline & $2-4$ & $6-8$ & $12-14$ & $14-16$ & $16-18$ & $18-20$ & $26-28$ & $30-32$ & $32-34$ & $34-36$ & $36-38$ & $38-40$ & $40-42$ & $42-44$ & $46-48$ & $48-50$ \\
\hline AlcTot & 10,8 & 9,39 & 8,87 & 9,37 & 8,26 & 7,99 & 10,27 & 10,40 & 11,00 & 10,23 & 9,88 & 15,02 & 15,07 & 10,91 & 12,33 & 9,64 \\
\hline CPI & 4,68 & 2,71 & 2,90 & 4,09 & 2,61 & 3,04 & 4,18 & 5,48 & 7,29 & 6,63 & 5,36 & 3,79 & 3,33 & 5,50 & 5,70 & 7,94 \\
\hline $\mathrm{ACL}_{23-33}$ & 28,6 & 28,2 & 28,5 & 29,0 & 28,2 & 28,0 & 29,0 & 27,7 & 28,7 & 28,4 & 28,0 & 28,7 & 28,9 & 28,8 & 28,2 & 28,5 \\
\hline Paq & 0,21 & 0,24 & 0,22 & 0,20 & 0,27 & 0,25 & 0,24 & 0,26 & 0,25 & 0,22 & 0,26 & 0,25 & 0,25 & 0,22 & 0,23 & 0,17 \\
\hline \multirow[t]{2}{*}{ Al } & 0,16 & 0,08 & 0,12 & 0,16 & 0,10 & 0,09 & 0,15 & 0,09 & 0,16 & 0,15 & 0,14 & 0,09 & 0,12 & 0,16 & 0,14 & 0,17 \\
\hline & $52-54$ & $54-56$ & $56-58$ & $64-66$ & $66-68$ & $68-70$ & $72-74$ & $74-76$ & $76-78$ & $78-80$ & $80-82$ & $82-84$ & $84-86$ & $88-90$ & $98-100$ & $102-104$ \\
\hline AlcTot & 12,56 & 7,69 & 9,86 & 11,10 & 11,02 & 9,48 & 11,30 & 11,79 & 10,89 & 17,70 & 15,25 & 12,37 & 13,35 & 11,31 & 10,47 & 2,27 \\
\hline CPI & 4,27 & 3,70 & 4,28 & 2,62 & 3,22 & 4,14 & 6,38 & 3,26 & 5,74 & 5,18 & 5,34 & 3,64 & 3,70 & 3,79 & 7,37 & 5,65 \\
\hline $\mathrm{ACL}_{23-33}$ & 28,4 & 28,0 & 28,2 & 28,7 & 28,4 & 28,0 & 28,2 & 28,4 & 28,7 & 28,3 & 28,2 & 28,4 & 28,4 & 29,0 & 28,2 & 28,1 \\
\hline Paq & 0,22 & 0,24 & 0,22 & 0,27 & 0,22 & 0,26 & 0,24 & 0,23 & 0,19 & 0,20 & 0,36 & 0,23 & 0,25 & 0,21 & 0,24 & 0,27 \\
\hline \multirow[t]{2}{*}{ Al } & 0,15 & 0,15 & 0,13 & 0,13 & 0,16 & 0,14 & 0,15 & 0,16 & 0,27 & 0,15 & 0,15 & 0,15 & 0,11 & 0,18 & 0,13 & 0,01 \\
\hline & $104-106$ & $108-110$ & $110-112$ & $114-116$ & $116-118$ & $118-120$ & $128-130$ & $140-142$ & $142-144$ & $144-146$ & $148-150$ & $150-152$ & $152-154$ & $154-156$ & $164-166$ & $168-170$ \\
\hline AlcTot & 13,26 & 9,48 & 13,78 & 7,53 & 10,96 & 11,92 & 11,38 & 2,70 & 1,93 & 3,19 & 3,81 & 2,96 & 2,39 & 2,96 & 3,40 & 2,87 \\
\hline CPI & 5,15 & 4,14 & 5,56 & 5,10 & 5,03 & 3,72 & 6,26 & 3,82 & 4,11 & 6,61 & 5,39 & 5,75 & 4,80 & 5,75 & 4,76 & 6,53 \\
\hline $\mathrm{ACL}_{23-33}$ & 29,0 & 28,0 & 29,0 & 28,6 & 27,6 & 28,4 & 28,7 & 29,0 & 28,5 & 28,7 & 28,9 & 28,6 & 28,4 & 28,6 & 28,9 & 28,9 \\
\hline Paq & 0,20 & 0,26 & 0,20 & 0,24 & 0,32 & 0,28 & 0,17 & 0,15 & 0,23 & 0,23 & 0,19 & 0,18 & 0,24 & 0,18 & 0,15 & 0,24 \\
\hline \multirow[t]{2}{*}{ Al } & 0,10 & 0,14 & 0,12 & 0,23 & 0,12 & 0,12 & 0,33 & 0,28 & 0,08 & 0,29 & 0,29 & 0,30 & 0,26 & 0,30 & 0,32 & 0,13 \\
\hline & $174-176$ & $176-178$ & $178-180$ & $184-186$ & $186-188$ & $188-190$ & 192-194 & $198-200$ & & & & & & & & \\
\hline AlcTot & 2,41 & 2,28 & 5,53 & 4,64 & 4,55 & 6,80 & 2,24 & 4,65 & & & & & & & & \\
\hline $\mathrm{CPI}$ & 5,01 & 4,60 & 4,72 & 5,88 & 4,81 & 4,96 & 7,52 & 5,77 & & & & & & & & \\
\hline $\mathrm{ACL}_{23-33}$ & 28,6 & 28,4 & 28,2 & 27,8 & 28,7 & 28,7 & 28,7 & 29,0 & & & & & & & & \\
\hline Paq & 0,20 & 0,21 & 0,24 & 0,36 & 0,18 & 0,16 & 0,20 & 0,15 & & & & & & & & \\
\hline Al & 0,32 & 0,30 & 0,12 & 0,14 & 0,27 & 0,30 & 0,30 & 0,45 & & & & & & & & \\
\hline
\end{tabular}


ANEXO 2: Valores dos parâmetros calculados com os $n$-alcanos detectados no CAN07.

\begin{tabular}{|c|c|c|c|c|c|c|c|c|c|c|c|c|c|c|c|c|}
\hline & $0-2$ & 4-6 & $6-8$ & $8-10$ & $12-14$ & $14-16$ & $18-20$ & $20-22$ & $22-24$ & $24-26$ & $26-28$ & $28-30$ & $30-32$ & $32-34$ & $34-36$ & $36-38$ \\
\hline AlcTot & 8,01 & 7,11 & 9,31 & 3,88 & 3,52 & 5,50 & 7,91 & 4,02 & 3,79 & 6,09 & 5,80 & 6,24 & 7,62 & 6,61 & 6,28 & 5,32 \\
\hline CPI & 3,79 & 3,25 & 3,56 & 3,72 & 4,24 & 4,62 & 3,59 & 3,36 & 3,34 & 3,09 & 4,07 & 4,02 & 5,98 & 4,46 & 2,85 & 5,78 \\
\hline $\mathrm{ACL}_{23-33}$ & 27,2 & 28,1 & 28,2 & 28,5 & 28,8 & 29,7 & 28,6 & 28,4 & 28,3 & 28,9 & 29,1 & 28,8 & 28,7 & 28,3 & 29,1 & 28,7 \\
\hline Paq & 0,50 & 0,27 & 0,28 & 0,24 & 0,20 & 0,17 & 0,20 & 0,27 & 0,27 & 0,19 & 0,22 & 0,18 & 0,18 & 0,24 & 0,24 & 0,18 \\
\hline \multirow[t]{2}{*}{ Al } & 0,34 & 0,13 & 0,36 & 0,38 & 0,40 & 0,63 & 0,31 & 0,33 & 0,38 & 0,34 & 0,47 & 0,41 & 0,27 & 0,32 & 0,35 & 0,32 \\
\hline & $38-40$ & $40-42$ & 42-44 & 46-48 & $48-50$ & $50-52$ & $52-54$ & $56-58$ & $58-60$ & $60-62$ & $62-64$ & 64-66 & $66-68$ & $68-70$ & $70-72$ & $72-74$ \\
\hline AlcTot & 6,25 & 4,75 & 6,87 & 5,43 & 12,66 & 4,28 & 4,01 & 3,86 & 4,39 & 5,21 & 4,45 & 3,54 & 0,91 & 4,52 & 4,23 & 6,58 \\
\hline $\mathrm{CPI}$ & 4,62 & 5,83 & 6,26 & 4,99 & 6,00 & 4,80 & 3,88 & 4,00 & 4,29 & 5,28 & 4,83 & 5,16 & 5,85 & 7,13 & 4,53 & 6,00 \\
\hline $\mathrm{ACL}_{23-33}$ & 28,4 & 28,5 & 28,7 & 28,7 & 28,9 & 28,4 & 28,7 & 28,4 & 28,3 & 28,9 & 28,3 & 28,7 & 28,8 & 28,7 & 28,4 & 28,9 \\
\hline Paq & 0,26 & 0,20 & 0,19 & 0,21 & 0,17 & 0,24 & 0,20 & 0,23 & 0,24 & 0,16 & 0,24 & 0,24 & 0,16 & 0,19 & 0,23 & 0,15 \\
\hline \multirow[t]{2}{*}{ Al } & 0,35 & 0,31 & 0,28 & 0,37 & 0,31 & 0,34 & 0,35 & 0,23 & 0,30 & 0,31 & 0,33 & 0,35 & 0,31 & 0,38 & 0,37 & 0,31 \\
\hline & $76-78$ & $78-80$ & $80-82$ & $82-84$ & $84-86$ & $86-88$ & $88-90$ & 90-92 & $98-100$ & $100-102$ & $102-104$ & $104-106$ & $108-110$ & $110-112$ & $112-114$ & $114-116$ \\
\hline AlcTot & 7,59 & 5,78 & 3,86 & 1,67 & 1,06 & 2,66 & 2,51 & 5,21 & 4,76 & 3,37 & 8,85 & 3,81 & 2,95 & 3,96 & 2,42 & 4,32 \\
\hline CPI & 4,74 & 4,90 & 4,05 & 2,89 & 4,15 & 2,70 & 3,59 & 5,83 & 4,65 & 4,83 & 5,60 & 7,06 & 4,70 & 4,38 & 5,39 & 5,15 \\
\hline$A C L_{23-33}$ & 28,7 & 28,9 & 286 & 28,0 & 29,0 & 28,5 & 28,1 & 28,7 & 28,5 & 28,4 & 28,8 & 28,7 & 28,8 & 28,6 & 28,5 & 28,8 \\
\hline Paq & 0,19 & 0,17 & 0,21 & 0,39 & 0,14 & 0,25 & 0,31 & 0,18 & 0,23 & 0,25 & 0,15 & 0,20 & 0,18 & 0,21 & 0,21 & 0,15 \\
\hline \multirow[t]{2}{*}{ Al } & 0,33 & 0,30 & 0,35 & 0,26 & 0,38 & 0,50 & 0,38 & 0,40 & 0,33 & 0,32 & 0,27 & 0,38 & 0,30 & 0,34 & 0,33 & 0,29 \\
\hline & $116-118$ & $118-120$ & $120-122$ & $122-124$ & 124-126 & & & & & & & & & & & \\
\hline AlcTot & 2,93 & 2,57 & 3,53 & 1,86 & 2,41 & & & & & & & & & & & \\
\hline CPI & 4,85 & 5,34 & 5,50 & 3,75 & 3,27 & & & & & & & & & & & \\
\hline $\mathrm{ACL}_{23-33}$ & 28,6 & 28,2 & 28,8 & 28,3 & 28,3 & & & & & & & & & & & \\
\hline Paq & 0,21 & 0,28 & 0,12 & 0,28 & 0,26 & & & & & & & & & & & \\
\hline Al & 0,39 & 0,36 & 0,27 & 0,41 & 0,37 & & & & & & & & & & & \\
\hline
\end{tabular}


ANEXO 3: Valores dos parâmetros calculados com os $n$-alcanos detectados no CAN10.

\begin{tabular}{|c|c|c|c|c|c|c|c|c|c|c|c|c|c|c|c|c|}
\hline & $0-2$ & $2-4$ & $4-6$ & $6-8$ & $8-10$ & $10-12$ & $12-14$ & 16 & $16-18$ & $18-20$ & $20-22$ & $22-24$ & $24-26$ & $26-28$ & $30-32$ & $32-34$ \\
\hline AlcTot & 31,8 & 31,9 & 25,2 & 17,5 & 26,9 & 27,7 & 25,8 & 28,4 & 31,8 & 20,1 & 31,9 & 29,4 & 31,6 & 30,2 & 27,8 & 31,6 \\
\hline CPI & 2,84 & 3,48 & 3,66 & 3,56 & 4,00 & 2,17 & 3,71 & 3,02 & 2,26 & 4,94 & 3,33 & 3,30 & 2,97 & 3,38 & 2,87 & 2,77 \\
\hline $\mathrm{ACL}_{23-33}$ & 28,5 & 28,4 & 28,4 & 28,4 & 28,5 & 28,7 & 28,6 & 28,6 & 28,7 & 28,6 & 28,7 & 28,5 & 28,9 & 28,8 & 28,4 & 28,7 \\
\hline Paq & 0,24 & 0,24 & 0,23 & 0,25 & 0,22 & 0,22 & 0,21 & 0,22 & 0,22 & 0,20 & 0,20 & 0,22 & 0,19 & 0,19 & 0,24 & 0,21 \\
\hline Al & 0,30 & 0,27 & 0,26 & 0,28 & 0,28 & 0,26 & 0,30 & 0,31 & 0,35 & 0,29 & 0,36 & 0,29 & 0,36 & 0,37 & 0,31 & 0,36 \\
\hline & $34-36$ & $36-38$ & $38-40$ & $40-42$ & $42-44$ & $44-46$ & $46-48$ & $48-50$ & $50-52$ & $52-54$ & $54-56$ & $58-60$ & $60-62$ & $62-64$ & $66-68$ & $70-72$ \\
\hline AlcTot & 23,4 & 24,0 & 27,7 & 26,6 & 29,0 & 17,3 & 23,0 & 21,8 & 19,4 & 17,3 & 6,35 & 10,1 & 18,0 & 20,6 & 12,1 & 11,8 \\
\hline CPI & 4,00 & 3,00 & 2,98 & 3,63 & 3,84 & 5,15 & 4,05 & 3,38 & 4,34 & 3,49 & 4,44 & 3,82 & 4,00 & 3,13 & 3,98 & 3,00 \\
\hline $\mathrm{ACL}_{23-33}$ & 28,5 & 28,2 & 28,4 & 28,5 & 28,7 & 28,4 & 28,2 & 28,2 & 28,5 & 28,7 & 28,5 & 28,5 & 28,5 & 28,2 & 28,9 & 29,3 \\
\hline Paq & 0,22 & 0,24 & 0,21 & 0,22 & 0,22 & 0,19 & 0,22 & 0,29 & 0,23 & 0,19 & 0,23 & 0,23 & 0,23 & 0,27 & 0,18 & 0,18 \\
\hline Al & 0,33 & 0,29 & 0,33 & 0,35 & 0,39 & 0,33 & 0,29 & 0,30 & 0,30 & 0,32 & 0,33 & 0,34 & 0,31 & 0,35 & 0,36 & 0,34 \\
\hline
\end{tabular}

\begin{tabular}{|c|c|c|c|c|c|c|c|c|c|c|c|c|c|c|c|c|}
\hline & $72-74$ & $74-76$ & $80-82$ & $82-84$ & $84-86$ & $90-92$ & $92-94$ & $94-96$ & $96-98$ & $98-100$ & $100-102$ & $102-104$ & $104-106$ & $106-108$ & $108-110$ & $110-112$ \\
\hline AlcTot & 7,48 & 7,74 & 9,26 & 7,98 & 11,3 & 18,6 & 11,8 & 9,05 & 8,62 & 8,42 & 16,3 & 8,47 & 8,80 & 9,30 & 7,28 & 16,3 \\
\hline CPI & 5,16 & 4,18 & 6,12 & 5,22 & 4,52 & 4,36 & 5,38 & 5,14 & 4,44 & 4,94 & 3,74 & 5,40 & 6,85 & 5,10 & 4,82 & 3,84 \\
\hline$A L_{23-33}$ & 28,1 & 28,6 & 28,3 & 28,7 & 29,0 & 28,5 & 27,7 & 28,3 & 28,5 & 28,4 & 28,6 & 28,4 & 28,3 & 28,2 & 28,3 & 28,3 \\
\hline Paq & 0,25 & 0,25 & 0,23 & 0,21 & 0,22 & 0,25 & 0,37 & 0,30 & 0,27 & 0,28 & 0,25 & 0,26 & 0,30 & 0,32 & 0,31 & 0,26 \\
\hline Al & 0,35 & 0,34 & 0,41 & 0,33 & 0,29 & 0,31 & 0,26 & 0,32 & 0,33 & 0,33 & 0,34 & 0,24 & 0,23 & 0,31 & 0,31 & 0,30 \\
\hline
\end{tabular}

\begin{tabular}{|c|c|c|c|c|c|c|c|c|c|c|c|c|c|c|c|}
\hline & $112-114$ & $114-116$ & $116-118$ & $118-120$ & $124-126$ & $126-128$ & $128-130$ & $130-132$ & $132-134$ & $136-138$ & $140-142$ & $142-144$ & $146-148$ & $148-150$ & $150-152$ \\
\hline AlcTot & 8,96 & 9,99 & 9,69 & 21,8 & 8,31 & 6,24 & 9,15 & 21,8 & 10,9 & 8,20 & 17,9 & 12,8 & 10,9 & 18,4 & 28,9 \\
\hline CPI & 5,67 & 5,10 & 5,23 & 4,72 & 4,80 & 5,53 & 3,92 & 4,72 & 5,54 & 6,58 & 5,35 & 5,57 & 4,26 & 5,12 & 4,58 \\
\hline $\mathrm{ACL}_{23-33}$ & 28,9 & 28,3 & 28,4 & 28,8 & 28,6 & 28,6 & 28,6 & 28,8 & 28,7 & 28,6 & 28,8 & 28,5 & 28,7 & 29,2 & 28,9 \\
\hline Paq & 0,26 & 0,28 & 0,28 & 0,21 & 0,24 & 0,24 & 0,24 & 0,21 & 0,22 & 0,23 & 0,21 & 0,23 & 0,23 & 0,24 & 0,18 \\
\hline Al & 0,24 & 0,30 & 0,30 & 0,31 & 0,31 & 0,32 & 0,32 & 0,31 & 0,32 & 0,31 & 0,29 & 0,31 & 0,31 & 0,29 & 0,33 \\
\hline
\end{tabular}


ANEXO 4: Valores dos parâmetros calculados com os $n$-alcanos detectados no CAN02.

\begin{tabular}{|c|c|c|c|c|c|c|c|c|c|c|c|c|c|c|c|c|}
\hline & $0-2$ & $2-4$ & $4-6$ & $8-10$ & $10-12$ & $12-14$ & $14-16$ & $16-18$ & $18-20$ & $22-24$ & $24-26$ & $26-28$ & $32-34$ & $36-38$ & $38-40$ & $40-42$ \\
\hline AlcTot & 6,54 & 10,6 & 13,5 & 10,2 & 9,33 & 10,4 & 7,19 & 8,90 & 7,70 & 5,31 & 10,8 & 7,78 & 5,77 & 4,06 & 5,68 & 3,86 \\
\hline CPI & 2,20 & 4,32 & 3,85 & 4,46 & 4,23 & 4,75 & 4,68 & 5,11 & 4,87 & 4,56 & 6,89 & 5,16 & 4,35 & 5,27 & 5,75 & 4,93 \\
\hline $\mathrm{ACL}_{23-33}$ & 29,0 & 29,0 & 28,9 & 29,4 & 29,3 & 29,2 & 29,3 & 29,0 & 29,1 & 28,7 & 28,9 & 28,9 & 28,7 & 28,9 & 28,5 & 28,8 \\
\hline Paq & 0,40 & 0,23 & 0,24 & 0,17 & 0,18 & 0,16 & 0,19 & 0,19 & 0,22 & 0,28 & 0,18 & 0,24 & 0,30 & 0,23 & 0,26 & 0,26 \\
\hline \multirow[t]{2}{*}{ Al } & 0,46 & 0,45 & 0,50 & 0,52 & 0,52 & 0,46 & 0,53 & 0,44 & 0,54 & 0,53 & 0,44 & 0,50 & 0,56 & 0,47 & 0,45 & 0,56 \\
\hline & $42-44$ & $44-46$ & $48-50$ & $50-52$ & $52-54$ & $56-58$ & $60-62$ & $62-64$ & $64-66$ & $66-68$ & $70-72$ & $72-74$ & $74-76$ & $76-78$ & $80-82$ & $82-84$ \\
\hline AlcTot & 4,81 & 3,60 & 7,94 & 3,95 & 4,67 & 5,26 & 5,13 & 3,67 & 5,38 & 4,52 & 4,26 & 4,96 & 5,91 & 6,05 & 8,25 & 8,63 \\
\hline CPI & 4,49 & 4,59 & 5,98 & 5,16 & 5,12 & 5,45 & 5,65 & 4,92 & 5,11 & 4,41 & 5,06 & 5,40 & 4,93 & 5,98 & 4,83 & 6,48 \\
\hline $\mathrm{ACL}_{23-33}$ & 28,5 & 28,7 & 29,3 & 29,0 & 28,9 & 29,0 & 29,2 & 29,3 & 28,9 & 29,2 & 29,2 & 29,1 & 29,2 & 28,8 & 29,5 & 29,2 \\
\hline Paq & 0,34 & 0,27 & 0,18 & 0,24 & 0,23 & 0,22 & 0,19 & 0,18 & 0,25 & 0,20 & 0,20 & 0,19 & 0,19 & 0,23 & 0,15 & 0,18 \\
\hline \multirow[t]{2}{*}{ Al } & 0,59 & 0,52 & 0,52 & 0,56 & 0,53 & 0,55 & 0,48 & 0,58 & 0,57 & 0,57 & 0,54 & 0,50 & 0,56 & 0,51 & 0,58 & 0,56 \\
\hline & $86-88$ & $88-90$ & $92-94$ & $94-96$ & $96-98$ & $98-100$ & $100-102$ & 104-106 & $106-108$ & $108-110$ & $112-114$ & $116-118$ & $118-120$ & $120-122$ & $122-124$ & $128-130$ \\
\hline AlcTot & 5,89 & 10,1 & 6,71 & 6,96 & 6,96 & 5,99 & 9,38 & 10,5 & 9,82 & 12,7 & 8,64 & 6,53 & 10,7 & 7,96 & 11,3 & 8,97 \\
\hline CPI & 5,22 & 5,15 & 5,20 & 5,20 & 7,24 & 5,91 & 6,42 & 5,68 & 6,26 & 6,93 & 5,49 & 5,47 & 5,35 & 5,37 & 5,23 & 6,01 \\
\hline $\mathrm{ACL}_{23-33}$ & 29,3 & 28,8 & 29,1 & 29,2 & 29,3 & 29,3 & 29,0 & 28,9 & 29,1 & 29,3 & 29,4 & 29,5 & 29,2 & 29,4 & 29,2 & 29,2 \\
\hline Paq & 0,19 & 0,26 & 0,22 & 0,21 & 0,14 & 0,16 & 0,20 & 0,25 & 0,20 & 0,14 & 0,18 & 0,16 & 0,18 & 0,14 & 0,19 & 0,18 \\
\hline Al & 0,56 & 0,54 & 0,56 & 0,59 & 0,48 & 0,56 & 0,51 & 0,53 & 0,52 & 0,47 & 0,58 & 0,58 & 0,54 & 0,54 & 0,56 & 0,54 \\
\hline
\end{tabular}

$\begin{array}{lllll}130-132 & 132-134 & 136-138 & 140-142 & 142-144\end{array}$

\begin{tabular}{cccccc}
\hline AlcTot & 11,0 & 14,3 & 5,6 & 10,5 & 14,2 \\
CPI & 5,39 & 5,45 & 5,22 & 6,24 & 6,40 \\
ACL $_{23-33}$ & 29,4 & 29,6 & 29,5 & 29,3 & 29,4 \\
Paq & 0,18 & 0,14 & 0,15 & 0,15 & 0,14 \\
Al & 0,56 & 0,57 & 0,58 & 0,57 & 0,56 \\
\hline
\end{tabular}


